Din 762

NDSIR 80-2145 (DOE) (R)

A Study of an Integrated

Appliance, the Air Conditioner/Heat Pump-Heat Recovery Unit-Water Heater

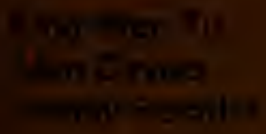



NBSIR 80-2145 (DoE)

\section{A STUDY OF AN INTEGRATED \\ APPLIANCE, THE AIR CONDITIONER/HEAT \\ PUMP-HEAT RECOVERY UNIT-WATER \\ HEATER}

King-Mon Tu

Alan Davies

Sidney Fischler

Center for Consumer Product Technology

National Engineering Laboratory

U.S. Department of Commerce

National Bureau of Standards

Washington, DC 20234

Final Report

November 1980

Issued February 1981

Prepared for

United States Department of Energy

and the

Oak Ridge National Laboratory

Oak Ridge, Tennessee 37830

Operated by Union Carbide Corporation

for the United States Department of Energy

(Contract No. W-7405-eng-26)

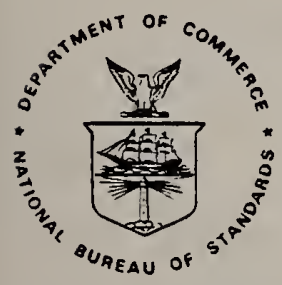

U.S. DEPARTMENT OF COMMERCE, Malcolm Baldrige, Secretary NATIONAL BUREAU OF STANDARDS. Ernest Ambler, Director 


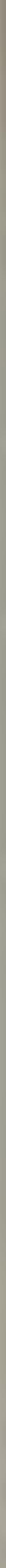


Abstract ....................... iv

Summary. . . . . . . . . . . . . . . . . . . v

1. Introduction .................... 1

II. Performance of Existing Systems $\ldots$

A. Typical AC/HP-HRU-WH System Operation .......... 3

B. Apparatus and Test Setup ............... . . 4

C. Test Procedure ........................ 7

D. Test Results and Analysis . . . . . . . . . 7

1. Figures for System 1.............. . . 8

2. Figures for System 2.................. . . . . 10

3. Tables for Systems 1 and 2................... 11

E. Conclusions .................... 12

III. Estimation of Seasonai Energy costs and Savings . . . . . . 12

A. Introduction and Principal Findings ............ 12

B. System Description and Operation ............. 14

C. Simulation Methodology ............... 17

D. Results ..................... 19

E. Alternative Estimation Methods . . . . . . . . . . 20

Tables

II-1: Time-Averaged Conditions and Thermodynamic Performance Data for Heat Pump 1 by Itself and as Part of Integrated HP-HRU-WH

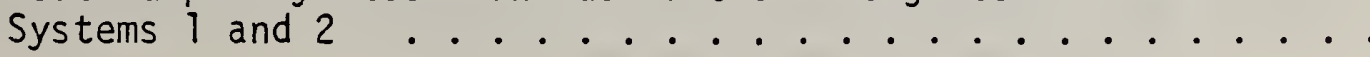

II-2: Comparison of Heat Pump Capacity, Power and Efficiency Performance Data for Systems 1 and 2 with Available Data Supplied by

Manufacturers ...............

II-3: Heat Recovery Rate, Thermal Energy Rate, Energy Consumption Rate, and Heat Recovery Efficiency for Integrated Systems 1 and 2 . .

III-1: Tank Size Simulation Results ............. 25

III-2: Alternative Calculation Comparisons . . . . . . . 26

Figures

I-1: Major Components of a Heat Pump . . . . . . . . . 27

I-2: Pressure versus Enthalpy Schematic for Refrigerant Cycle in a Heat Pump ..................

II-1: Detailed Sample Pressure versus Enthalpy Diagram . . . . . . 28

II-2: Schematic of Integrated Systems 1 and 2 . . . . . . . . 29

II-3: Schematic Representation of the Heat Recovery Unit No. 1 . . . 30 
Figures (cont.)

II-4: Schematic Representation of the Heat Recovery Unit No. 2....

II-5: Schematic for Integrated System 3

II-6: Schematic Representation of the Heat Recovery Unit No. 3 .

II-7A-C: Water Temperatures at Various Locations in the WH versus Time of Operation of the HP-HRU-WH Integrated Appliance, using HRU No.

II-8A-C: Heat Recovery versus Time of Operation of the HP-HRU-WH Integrated Appliance, using HRU No.

II-9A-C: Refrigerant Temperatures versus Time of Operation for the HP-HRU-WH Integrated Appliance, using HRU NO.

II-10A-C: Refrigerant Pressures versus Time of Operation of the HP-HRU-WH Integrated Appliance, Using HRU No.

II-11A-C: Energy Consumed versus Time of Operation of the HP-HRU-WH Integrated Appliance, using HRU No. 1

II-12A-C: Water Temperatures at Various Locations in the WH versus Time of Operation of the HP-HRU-WH Integrated Appliance, using HRU No. 2

II-13A-C: Heat Recovery versus Time of Operation of the HP-HRU-WH Integrated Appliance, using HRU No. 2

II-14A-C: Refrigerant Temperatures versus Time of Operation for the HP-HRU-WH Integrated Appliance, using HRU No. 2

II-15A-C: Refrigerant Pressures versus Time of Operation of the HP-HRU-WH Integrated Appliance, using HRU No. 2

II-16A-C: Energy Consumed versus Time of Operation of the HP-HRU-WH Integrated Appliance, using HRU No. 2

III-1: Modified AE/HP-HRLi-WH Integrated Appliance System

III-2a-c: Heat Status versus Time of Day for Washington, D.C.; $a$ and $b$ : different days; $b$ and $c$ : same day.

III-3: Heat Recovery Factors versus Outdoor Temperature . . . . .

III-4: NBSLD House Heating and Cooling Loads versus Outdoor DryBuTb Temperature

III-5: Simulation Outline Diagram 
Bibliography

Appendix A: Simulation Background and Related Data

AI: $\quad$ House Heating, Cooling, and Hot-Water Loads

AII: Heat Pump and Heat Recovery System

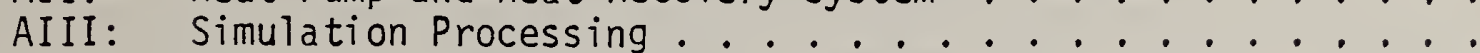

AIV: Additional Temperature Profiles............

Table Al: Water Draw Schedule .................

Table A2: Heat Pump Capacities (CAP), Heat Pump Coefficients of

Performance (COP) and Water Heating Factors (WHF) . . . . . .

Figures

Al: Computational Flow Diagram for Hourly Simulation Method . . . . .

A2: Computational Flow Diagram for Bin, Average and Bin, Linear Methods

A3-A13: Bin Hours per Year versus Dry-Bulb Bin Temperatures for Andrews AFB, MD: Dobbins AFB, GA; O'Hare IAP, IL: Everett, WA; Hanscom Field, MA; Homestead AFB, FL; Davis-Monthan AFB, AZ; Kansas City, MO; Carswell AFB, TX; Monterey NAF, CA; and Los Angeles, CA . . . . 


\section{Abstract}

Three integrated heat pump-heat recovery unit-water heater appliances were tested under various environmental conditions to measure the functional parameters and study the operating characteristics of these systems. It was found that the heat recovery, heat recovery rate and heat recovery efficiency were dependent on the heat recovery unit's characteristics. The use of the heat recovery unit in the system resulted in a reduced work load for the heat pump's compressor and slightly improved the heat pump's performance.

A computer simulation model of the integrated system was developed to study the interactions between several of the pertinent system variables on an hourly basis for selected situations and to estimate energy savings. Two alternative estimation methods that utilize five-degree temperature hin data were also developed. The estimated savings determined by using the alternative methods were about the same as those estimated using the hourly data. Conclusions were also reached concerning the use of water heaters with different tank capacities and on methods of increasing potential energy savings. 
Three different integrated heat pump-heat recovery unit-water heater appliances were tested under various environmental conditions in order to measure and study the operating characteristics and parameters of these systems. Tests were conducted on the same heat pump and water heater with two different heat recovery units to determine the heat recovery, heat recovery rate and heat recovery efficiency. For these same two integrated systens, the heat recovery, heat recovery rates and heat recovery efficiencies were substantially greater during the cooling mode operation than during the heating mode operation. The heat recovery units were installed and used in the systems as received from the manufacturers. No adjustments were made to optimize or otherwise alter the asreceived performance, Since the third system was discovered to be operating improperly, only a limited discussion of this system is included in this report.

It was also determined that the heat recovery units had no adverse effects on the heat pumps' performance. In fact, they slightly imoroved the performance by reducing the work load on the compressor.

A modified integrated appliance system that utilizes a water heater with an upper electrical resistance heating element and a heat pump with supplemental resistance heat was analyzed to estimate energy savings potentials. A computer simulation model was developed to study the interactions among several of the pertinent system variables on an hourly basis for selected situations. Information generated by the computer simulations for four locations in the U.S. indicated yearly point-of-use savings in the range 800-1200 kWh, representing. 40-60 dollars for an electricity cost rate of 5 cents per $\mathrm{k} w \mathrm{~h}$, for a particular residential application. Since hourly data are available for few locations, specific house characteristics and operating strategies, two alternative estimation methods were developed that use five-degree temperature bin data, which are available for numerous locations throughout the U.S.

It was also concluded from the analysis that: ( 1 ) the use of a 52 gallon water heater tank would permit greater flexibility in scheduling residential hot water usage than would a 40 gallon tank but it would add about 3 dollars a year in operating costs due to jacket losses: (2) the use of tanks with more than a 52 gallon capacity increase energy costs without providing sufficient additional benefits; (3) energy savings could be increased by controls which account for the thermal efficiency of the heat recovery unit and utilizing ventilation when it can achieve and/or maintain satisfactory indoor conditions; and (4) the use of averaged weather data for energy estimation and decision purposes, by consumers, is justified. 

The work described and analyzed in this report was nerformed hy the Product Performance Fngineering Division (PPED) of the Center for Consumer Product Technology (CCPT), National Bureau of Standards (NBS), in partial fulfillment of "Task B, Air Conditioner/Heat Pump - Water Heater Pro.ject." Funding for and management of the project, in accordance with Interagency Agreement DOE NO. EN78-I-05-5750, was provided by the Department of Energy through the Oak Ridge National Laboratory (ORNL).

The purposes of the project were to gain a better understanding of AC/HPHRU-WH systems and how they may contribute to energy conservation, and to identify areas in which potential improvements may result in increased energy savings.

The "Air Conditioner/Heat Pump - Water Heater" specified in the task title is a new and currently available integrated major home appliance whose principal components are a central air conditioner (AC) or heat pump (HP), a heat recovery unit (HRU), and a storage type water heater (WH). In view of these principal components, the integrated appliance will hereinafter be abbreviated as AC/HPHRU-WH or, when a heat pump is used, as HP-HRU-WH.

The purpose of integrating the three principal components is to construct an appliance that will use less energy than would ordinarily be used by the $\mathrm{AC} / \mathrm{HP}$ and the WH. In the AC/HP-HRU-WH, the AC performs its normal cooling function and the HP its normal heating and cooling functions, and the stores and provides potable hot water for normal use. The FRU is the added unifying component that makes energy savings possihle; its function is to provide the means for and to control the transfer of thermal energy from the superheated refrigerant gas discharged by the compressor of the AC/HP to the water in the VH tank. Figures I-1 and I-2 show, schematically and respectively, the major components of an AC/HP and a typical pressure - enthalpy diagram for the refrigerant cycle in an $\mathrm{AC} / \mathrm{HP}$.

The HRU has two inlets, one for superheated refrigerant gas that is discharged from the compressor of the AC/HP and the other for water from the drain outlet of the WH, and two outlets, one to allow the refrigerant gas to flow to the condenser of the AC/HP, and the other to allow the water to flow to the hot water outlet of the WH. Inside the HRU are a counterflow heat exchanger (HX) and the gas and water flow control system.

Utilization of thermal energy that would otherwise be wasted by discharging it into the outdoor air during cooling mode operation results in energy savings as less conventional energy is required to attain and maintain the desired water temperature in the WH tank. As a result of the advertized claims of energy savings and user interest in saving energy, thousands of AC/HP-HRU-WH systems have been installed in residences, supermarkets, restaurants, hotels, hospitals and other structures. Some of the installed AC/HP-HRU-WH systems are of the retrofit type, and others are supplied as complete or almost complete systems. In the retrofit installation, an appropriately sized HRU is added to interface with a previously installed AC/HP and WH. In the complete or almost complete 
syster installation, an entire AC/HP-HRU-WH system is installed, or an integrated $\mathrm{AC} / \mathrm{HP}-\mathrm{HRU}$ system is interfaced with an existing $\mathrm{WH}$. Few comcanies manufacture the entire AC/HP-HRU-WH system or an integrated AC/HP-HRU system. Many companies mamufacture an assortment of HRUs for retrofit purposes.

The obvious goal in using the AC/HP-HRU-WH integrated appliance in commercial or residential applications is to optimize energy usage, i.e. maximize energy and dollar savings, while performing the required cooling or heating functions and satisfying normal hot water needs. However, there are many technical factors involved in the operation and assessment of potential energy savings of such systems that have not been fully addressed and, therefore, require investipation. Some of these factors are ambient conditions; incoming, storage and operating water temperatures; hot water draw schedules; water storage tank size; and the heat recovery unit design.

Ambient conditions have a significant effect on the thermal energy available for heating water. During the cooling season, for example, higher outdoor temperatures result in greater quantities of thermal energy available for recovery. During the heating season, thermal energy available for heating water decreases.

Incoming water temperatures are higher in southern than in northern states; storage temperatures, in the water heater, are dependent upon the settings of the water heater thermostatic control; and operating water temperatures will depend upon the user.

Hot water draw schedules vary from application to application derendent upon the number of users and appliances. Furthermore, even draw scherules for a particular apolication may vary daily, and from month to month, repending upon any number of water usage variables, such as for bathing, cooking, dishwashing and clothes washing, and different hot water temperature preferences.

Water storage tank size will also affect the energy savings potential. Since the storage tank is to provide adequate amounts of water at sufficiently elevated temperatures, it is imnortant to select a $\mathrm{WH}$ tank size that will have sufficient capacity with an appropriate backup heater to handle major drats. If the heat recovery unit in the AC/HD-HRU-WH is designed to heat large quantities of water using a high flow rate, the increase in water temperature will be slight. However, if the design is to handle smaller flow rates, the increase in water temperature will be large. In either case, a prolonged iraw rate may result in depletion of the hot water if the storage tank capacity is too small for the application.

The HRU must be properly designed for effective heat recovery. Some manufacturers of HRU have claimed that their use in the integrated appliance not only provides "free heat" for heating water, but, it also improves the capacity and efficiency of the AC or HP. However, others have indicated that such improvement is marginal at most. Namufacturers of compressors used in $\mathrm{AC}$ and $\mathrm{HP}$ have expressed concerns about the possihility that use of the HRU may increase compressor head pressure which may lead to premature compressor failure. 
Two different types of HP and three different HRU were selected for this investigation hecause they were judged to be typical of the integrated $\mathrm{AC} / \mathrm{HP}-$ HRU-WH systems presently in the field. When operated in the cooling mode, the $\mathrm{HP}$ is considered to be an AC. These systems are described in the section dealing with the apparatus and test setup.

The investigation consisted of two major phases. One was an experimental phase during which the HP was operated with and without the HRU and WH. This was to verify the manufacturers data for the HP, to determine how the integrated appliance performed, and to provide the technical basis on which a test procedure for evaluating the performance of the HRU may be developed. In the other phase a computer model was developed to study the interactions between several pertinent system variables for selected situations. Analytic methods were developed to utilize the performance data in estimating and optimizing energy savings.

\section{Performance of Existing Systems}

A. Typical AC/HP-HRU-WH System Operation

A pressure-enthalpy diagram for a refrigeration cycle is presented in Figure II-l. The enthalpy differences $h_{C}-h_{B}, h_{D}-h_{C}$, and $h_{D}-h_{A}$ represent, respectively, the cooling capacity, the compressor work input and the heating capacity. If losses are ignored, the thermodynamic coefficient of performance for cooling, $\mathrm{COP}_{C}$, is calculated as

$$
{ }^{{ }^{C O P}}{ }_{C}=\frac{{ }^{h_{C}-h_{B}}}{h_{D}-h_{C}}
$$

and for heating, $\mathrm{COP}_{\mathrm{H}}$, is calculated as

$$
\mathrm{COP}_{\mathrm{H}}=\frac{{ }_{\mathrm{h}-\mathrm{h}_{A}}}{{ }_{\mathrm{D}-\mathrm{h}_{C}}} .
$$

The superheat portion for the refrigerant in this cycle, following discharge from the compressor, is ketween points $D$ and $F$ in the figure. Mypical refrigerant temperatures are $220 \mathrm{~F}$ at point $\mathrm{D}$, the compressor discharge, and $115^{\circ} \mathrm{F}$ at point $\mathrm{F}$, the condensing temperature. The amount of thermal energy that might be utilized in heating water is determined by the enthalpy difference, $\left(h_{-}-h_{7}\right)$, times the refrigerant mass flow rate. If the controls in the HRU confine the water flow only to desuperheating the refrigerant gas, then the quantity of thermal energy available for heat recovery would be reduced to ( $h_{D}-$ $h_{\mathrm{T}}$ ) times the refrigerant mass flow. An important carameter that is used in Section III of this report concerns the thermal energy available for water heating and is called the "water heating factor": it is defined as the ratio of the heat available for water heating per pound of refrigerant to the 
corresponding cooling or heating effect. Its variability with respect to outdoor dry-bulb temperature is show in Fioure III-3a.

That part of the cycle between points $G$ and A represents refrigerant subcooling. In passing through a metering device, generally a capillary tube or thermostatic expansion valve, the refrigerant pressure drops from the high side (or discharge) pressure, at point A, to the low side (or suction) pressure, at point $B$. From point $B$ to point $B^{\prime}$, the refrigerant passes through the evaporator ahsorbing thermal energy and vaporizing. Petween points $B^{\prime}$ and $C$ the refrigerant is superheated (about $15^{\circ} \mathrm{F}$ in the example shown) before entering the compressor. The compressor raises the refrigerant pressure and temperature from point $C$ to point $D$.

\section{B. Apparatus and Test Setup}

The performance of each of three HP-HRU-WH integrated appliances was investigated in this phase of the study. The common major components of the first two integrated appliances, or systems, are a HP (cooling capacity of 35,000 and $38,000 \mathrm{Btu} / \mathrm{h}$ at outdoor temperatures of 95 and $75 \mathrm{~F}$, respectively; and heating capacity of 34,000 and $39,300 \mathrm{Btu} / \mathrm{h}$ at an outdoor temperature of 40 and $50^{\circ} \mathrm{F}$, respectively) and a nominal 52 gallon storage type wH whose electric heating elements were disconnected for this work. The third major component of the first system was a retrofit HRU intended for use with an AC or HP rated for 18,000 to $60,000 \mathrm{Btu} / \mathrm{h}$. The third major component of the second system was an HRU produced by the manufacturer of the HP described above and intended for use with any AC or HP rated for 18,000 to $42,000 \mathrm{Btu} / \mathrm{h}$.

A schematic representation of the these two integrated systems, referred to as System 1 and System 2, are presented in Figure II-2. The figure shows an indoor unit, called an air handler, in the "indoor room" of a three room environmental chamber. This chamber was set and maintained at a nominal $80^{\circ} \mathrm{F}$ and $50 \%$ relative humidity (RH) when the HP was operated in the cooling mode, and a nominal $70^{\circ} \mathrm{F}$ and $50 \% \mathrm{RH}$ when the $\mathrm{HP}$ was operated in the heating mode. The coil in the indoor unit served as the evaporator coil during cooling mode operation and the condenser coil during heating mode operation. The outdoor unit was located in the "outdoor room" of the environmental chamber. This chamber was set and maintained at nomina 95,85 and $75^{\circ} \mathrm{F}$, and $50 \% \mathrm{RH}$, during cooling mode operation, and a nominal $20^{\circ} \mathrm{F}$ during heating mode operation. The reversing valve, accumulator, compressor and capillary tube of the outdoor unit are identified in the figure. The coil in the outdoor unit served as the condensing coil during cooling mode operation, and the evaporator coil during heating mode operation. The "basement room" of the environmental chamber, which was set and maintained at a nominal $65^{\circ} \mathrm{F}$ and $50 \% \mathrm{RH}$, contained the HRU and the Wh. Water flow direction is show in the "basement room", and refrigerant flow direction is show in all rooms for cooling mode (hlack arrows) and heating mode (white arrows) operations.

Schematics of the HRUs used in System $I$ and Systen 2 are presented in Figures II-3 and II-4, respectively. The water and refrigerant inlets and outlets of the HRU are appropriately identified. For both systems, the refrigerant flow through the heat exchanger in the HRU is governed by the condenser and evaporator temperatures seen by the compressor. 
In System 1, the water circulating pump of the HRU operates when the HP compressor operates and the inlet water temperature sensed by the thermally controlled switch is less than about $150^{\circ} \mathrm{F}$. When the inlet water temperature rises to about $150^{\circ} \mathrm{F}$, the switch deactivates the circulating pump. When the inlet water temperature decreases to about $140^{\circ} \mathrm{F}$, the switch reactivates the circulating pump. Although the circulating pump is the driving force for circulating water, the water temperature at the modulating flow control valve must exceed some set value which in this case was $140+5 \mathrm{~F}$ before the valve opens allowing the water to flow. For this HसU the control valve temperature is settable in the range of $120-160^{\circ} \mathrm{F}$. The circulating pump has a sealess type impeller with magnetic coupling to the drive motor which has thermal overload protection; it is rated at I/200 HP, $1725 \mathrm{RPM}, 230 \mathrm{~V}, 60$ Hertz, I phase and 0.26 amps. Although the maximum rated flow rate of the circulating oump is 3 gallons per minute, the actual flow rate is intermittent and modulated from less than 0.1 gallon per minute to the maximum by the temperature sensitive flow control valve. The heat exchanger in HRU $I$ is well insulated, being completely encapsulated in polyurethane foam insulation.

In System 2, the water circulating pump of the HRU operates whenever the HP compressor operates. The flow of water is controlled by a temperature sensitive modulating flow control valve. This valve, commonly called a reverse acting valve, opens when the temperature at its sensor reaches the control temperature, which can be set between 130 and $160 \mathrm{~F}$. When the water temperature at the valve equals or exceeds the set temperature, the valve allows the water to flow. For more rapid thermal response, the valve contains a small internal bleed port, through which a small steady stream of water flows over a temperature sensitive bulb. Another important component in this HRU is the 3-way flow control valve, which directs the incoming water to either the heat exchanger or the heat exchanger by-pass Ioop, or both, depending upon the temperature of the inlet vater. The recommended temperature set point for this valve is $150 \mathrm{~F}$. When the inlet water temperature is below $160 \mathrm{~F}$, it flows through the heat exchanger; between about $160-170^{\circ} \mathrm{F}$ both paths are open; and when the inlet water exceeds the set-point by about $10 \mathrm{~F}$, the water by-passes the heat exchanger and will not extract any heat from the hot refrigerant gas. The heat exchanger in HRU 2 is enclosed in a fiherglass insulated compartment that is open on one side and allows venting of the HRU through louvers in the HRU casing.

In both Systems 1 and 2, the heat exchanger is of the counterflow tube-intube type. Hot refrigerant gas passes through the outer tuhe and water flows through the concentric inner tube which has a convoluted outer surface for increased heat transfer on the refrigerant side.

The schematic representation of the third integrated system investigated is shown in Figure II-5. The HP in this system contains a thermal expansion valve and a capillary tube for metering the refrigerant flow during heating and cooling mode operation, respectively. In addition, the heat pump is a single package unit that mounts completely within the outdoor chamber. The rated cooling capacity of this HP is a nominal 36,000 Btu/h. A schematic of the HRU is shown in Figure II-6. The water circulating pump of the HRU operates only when the HP compressor operates. When water is circulating at a temperature below the set temperature, the two solenoids valves are normally open (N.O.) and 
normally closed (N.C.). as shown in Figure II-5. lihen the temperature of the leaving water exceeds the set temperature it causes the temperature sensors on the water outlet line to reverse the two solenoid valves positions and the hot refrigerant gas to by-pass the heat exchanger. When the ternperature sensor on the refrigerant gas outlet senses the set temperature of the gas in the gas outlet line it deactivates the circulating pump. It should be noted that all flow control set temperatures may he mamaliv ad iusted. The heat exchanger in this HRU is of the counterflow 2-tube type.

For Systems 1 and 2 a twelve foot 0.5 inch $0 . D$. copper tube was used to connect the refrigerant outlet from the HP compressor discharge to the refrigerant inlet of the HRU. A similar length of tubing was used to connect the refrigerant outlet of the HRU back to the HP reversing valve. By-pass valves were installed near the compressor discharge to permit the HRU to be switched either into or out of the system. For System 3, two 25 foot 0.5 inch O.D. copper tubes were used to connect the inlet and outlet of the HRU to the refrigerant lines of the HP; no HRU by-pass provisions were made for this system, since such provision is an integral part of the HRU used in this system.

For all systems a six foot 0.5 inch $0 . D$. copper tube was installed to connect the water inlet of the HRU with the drain outlet of the $\mathbb{H}$, and a ten foot 0.5 inch O.D. copper tube was installed to connect the water outlet of the HRU with the hot water outlet of the WH. All of the interconnecting tuoing between the HP, HRU and WH was insulated with RF-16 fubatex FS 4003, 5/8 ID x 3/8" wall thickness.

For Systems 1 and 2, sheet metal ducting was installed on the indoor air handling unit to obtain the manufacturer's specified airflow rate and pressure drop across the indoor coil. For System 3, the airflow rate through the indoor side was adjusted to the manufacturer's specifications by use of a baffle installed in the indoor section. The proper airflow pattern was obtained by using an air deflector.

Standard copper-constantan thermocouples were used to measure the following: (1) dry-bulb and wet-bulb temperatures of the air on the domside of the coil within the indoor unit and at the air inlet and outlet of the IP indoor unit, (2) dry-bulb temperatures in each of the three environmental comcartiments ("outdoor", "indoor" and "basement"), (3) water temperatures entering and leaving the HRU, (4) water temperatures at 6 different levels in the temperatures at various locations along the refrigerant flow line.

Calibrated pressure gauges were used to measure high side and low side refrigerant pressures in the refrigerant line. Calinrated watt-hour meters were used to record the electrical energy used by (1) the compressor and outdoor fan and (2) the indoor side blower. The locations of the thermocouples, pressure gauges and air flow meters are indicated in Pigure II-2 for Systems 1 and 2. The six thermocouples in the VH are attached to a "thermocouple tree"; their junctions were located at the level of the central horizontal plane of each of 6 non-overlapping but approximately equal volumes from the top to the bottom of the it tank. 
Finally, after making all refrigerant line connections to the HRU, refrigerant R22 was added to the system in accordance with the HRU manufacturer's instructions. During this refill, all valves between the IPP compressor and reversing valve were open and the "indoor", "gutdoor" and "basement" room temperatures were equal, at approximately $75 \mathrm{~F}$.

\section{Test Procedure}

The test procedure generally followed during the experimental phase of this study was to begin operation of the HP with the HRU in the line (not by-passed) and record the relevant data every half during the first 5.5 hours of HP operation, after which time the HRU was by-passed. With the HRU by-passed, the HP operation was continued for an additional 1.5 hours with measurements made each half hour before the run was terminated.

Heating elements in the water heater were disconnected and no water was drawn during the test periods. The indoor conditions were controlled to maintain nominal values of 50 percent relative humidity with an indoor room temperature of $80^{\circ} \mathrm{F}$ during cooling mode operation and $70^{\circ} \mathrm{F}$ during heating mode operation. The series of tests for each of the systems was run in order with a nominal "outdoor" temperature of $20,95,85$, and finally $75^{\circ} \mathrm{F}$.

D. Test Results and Analysis

The data recorded during the experimental investigation of integrated HPHRU-WH Systems 1 and 2 were used to develop Figures II-7A-C, through II-16-A-C, which depict water temperatures, heat recovery, refrigerant temperatures, refrigerant pressures, and energy consumption as a function of time during continuous HP operation. In addition, these data were also utilized in the development of Tahle II-1, which presents thermodynamic nerformance data for the HP with and without the HRU in the refrigerant line; mable II-2, which presents HP capacity, power, and efficiency performance data with and without the HPU in the refrigerant line; and Table II-3, which presents mean heat recovery rate, thermal energy rate, energy consumption rate and heat recovery efficiency.

Furthermore, it should be noted that due to time constraints of stabilizing the environmental chamber in which the tests were conducted and limitations on personnel availability it was not possible to carry out any runs to the point where the HRU control systems would shut dow the heat recovery operation. Thus, the design cutout temperatures were never determined. This problem could have been alleviated by using a smaller water storage tank, but this would not have been consistent with the objective of determining the time required for a complete recovery with a standard 52 gallon storage type water heater. The recovery time for the two systems tested is obviously greater than 5.5 hours., the maximum of any of the runs.

It was found that there were unexplanable inconsistencies in the data for the cooling mode run with nominal outdoor temperature of $85^{\circ} \mathrm{F}$ for System $I$ and the heating mode run for System 2; thus, no data for these muns are presented.

Before discussing the figures and tables, an explanation of why they do not include System 3 is appropriate. While running System 3, it was apparent that 
the heat recovery was much less than expected. However, the runs were contimed in the belief that the system was performing as it should and that its heat recovery performance was just poor. This unsatisfactory performance, which was highlighted during the analysis of data, led to a trouble shooting investigation of why the performance was so poor. From this investigation it was determined that the automatic by-pass control, which by-passes the refrigerant around the heat exchanger when the water in the tank is sufficiently hot, operated incorrectly during these mun, resulting in invalid test data. In other words, the poor heat recovery had resulted from the refrigerant by-oassing the heat exchanger when it should not have, due to a faulty automatic by-pass control. Since the data taken for System 3 are invalid they are not presented or further discussed in this report, nor is it planned to repeat these tests at this time.

\section{Figures for System 1}

Figures II-7A-C show the water temperatures within the storage type WH as a function of time during contimuous HP operation over a perion of 5 or 5.5 hours. As may be expected, the system provides more hot water at usable temperature when the outdoor temperature ( $T$ ) is higher than when it is lower. When $T_{0}=20^{\circ} \mathrm{F}$, little usable hot water is provided. In addition, the figures also show the thermal stratification in the water tank and the decrease in the time required for all of the water in the tank to reach an "equilibrium" temperature, of ahout $140-145^{\circ} \mathrm{F}$, as the T. increases. The cut-in and cut-out temperatures are the maximum and minimum temperatures respectively, at the water outlet of the HRU. These temperatures are influenced by the location and temperature setting of the flow control valve, its operational temperature tolerances, the heat exchanger insulation and heat transfer characteristics, the lengths of piping between the heat exchanger and the flow control valve, and the insulation on the copper tubing within the YRU. As the water in the heat exchanger increased in temperature, the water near and at the flow control valve also increased in temperature, by thermal conduction. When the flow control valve sensed a high encugh temperature it opened. Since the temperature of the water between the flow control valve and the heat exchanger and that in the heat exchanger was higher than that at which the flow control valve opened, flow contimed until water oassing through the heat exchanger gained insufficient thermal energy to maintain a temperature high enough to keep the flow control valve open.

Figures II-8A-C show the increase in heat recovery as a function of time of system operation. The values used to plot the curves were calculated using the water heater themoccuple tree temperature data taken each half hour. It is apparent that heat recovery during cooling mode operation is substantially larger than during heating mode operation. These curves also serve as a basis for determining some of the heat recovery rates shown in Tahle II-3 determined for the period between $I$ and 3 hours following the start of system operation, as will be described below.

Figures II-9A-C show the temperatures of the refrigerant gas discharged from the compressor $\left(T_{C D G}\right)$, entering the HRU $\left(T_{P G D}\right)$, leaving the HRU $\left(\mathrm{T}_{R G L}\right)$, and entering the compressor $\left(\mathrm{T}_{\mathrm{SGE}}\right)$ as a function of $\mathrm{HP}$ 
contimuous operating time. In the heating mode of operation with $m=$ $20 \mathrm{~F}$, the temperature of the compressor discharge gas at the inlet fo the HRU is relatively low, approximately $155^{\circ} \mathrm{F}$; thus, the relatively small magnitude of the refrigerant gas enthalpy in the superheat region results in a low heat recovery rate. In the cooling mode of operation the heat recovery rates are much larger than for the heating mode, since the higher refrigerant gas temperature at the compressor discharge provides a much higher enthalpy and, consequently, greater quantities of thermal energ. are available for the HRU. After some time of operation, the rise in the temperature of the refrigerant gas leaving the HRU (T ${ }_{\mathrm{RGT}}$ ) reflects a decrease in thermal energy transfer due to the rise in the temperature of the water returning to the HRU from the WH tank. This occurred after approximately 2.0-3.5 hours for this system when operating in the cooling mode, Figures II-9B-C. When the HRU was removed from the refrigerant line, there appeared to be a slight initial drop, followed by a slight rise, in the refrigerant gas temperature at the compressor discharge port, ${ }^{\mathrm{T}}{ }_{\mathrm{CDG}}{ }^{*}$

Figures II 10A-C show the refrigerant pressures at the compressor discharge $\left(P_{C D}\right)$, downstream of the 12-foot gas line from the HRU $\left(P_{R C}\right)$, just downstream of the condenser $\left(P_{R T C}\right)$, and in the suction line to the compressor $\left(\mathrm{P}_{\mathrm{CS}}\right)$ as a function of time of continuous HP operation. The discharge pressure is more than 50 psi higher for $\mathrm{T}=95^{\circ} \mathrm{F}$ than for $\mathrm{T}_{\mathrm{O}}=$ $75^{\circ} \mathrm{F}$, while the suction pressures differ by only $10^{\circ} \mathrm{psi}$ for this $20^{\circ} \mathrm{F}^{\circ}$
variation of outdoor temperatures. The pressure drop due to the HRU and the two 12 foot tubing lines connecting the HRU to the HP is about 5-8 psi at $\mathrm{T}_{0}=75^{\circ} \mathrm{F}$ and $8-10$ psi at $\mathrm{T}_{0}=95^{\circ} \mathrm{F}$; it is only $2-4$ psi at $\mathrm{T}=20^{\circ} \mathrm{F}$. The Pressure drop between the compressor discharge and the condenser outlet decreased Irom an average of about $17.4 \mathrm{psi}$ with the HRU in the refrigerant Iine to an average of about $15.3 \mathrm{psi}$ with the HRU by-passed, during cooling mode operation. During heating mode operation the pressure difference averaged about $40.8 \mathrm{psi}$. Suction pressure generally rase slightly when the HRU was by-passed.

Figures II-IIA-C show the total electrical energy consumed by the indoor blower, condenser fan and compressor as a function of HP continuous operating time. As may be noted, the rate of energy consumption show in mable II-3 remained essentially constant whether or not the HRU is in the refrigerant line.

Mean heat recovery rates for the muns at nominal $\mathrm{T}_{\mathrm{O}}=20,75$ and $95^{\circ} \mathrm{F}$ for system I were determined from the difference between the total heat recovery at 1 and 3 hours following the start of system operation, see Figures II-8A-C, and are presented in Table II-3. The thermal energy rate of the refrigerant gas was determined from the difference between the inlet and outlet enthalpy and the refrigerant mass flow rate at 2 hours following the start of system operation. The refrigerant pressure used in the determination of the inlet and outlet enthalpies was taken as the mean of the compressor discharge pressure, $\mathrm{P}_{\mathrm{CD}}$, and the outlet pressure of the HRU, $\mathrm{P}_{\mathrm{RG}}$, at the 2 hour mark, see Figures $I I-10 \mathrm{~A}-\mathrm{C}$. The inlet and outlet temperatures used in determining the enthalpies were $T_{P G F}$ and $T_{R G T}$, were taken at the 2-hour mark, see Figures II-9A-C. Refrigerant mass Iow rate 
was determined from the mamufacturer's data for this compressor at the appropriate evaporator and condenser temperatures.

\section{Figures for System 2}

Figures II-12A-C are similar to Figures II-TB,C, showing that the higher the $T_{0}$, the more hot water was nrovided at usable temperatures. The hot water in the $\mathrm{WH}$ tank generally reached a first pass mean temperature of ahout 135-138 $\mathrm{F}$ with a cut-in temperature of 140 $\mathrm{F}$ as compared to the 140 $145^{\circ} \mathrm{F}$ mean temperature and $149^{\circ} \mathrm{F}$ cut-in temperature for System 1 .

Obviously, the temperature settings of the flow control valves in System 1 and 2 as set by the two HRU manufacturers, were not identical.

Figures II-13A-C are similar to Figures II-8B,C and were used in the same manner to calculate the experimental mean heat recovery rates shown for System 2 in Table II-3.

Figures II-14A-C are similar to Figures II-98,C. The comnressor discharge gas temperature, ${ }^{T} C D G$, for the ${ }^{m}=75 \mathrm{~F}$ run was higher than expected hecause of the increased load tha? resulted from an excessively high indoor temperature (Table II-1). The result of this condition was an increased heat recovery for the $T=75{ }^{\circ}$ mun to about the same magnitude as for the $T=85 \mathrm{~F}$ run, as may $\mathrm{P}_{\mathrm{T}}$ seen hy comparing Figures II-13A-B. For the $T_{Q}=95{ }^{\circ} \mathrm{F}$ run, the magnitude of $\mathrm{T}_{\mathrm{RGT}}$ at 5 hours of operation is much grealer than for the other runs, due the increased temperature of incoming water (Figure II-12C) that resulted from a high heat recovery rate. Thereafter, the small difference between $\mathrm{T}_{\mathrm{DGE}}$ and $\mathrm{T}_{\mathrm{PG}}$ resulted in a decrease in heat recovery, as seen in Figure II-ISE. About 2.5-3.5 hours of cooling mode operation were required before $\mathrm{T}_{\mathrm{RGE}}$ began to increase.

Figures II-15A-C are similar to Figures II-10B,C. As occurred in System 1 , the discharge pressure of System 2 increased substantially with $T$ while the suction pressure increased only slightly. The pressure drop die to the HRU and the two 12 foot lines connecting the HRU to the HP was relatively constant at $8-10$ psi for the mus at $T=75$ and $85^{\circ} \mathrm{F}$ and $6-8$ psi for the run at $95 \mathrm{~F}$. Removal of the HRU from the refrigerant line resulted in an apparent increase in the discharge pressure for the $T=75$ and $85^{\circ}$ runs and little change for the $\mathrm{T}=95 \mathrm{~F}$ run. The oressure $\mathrm{drop}$ betreen the compressor discharge and the condenser outlet, during cooling mode operation, decreased from an average of about 15.8 psi to an averafe of ahout 8.4 psi, when the HRU was by-passed. Suction pressure generally increased slightly when the HRU was by-passed.

Figure II-I6A-C are similar to Figures II-IIP,C. The total energy consumed by the indoor blower, condenser fan and compressor increased linearly with time and directly with $\mathrm{T}$. The rates of energy consumption for cooling mode operation did not noticebly change when the refrigerant gas was rerouted to by-pass the HRU.

The same methods used for calculating the mean heat recovery rates for the $\mathrm{VH}$ and thermal energy rates for the refrigerant for System $I$ were 
used for System 2. The results of these calculations are also summarized in Table II-3.

3. Tables for Systems 1 and 2

Table II-I shows the time averaged ambient conditions and thermodynamic performance data for the HP operating by itself and as part of an integrated HP-HRU-WH system. As may be noted, the condenser and evaporat ir pressures and temperatures, the compressor discharge pressures, the compression ratios, and the refrigerant mass flow rates were consistently lower when the HRU were in the refrigerant line than when they were by-passed. The compressor discharge temperatures, work of compression, and refrigeration effect were almost alivays larger when the HP operated as part of the HP-HRU-WH system rather than as an independent unit. Finally, the values calculated for the thermodynamic coefficient of performance during cooling mode operation and the cooling capacity when the HP operated with the HRU in the refrigerant line were ahout equal to those calculated for the HP when it operated as an independent unit.

Table II-2 presents overall performance data, which includes all fans and pumps, and shows the capacity, power and efficiency of Systems $I$ and 2, and the HP data provided by the HP manufacturer. Agreement of the exnerimental data with the mamufacturer's data for the HP was almost spectacular when it is considered that this was a reproducibility experiment which compared a specific unit with a representative average for the manufacturer's product. As for the average power, it may be noted that using the HRU resulted in a decrease in power usage. The EYR, calculated by dividing the capacity by the power, almost always increased (mainly due to the decreased power requirement) when the HRU were used.

These data indicate that the HRU effectively increased the capacity of the condenser, which led to an improvement in the performance of the HP, since the increase in pressure drop through the condenser was not excessive. In addition, the reductions in the compressor discharge pressure and compression ratio indicate less loading on the compressor, which would tend to improve the operation and prolong the useful lifetime of the compressor.

Table II-3 summarizes the mean heat recovery rate, thermal energy rate, energy consumption rate, and heat recovery efficiency for Systems 1 and 2. The table shows consistently better performance, i.e., greater heat recovery rate and heat recovery efficiency, for System $I$ when the HP is operated in the cooling rather than the heating mode. The mean heat recovery rates for the WH and the thermal energy rates for the refrigerant also appear to increase with increasing outdoor temperature. Furthermore, it is apparent that the thermal energy rates for the refrigerant are consistently greater than the mean heat recovery rates for the $\mathrm{WH}$; the differences, which average 7.2 and 8.3 percent during cooling mode operation for Systems 1 and 2, respectively, are to be expected and may be attributed to generalized heat loss characteristics of the HRU. The sizable percentage difference for heating mode operation, for System 1, may 
be attrihuted to the uncertainty in the determination of the mean heat recovery rate and the heat loss characteristics of the HRU. Regarding the heat recovery efficiency, which is the ratio of the mean heat recovery rate to the energy consumption rate, there appears to be no consistent trend with varying nominal outdoor temperature; although the heat recovery efficiency increased from 1.86 to $1.96 \mathrm{Btu} / \mathrm{h} h$ for System 1 operation at $\mathrm{T}$ $\simeq 75$ and $95^{\circ} \mathrm{F}$, respectively, it was an average of $1.68 \mathrm{Btu} / \mathrm{Wh}$ for System 2 operation at $\mathrm{T}_{0} \simeq 75,85$ and $95 \mathrm{~F}$.

\section{E. Conclusions}

The major conclusions drawn from the experimental phase of this work as follows:

1. The HRUs used in HP-HRU-WH Systems 1 and 2 were adequately controlled so that they produced no discernable adverse effects on either the HP or the WH.

2. The use of the HRU in Systems 1 and 2 resulted in improved performance of the HP, mostly due to a decrease in the power requirement for its compressor.

3. The use of the IRU in Systems 1 and 2 resulted in a reduced work load for the HP compressor, as shown by the decreased discharge pressure and compression ratio.

4. The heat recovery rate and heat recovery efficiency for System 1 is substantially lower during Ho heating mode operation than during HP cooling mode operation.

5. To increase the water temperature from 50 to $1400^{\circ}$ for a 52 gallon WH tank using a continuously operating HP-HRU-WH system the equivalent of Systems 1 and 2 would require in excess of 6 hours during the cooling season and much longer during the heating season.

III. Estimation of Seasonal Energy Costs and Savings

A. Introduction and Principal Findings

Seasonal energy costs and savings refer to a full annual cycle of heating and cooling a house with a HP and meeting hot water requirements. The savings are the differences between total household electricity usage with and without heat recovery, expressed in kith per year. Energy savings may be converted to dollar savings using local rate schedules for the time frame of the estimate. Note that marginal cost rates vary with locality, amount of energy used, power companv success in obtaining higher rates during the estimation period, and in some cases the tyoe or class of service provided to the particular residence. Hourly simulations were conducted in which house construction and operation were held fixed. 
Weather was varied by using data from Washington, D. C., Atlanta, GA, Chicago, II, and Seattle, WA. Fstimated savings are in the approximate range of 800 to $1200 \mathrm{kWh}$ per year, or \$40 or \$60 per year at \$0.05 per kin. (See Table III-1)

Simulation details about the house, the heat recovery system and house operation are given below and in Appendix A. Significant operating assumptions were to set the thermostat for cooling at 10 F above the setting for heating and to use ventilation where the results would be acceptable. These assumptions led to a zero house load for more than a third of the hours per year at each of the tested locations. This consideration is important because heat recovery is possible only if the house places a demand on the HP.

Tank size was varied at Washington and Atlanta. Different analytical methods were compared to test the need for detailed simulations in making decisions on heat recovery systems.

Principal Findings

1. Tank size selection involves compromise. Increasing the tank size increases the ability to accept recovered thermal energy whenever it is offered and increases the amount of "reserve" hot water that is available when no recovered heat is being provided, hut decreases efficiency by increasing heat losses through the storage tank's insulating jacket. The ability to accept offered thermal energy was not a problem under the simulated conditions using tanks of 40 gallons or larger. Based on a quarter tank resemre, a 40 gallon system with a good heating rate from its backuo resistance heater might meet dishwasher or clotheswasher demands. A 52 gallon system would permit more flexibility in scheduling hot water use, at an additional cost of about $\$ 3$ per year (at 5 cents per $k W h$ ) in jacket losses. Iarger tanks are not particularly attractive, increasing energy casts without providing important benefits.

2. The fraction of the offered thermal energy that was accepted was at or near 1.0 for all the cases covered in the simulations. This is the "decoupling factor" show in Table III-1. This means that the tanks were quite successful in accepting thermal energy whenever it was offered and making it available for later use. In this sense the time sequence of offerings is decoupled or rendered independent of the time sequence of water uses. Where time sequences are unimportant, the hourly data may be arranged in ways that are analytically more convenient and the benefits of hourly simulations for system performance estimation purposes are minimal. Holding the house load profiles fixed, the decoupling factor will remain hign for higher hot water usage. Fixing hot water usage, the decoupling will also be high for lower house load profiles and for lower HP capacities.

3. It should be expected that thermal energy recovered during the heating season will not meet hot water requiraments even under 
favorahle conditions. This means that heat from the backup heater in the WH will be needer on a regular basis and that the tank will commonly be at or near its "reserve" status during this season.

4. Some thermal inefficiencies must be expected in the loop connecting the HRU and the WH. If this loop is less efficient than the heating element in the tank in providing thermal energy to the water, the heat recovery system should be shut off when supplemental resistance heat is being provided to the house.

5. The operating cost of the HP is unchanged by heat recovery operations during the cooling season, except for the possibility of some second order effects involving performance of the refrigerant coils. Total operating costs during the heating season for the HP, supplementary heater and backup heater vary with tank size because jacket losses depend upon tank size. However. since all the offered heat was accepted during the heating season, there was no difference in the combined operating costs of the HP and the supplemental heater with respect to tank size in the simulated cases. (Coil defrosting costs were not estimated. The modeling assumption is that heat recovery operations would be suspended during defrosting and that defrosting cycles do not interfere with HP heating cycles.)

6. It is possible during some parts of the cooling season to achieve satisfactory indoor conditions by ventilation instead of keeping the house closed and depending on the HP. Ventilation is economically sound since more energy is saved by not running the HP than would be provided "free" to the $\mathrm{WH}$.

7. The weather at any given location can vary considerably from year to year and within the service area of a weather data source, with corresponding effects on HP Ioads and heat recovery savings. Since system paybacks will take years, the data and analysis should cover a significant number of years and the use of averaged weather data in the estimating procedures is justified.

8. Simplified estimation methods that would be adequate for consumer decision purposes appear practical. Development of such methods is suggested.

\section{B. System Description and Operation}

A schematic diagram of the integrated HP-HRU-IH system to be discussed is shown in Figure III-1. The main elements are a HP, a HRU and a conventional electric,$\pi$ with its lower heating coil disconnected (and omitted from the diagram). The upper electric heater is called the backup heater in the discussion. A supplemental resistance heater is provided to augment the HP when the overall demand for heat by the house and the heat recovery system exceeds the IP capacity. House thermostats control the HP and the supplemental heater. The circulating pump in the HRU operates steadily when the HP is operating. Water is allowed to flow from the HRU only when it is hot enough (nominally $145^{\circ} \mathrm{F}$ in these simulations). 
The symbol. $Q$, on the scale next to the tank represents the heat status of the tank. There will be some mixing between the hot water at the top and the cold water at the bottom of the tank, but a sharp temperature transition is used for purposes of exposition. Q increases (i.e., moves down in the diagram) when the HRU is providing hot vater and moves up when hot water is drawn or thermal energy is lost during standby. The backup heater will come on when $Q$ is less than the "reserve" hot water level, Q1, and will turn off when Q reaches QI. If the HRU supplies enough thermal energy to increase $Q$ to $Q 9$, then the pump will draw hot water, signaling that the tank has reached its maximum heat capacity, and no further thermal energy offerings by the HRU will be accepted.

Figures III-2a-c show the hour-hy-hour heat status of the tank in percent of heat capacity, Q9, for selected days from the Washington, D.C. simulation. Figures III-2a and $\mathrm{b}$ are for a 40 gallon tank on different days, and Figures III-2b and $c$ are for 40 and 52 gallon tanks on the same day. Status is shown after all gain and loss transactions for an hour have been completed.

Therefore, $Q$ is never shown below the reserve status, $Q 1$, and $Q$ is never allowed to rise above the heat input limit, Q9. Except for extraordinary cases, backup heat is needed whenever the ending status is less than Q1, and some of the offered heat is not used when the ending status is 09. It is seen that the tank heat'status can be quite dynamic when the HP is active and that larger tanks are able to accept more of the offered heat than smaller capacity tanks.

Further understanding of the general interactions inyplving the house system and local weather may be gained from Figure III-3 ${ }^{1}$, in wich several heat recovery factors are presented in schematic form as functions of the primary independent variable, the outdoor dry-bulb temperature. The HP operating regimes of heating and cooling are separated by a zone of zero house load, in which the HP does not operate.

The water heater factor, WHF, is shown in the top graph, III-3a. WHF is the fraction of the HP output that is offered to the water tank. WHF rises with outdoor temperature because the discharge temperature of the refrigerant coming from the HP compressor increases with the temperature of the outdoor coil whereas the minimum temperature to which the refrigerant may be cooled in the heat exchanger is determined by the required output water temperature.

House load and HP capacity vary with outdoor temperature, as indicated in Figure III-3b. The two capacity curves are for a nominal three-ton IP. House loads are shejp here and in Figure III-4 solely as functions of cutdoor temperature. The general effect of a ventilation option during the cooling season is show. The load curve slopes and intercepts on the temperature axis are determined mainly by house size, construction and operation. Geographic location may affect the load through wind, air quality, cloud cover and outdoor humidity characteristics of the locality. Iatitude affects the amount of daylight through the seasons and the incident angle of solar radiation. Houses have thermal masses that cause loads to lag the forcing functions. Even though

(1) Information from several sources was used to develop Figure III-3, including Bibliography items 6 and 14, test data, engineering calculations and externally supplied simulation results.

(2) Hourly house load data and corresponding outdoor dry-bulb temperature were obtained from another NBS project. These data were sorted according to five-degree temperatu bins, averaged within bin, and plotted. 
the load can vary considerably at any given temperature, the axtioor temperature can serve alone as an effective indicator of house loar for present purposes. (Estimating methods using: outdoor temperatures are discussed in Section $E$ and numerical results are compared in Table III-2 with those from simulations using hourly heating, cooling loads and temperature.)

Supplemental resistance heat is needed when the combined house heating and HRU loads exceed HP capacity. The effect of offering thermal energy to the iH during heating mode operation is shown as a cross-hatched area, reducing the HP heating capacity available to the house. This capacity reduction does not occur during cooling mode operation. If the house load exceeds the HP capacity in the cooling mode, the indoor temperature will rise appropriately.

There is a ten-to-one scale expansion from III-3b to III-3c. The domeshaped curve in III-3c labeled "From Heat Pump" corresponds exactIy to the heat flow segment in III-3b labeled "To Water Heater". Figure III-3c shows the average hourly heat requirement for the WH without regard for time of day, and the thermal energy sources in the integrated water heating system. Thermal energy offerings from the HP (the curves labeled "From Heat Pump") are found by multiplying the WHF by the lesser of the HP load or the HP capacity. The HP load is the same as the house load in the cooling mode, but includes the thermal energy given to the water by the HRU and the house load in the heating mode. Some of the offered thermal energy at the higher outdoor temperatures is more than can be accepted on a steady-state hasis. However, some of this excess thermal eneroy can be used if the tank status before the offering is below the maximum level that is allowed. (High outdoor terperatures accounted for all cases in the simulations in which some of the offered heat could not be used, thus reducing the decoupling factor.) The backup heater must be capable by itself of meeting the full water-heating load when the HP will not be operating.

A sample climate profile in terms of hours per year as a function of outdoor temperatures is shown in Figure III-3d. This profile is for Washington, D. C. and the single year of 1957. Profiles of this type for other locations in the United States are given in Figures A-3 through A-13 of Appendix A. These latter profiles, representing data over at least ten years, orovide a useful set of weighting factors for judging. system attractiveness in various regions. Data for these curves came from Item 6 in the Bibliography, in which olots for many more sites are available. The attractiveness of HP-WH systems is greatest at those locations having many hours per year in the temperature ranges where the IIP offerings (III-3c) are high.

House load data for the simulations were generated for the same hypothetical house at four locations, using a particular weather year at each location. These load data were sorted into five-degree temperature bins, averaged within bin and plotted against bin temperature in Figure III-4 for Washington, D.C. and Atlanta, GA. Sensible and latent loads were added to obtain the total load for each hour. Differences in climate and sun elevation may account for the differences betiveen sites.

Some general inferences that are borne out by the simulations may be deduced directly from Figure III-3. 
1. The WFF declines as the outdoor temperature goes down, for both heating and cooling applications, reaching zero where the temperature of the refrigerant coming out of the compressor is too low to transfer thermal energy to water in the HRU at the required water output temperature. Hours at temperatures below these zero points could be dropped from consideration for purposes of heat recovery analysis.

2. There is some temperature below which supplemental resistance heat will be needed, given reasonable sizing of the HP with respect to the house load profile. The supplemental heater must make up any shortfall in the heat that the HD supplies to the house. Therefore, no advantage is seen in giving HP thermal energy to the WH if it must be replaced by the supplemental heater. The simulation does not include any allowances for thermal inefficiencies between the HRU and the WH, and thus treats the energy used by the tank's backuo heater or the supplemental heater as equivalent in the energy totals. Any such inefficiencies mean that the heat recovery system should he turned off when the supplemental heater is needed.

3. The backup heater will have to carry much of the water heating load during the heating season, with the further implication that the tank heat status will be at or near the reserve level, Q1, during this season. Referring to the Water Heater Operation graphs in Figure III-3, the dashed line labeled Average Hourly Requirement is one twenty-fourth of (64.3 gallons per day $x 8.25$ pounds per gallon $x$ $90^{\circ}$ F temperature rise plus 1 percent per hour for hea.t loss during standby), or a total of about 2100 Btu per hour. The highest offerings during the heating season occur in the 25 to $35{ }^{\circ}$ temperature range and are about half of these average demands. Some combination of major reductions in water use and increased thermal energy offerings (by increasing both house heating. loars and heat oump capacity) would be needed to close the gan in this limited temperature range. Also, where all the thermal energy offered during the heating season is accepted, the total annual electricity consumption by the IP and the supplemental heater is independent of tank size. However, wH jacket losses do vary with tank size, affecting annual energy use by the backup heater and hence the total anmual consumption of electricity.

4. The practice of ventilation during the cooling season is economically sound as long as satisfactory indoor temperature and humidity conditions can be maintained. Some "free" thermal energy to the WH would be missed, but this loss would be outweighed by the savings in HP operation.

\section{Simulation Methodology}

There are many variables affecting the amount of thermal energy that is available from a HP-HRU-WH system and the operating cost of obtaining this heat. A computer simulation model was developed to study the interactions of several of these variables on an hourly basis for selected situations. The hourly steps 
in this simulation are outlined in Figure III-5 and the simulation is described further in Appendix A. The purpose of the simulation is to generate mumerical information bearing on the economics of HP-HRU-WH systems in terms of ma,ior system variables. Several of these variables and their interactions have already been introduced.

The thermal performance of houses and other buildings is a significant study topic at NBS for which a highly detailed computer program, called the NBS Load Determination, or NBSID (Bibl. 8), program, has been written. NBSID was used on another INS project (a retrofitting study using 1800 square foot houses and four-person families) to generate hour-by-hour house load values for selected locations and weather years. Thermostats inside the house were set at $68^{\circ} \mathrm{F}$ during the heating season and $78^{\circ} \mathrm{F}$ during the cooling season. Ventilation was used when a 68 to 78 F indoor temperature and an indoor relative humidity below 60 percent could be maintained by this method. Neither ventilation nor the HP were used when satisfactory conditions could be maintained wi thout them. The present simulation makes use of these house load data and the corresponding outdoor temperatures. An average hot water usage rate of 64.3 gallons per day (450 gallons per week) with a $90 \mathrm{~F}$ temperature rise was used. The key parameters of HP coefficient of performance (COP) and output canacity (CAP) and the water heater factor (WHF) were expressed as functions of outdoor temnerature. (See Appendix A, Table A2.) The COP and CAP values in the simulation are consistent with NBS laboratory data. An hourly hot water draw schedule developed by NBS was used for each day of the simulation year. (See Appendix A, Table AI.) The heat status of the $W H$ at the end of the previous hour is the beginning status in the current hour.

The computational steps for each hour are:

1. Subtract from the initial heat status, Q, the standby heat loss and the thermal energy in any hot water that was drawn during the hour to produce the pre-offer heat status. A standby thermal energy loss rate of one percent per hour of the initial heat status of the tank was used.

2. If there is any load on the IP, determine which alternative will set the limit on the amount of thermal energy that the tank will accept.

a) The tank can only accept thermal energy up to its heat capacity, 29.

b) - The maximum thermal energy offering is the product of the HP capacity and the WHF at the temperature for the hour.

c) If the HP load is at or below the HP capacity, then the thermal energy offering is determined by the product of HP load and the WHF. The IP load is solely the house load in the cooling mode, but includes thermal energy for the $\mathrm{WH}$ in the heating mode.

3. Compute the new tank status and the following items for accumulation and eventual printout: 

a. Heat recovery unit offering
b. Heat recovery unit output (= water tank acceptance)
c. Backup heater load
d. Supplemental heater load
e. Heat pump electricity used.

The hackup heater is used only when necessary to achieve the minimum (or reserve) heat status, QI, at the end of the hour. Calculations of electricity use by the HP include adjustments for efficiency degradation during cyclic operation.

4. Go on to the next hour.

\section{Results}

Results from ten simulation runs are summarized in Table III-l. Two runs were conducted for each city using systems with 52 gallon tanks, one without heat recovery (the base case) and the other with heat recovery. These pairs indicate regional variations in energy use and savings potential. Tank size effects were also tested with runs for Washington and Atlanta using heat recovery systems with 40 gallon and 80 gallon tanks. Both the 52 and 80 gallon tark systems accepted all offered thermal energy. Jacket losses for the 80 gallon tank system were higher than for the 52 gallon tank system, so the 80 gallon results are not presented. The operating mules with and without heat recovery are identical except that no thermal energy is accepted from the HRU in the base case. All water thermal energy in the base case comes from the backup heater and the tank is restored to the reserve status, Q1, at the end of each hour.

Two system performance measures are provided. The one of greatest interest to a homeowner is annual electric energy saved, measured relative to a $\mathrm{HP}$ and $\mathrm{WH}$ system without heat recovery and in which the lower coil in the WH is similarly disconnected. The second will he called the decouvling factor and is the ratio of thermal energy accepted by the WH to the thermal energy offered by the HRU. This factor is an index of the system's ability to decouple the two time series of thermal energy offerings and thermal energy uses by storing offered thermal energy for later use.

Electric energy savings are show on line $M$ and decoupling factors are shown on line iv. Savings are affected by tank size to a minor degree through differences in the energy lost during standby and the ability to accept offered thermal energy. Iarger tanks have larger hot water reserves and therefore have more hot water exposed to standby losses. Hot water reserves of 10 and 13 gallons were used in the simulation respectively for the 40 and 52 gallon systems. Iine O, labeled "QI Hours," shows hours for the year ending in the reserve status. At least for these hours in common, the 52 gallon system has 
three more gallons of hot water losing heat during standby than the 40 gallon system. Based upon the savings indicated on line $M$ and energy costs of 3.5 to 5 cents per kilowatt-hour, use of the smaller tank would save \$2 - \$3 per year over the larger tank in Washington and Atlanta.

The obvious next question is why not go to still smaller tanks? It is seen that any tank will spend much of its time in the reserve status, 01 , and that major hot water draws such as for washing clothes and dishes must be anticipated when in this status. The largest single draws used in the simulation are one 15 gallon draw in the morning and another in the evening. Both exceed the 13 or 10 gallon reserves, and could be a basis for insisting on a tank of 60 gallons or larger. However. the tanks under consideration have recovery rates of 17 to 25 gallons per hour, and recovery heat will he available during the actual period of the draw to reduce or eliminate the possible shortfall. As a practical matter, the 52 gallon system offers some flexibility in scheduling hot water use, whereas the 40 gallon system requires more scheduling care. The general conclusion is that the most economical system uses the smallest tank that has enough reserve hot water as long as the decoupling factor is high.

The decoupling factors on line $N$ are high for both tank sizes and at all locations, indicating that, at least for the particulars of these simulations, there is little problem in making full use of the thermal energy offered by the HRU. The simulation for Washington indicates a minor inahility of the 40 gallon tank system to take all of the offered thermal energy. Thirteen kBtu that vere accumulated during eight hours (line P) during the year could not be used (line E-line D). These hours occurred during the hottest part of the summer. The 52 gallon systems were able to accept all of the offered heat in Atlanta and Seattle, and all hut one $\mathrm{kBtu}$ in Washington and Chicago.

Unused thermal energy and the $Q 9$ hours increase as tank size decreases and also as the hours at very high outdoor temperatures increase. The decoupling factor decreases under these circumstances, making the time phasing between thermal energy offerings and the water draws more important.

Combined electric energy used by the HP (Iine I) and the supplemental heater (line K) is independent of tank size as long as all the unusable thermal energy is offered during cooling operations. Unusable thermal energy, if any, offered during heating operations leads to a decrease in the year's combined HP and supplemental heater energy use and to increased energy use by the backup heater.

\section{E. Alternative Estimation Methods}

One objective in detailed simulation is to preserve the effects that events in one time period (hour-to-hour or day-to-day, for examole) have on events in another period. Another is to provide a haseline from which the acceptability of alternative analytical methods may be judged. As will be show, certain aspects of the simulation procedure may be reshaped to good effect and without changing the numerical results enough to affect most consumer decisions.

Hourly data on house loads and corresponding weather data are available for only a few locations and quite specific house characteristics and operating 
strategies. This places severe limits on the ahility to extend results to other locations and situations. Therefore, the mumerical significance of making two adjustments to the more rigorous hour-by-hour simulation was examined. The first of these was to sort the load data by five-degree temperature bins, compute bin averages and then compute the various heat recovery output results. Average house loads by bin are shown in Figure III-4 for Washington and At lanta. The issues being examined are the importance of specific sequences of hourly loads and the effects of nonlinear relationships on the results. The second change was to replace the bin averages of the house loads with loads derived from linear regressions of the bin averages. If the first adjustment is acceptahle, then annual summaries of temperature data could be used. If the second adjustment is acceptable, the characterization of houses and their operations can be much more flexible and parametric studies become more practical.

Comparative results are summarized in Table III-2 for four locations and three computation methods. Systems with 52 gallon tanks were used throughout. The reference case for computing savings is a 52 gallon tank maintained at a 13 gallon reserve level, Q1, by a backup heater. Both the Bin Average and the Bin Linear methods are based on steady state conditions of heat recovery within each temperature bin and do not allow for thermal energy acceptances within the dynamic range of the tank heat capacity when the average offering rate exceeds the acceptance rate, accounting for most of the difference in savings among the methods. Nonlinearities and approximations of constants account for the remaining differences in savings estimates.

The difference in numerical results among the methods do not appear to be important with respect to the most important consumer decision on whether a heat recovery system of this kind should be installed or not. The differences are well within common year-to-year weather variations. Although these few examples hardly constitute proof, the strong inference is that the simpler computing methods are adequate. Furthermore, they offer opportunities for parameteric examination of several house and recovery system variables without expensive and scmetimes unavailable weather data and preparatory load calculations. The various curves in Figure III-3 and COP values could be nypothesized, for example, in order to explore the circumstances of economic feasibility for stuch systems. Sibliographic item 6 or its equivalent provides a rich compilation of weather data, house load curves could be hypothesized, and so on. AII of the reported aporoaches use discrete weighting and summation methods to produce the main results. There is an untested possibility that the various curves could be expressed in continuous algebraic form and dealt with at that level for sensitivity analysis purposes. 
$\stackrel{10}{\circ}$

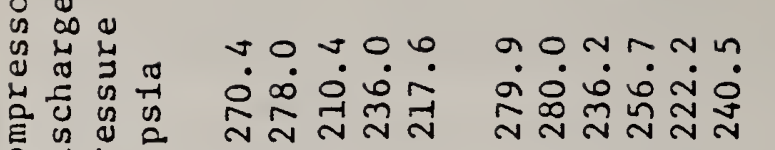
ठํำ

量

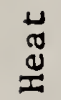

क्ष

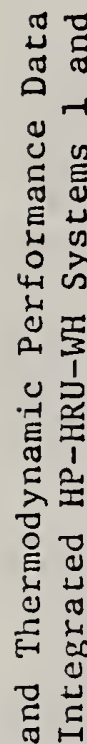

(2)

유

$\rightarrow$ कृ

पृ क

రृ

$\infty \pi$

กิ

过

$\gtrless$

d)

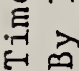



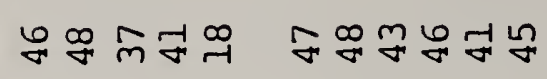
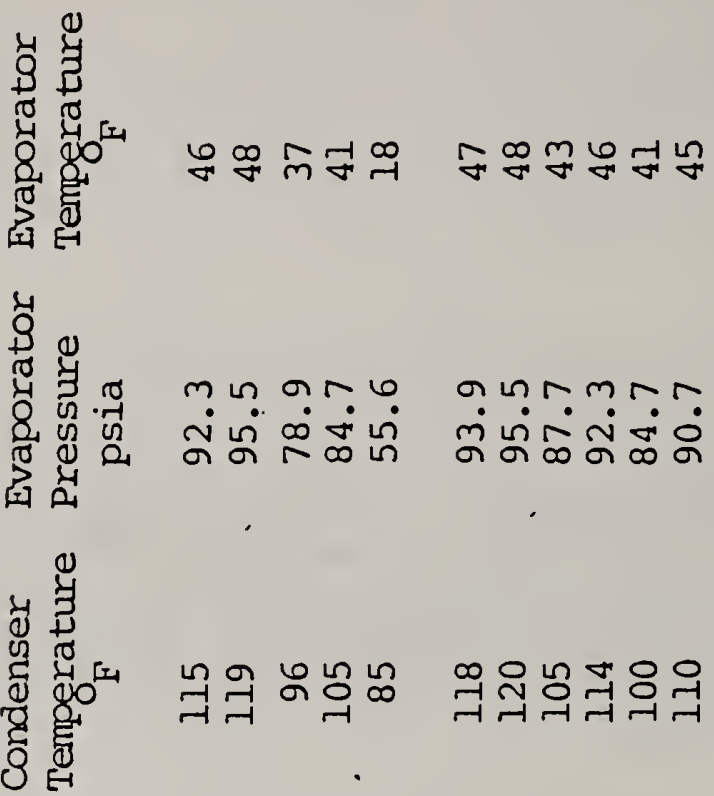

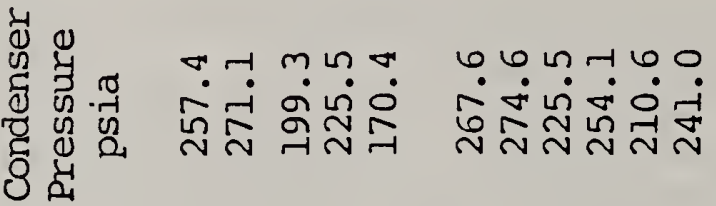

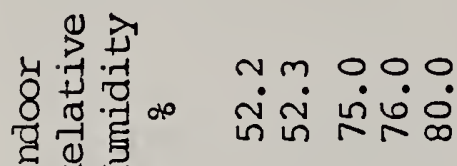

0 in 0000

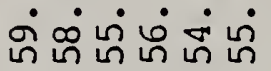

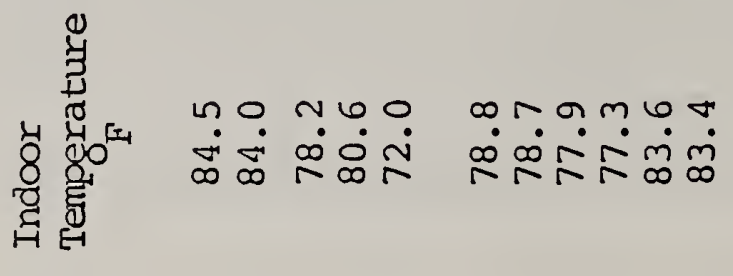

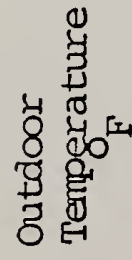

n $m m-$ वृँ

$\sim m \sim \sim 6 \infty$

舟

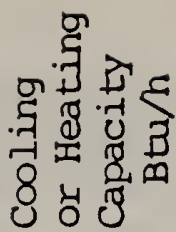

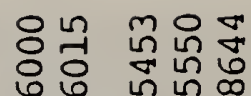
ติ

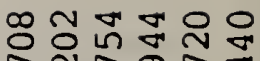
ㄱำ

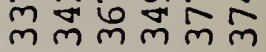

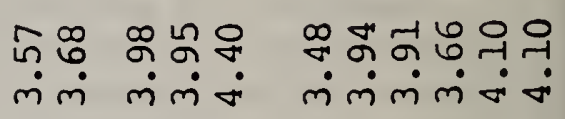
है है

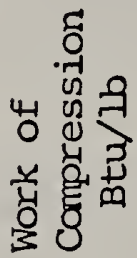

0.0 L 0.0 নi் orogoo

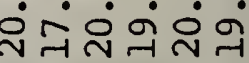

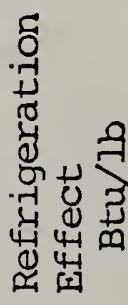

ט

党亦

글

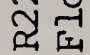

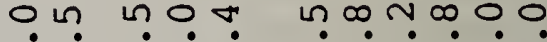
ம்

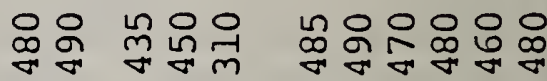

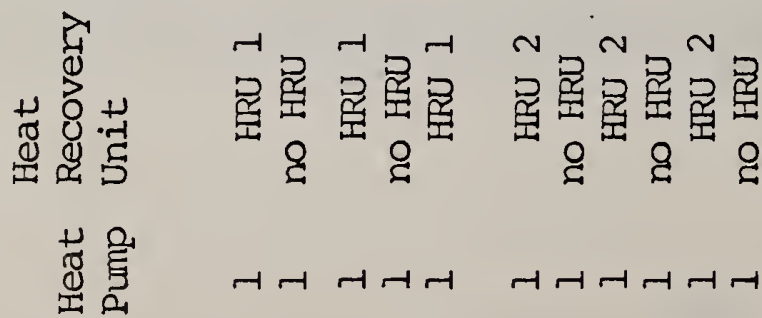

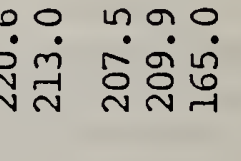

am a $\infty \mathrm{mo}$ ต் ન્ન 유규워

员

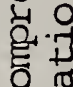

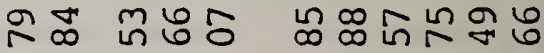
نें

d

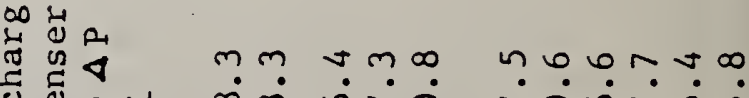

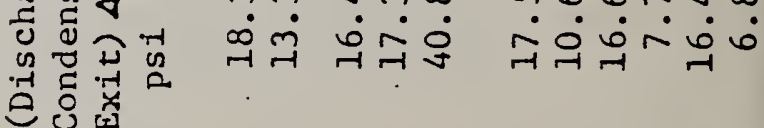

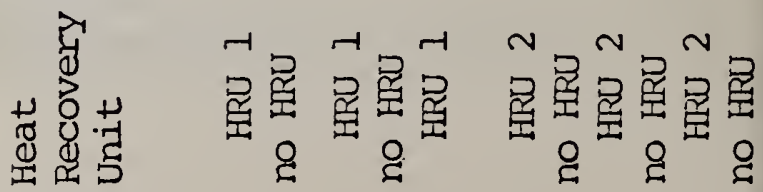

茛号 


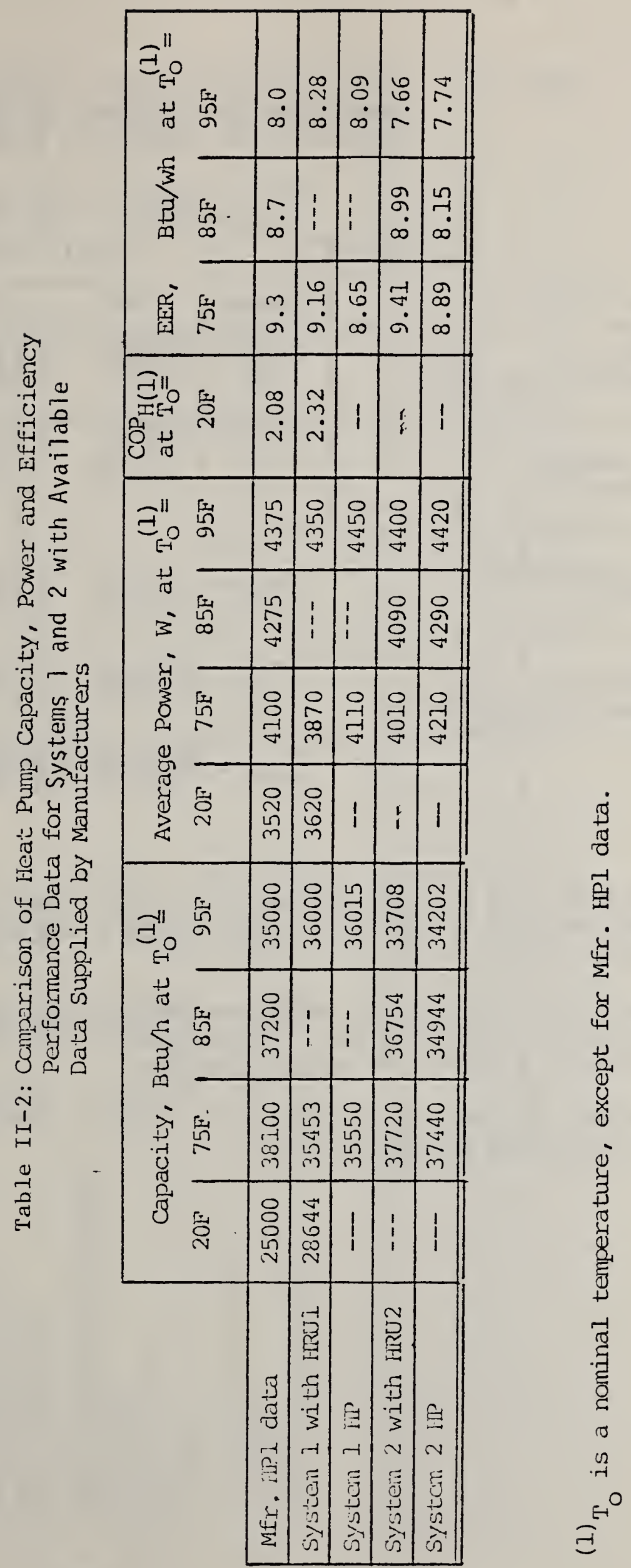


Table II-3: Mean Heat Recovery Rate, Thermal Energy Rate, Energy Consumption Rate, and Heat Recovery Efficiency for Integrated Systems 1 and 2

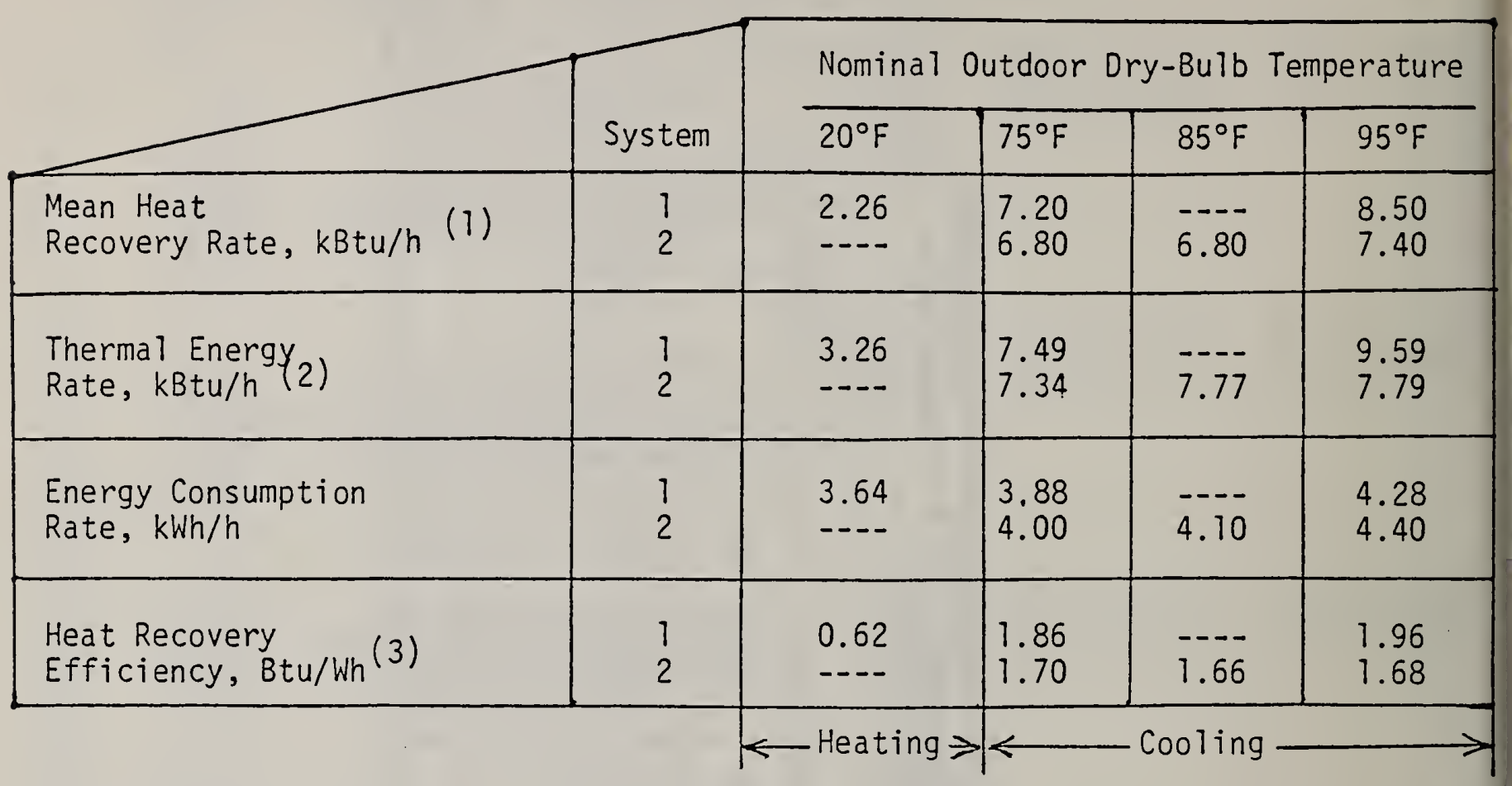

Notes:

(1) The Mean Heat Recovery Rate was determined from the difference in total heat recovery by the water between 1 and 3 hours following the start of system operation.

(2) The Thermal Energy Rate was determined from the refrigerant mass flow rate and the difference in the inlet and outlet enthalpy of the HRU 2 hours following the start of system operation.

(3) The Heat Recovery Efficiency is the ratio of the Mean Heat Recovery Rate to the Energy Consumption Rate. 


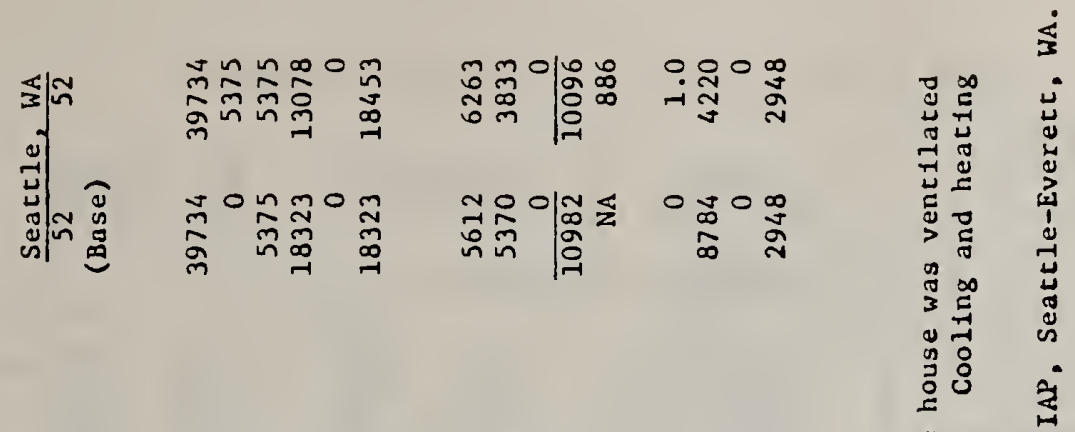

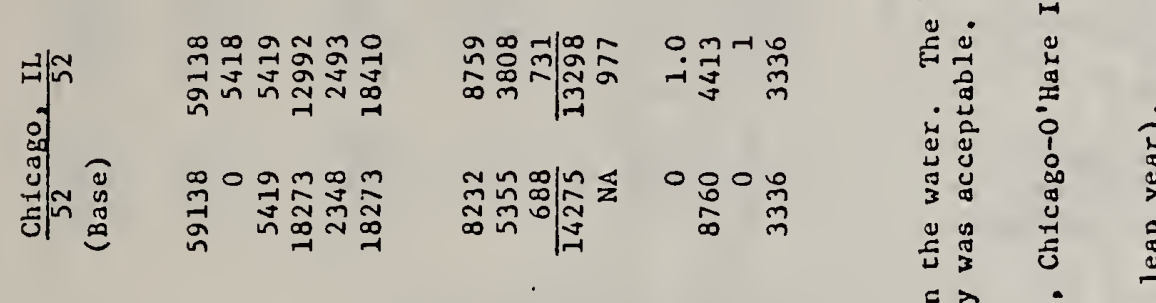

转要

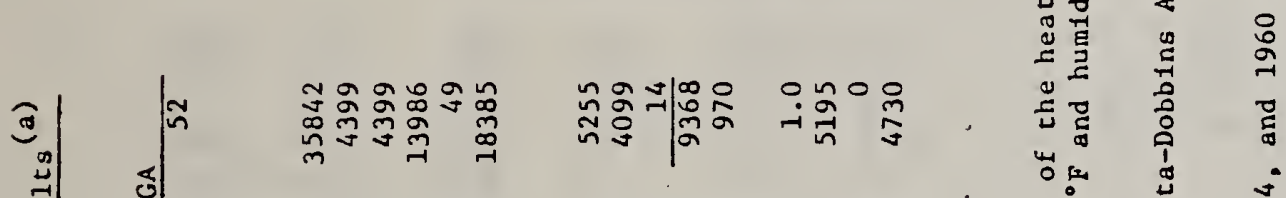

:

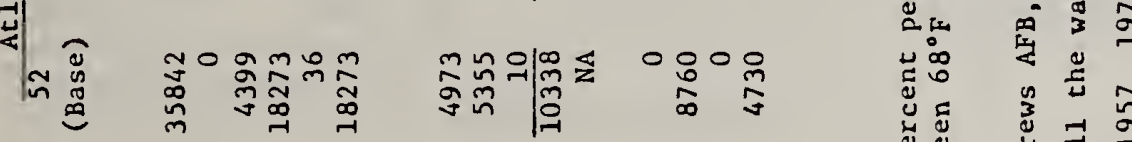

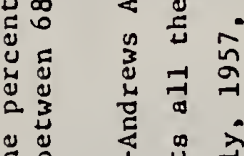

:

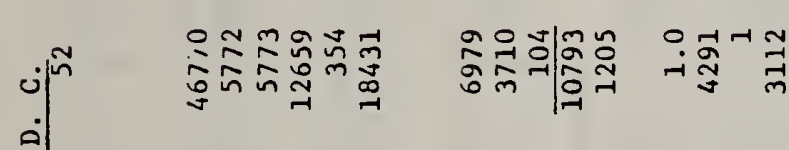

.

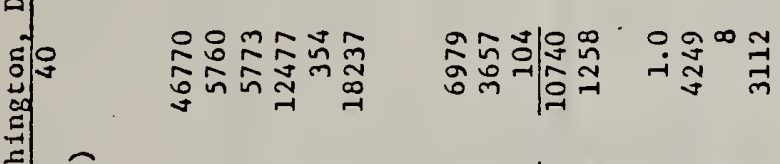

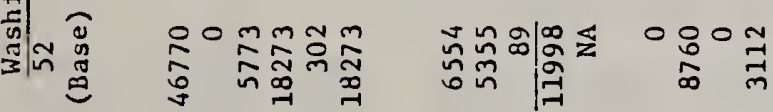

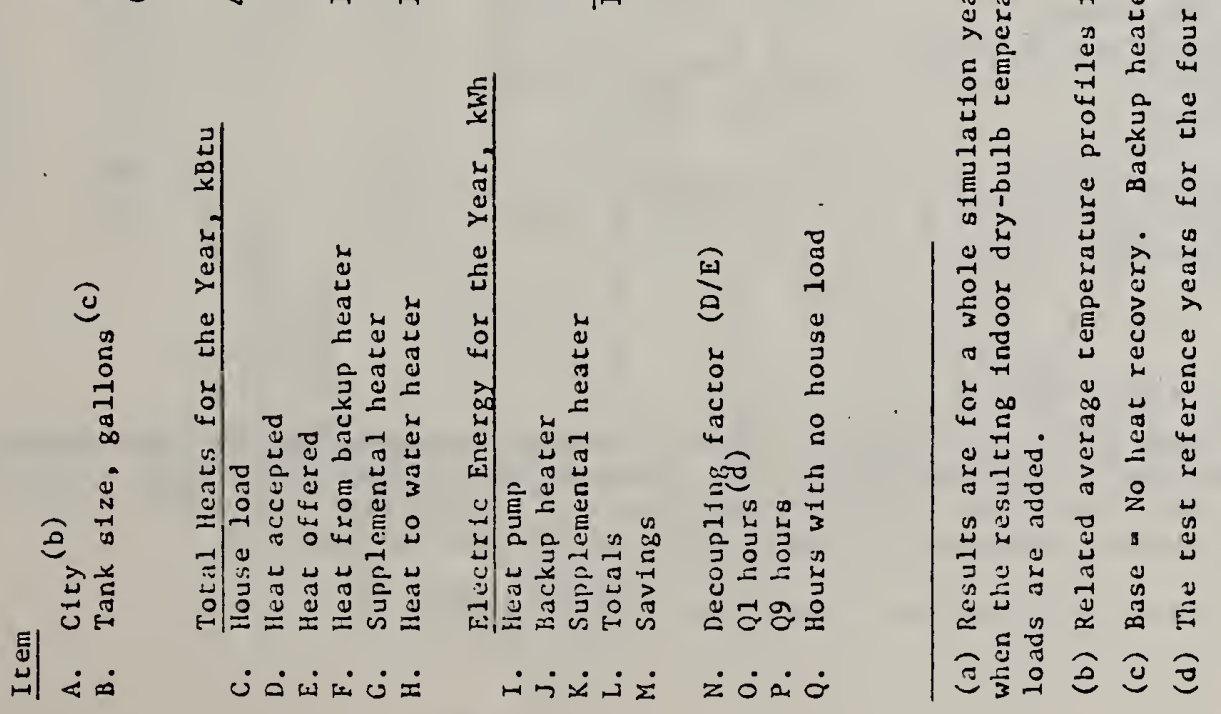


Table III-2: Alternative Calc'slation Comparisons

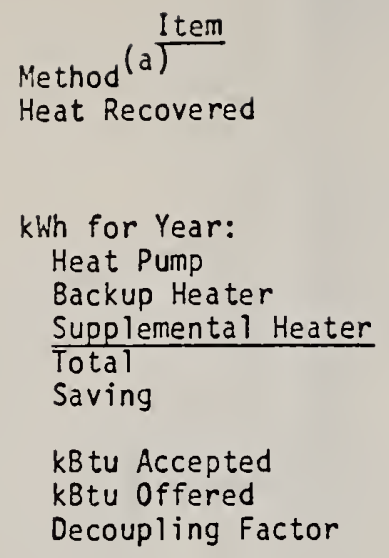

$$
\begin{aligned}
& \text { No } \frac{\text { Hourly }}{\text { Yes }} \quad \frac{\text { Bin Average }}{\text { No Yes }} \\
& \text { Location: Washington, O.C. }
\end{aligned}
$$

\begin{tabular}{|c|c|c|c|c|c|}
\hline $\begin{array}{r}6554 \\
5355 \\
89 \\
11998 \\
\text { NA }\end{array}$ & $\begin{array}{r}6979 \\
3710 \\
104 \\
10793 \\
1205\end{array}$ & $\begin{array}{r}6641 \\
5356 \\
\quad 58 \\
12061 \\
\text { NA }\end{array}$ & $\begin{array}{r}7083 \\
3710 \\
\quad 80 \\
10873 \\
1188\end{array}$ & $\begin{array}{r}6779 \\
5356 \\
36 \\
12171 \\
\mathrm{NA}\end{array}$ & $\begin{array}{r}7245 \\
3673 \\
\quad 40 \\
10958 \\
1213\end{array}$ \\
\hline 0 & $\begin{array}{r}5772 \\
5775 \\
1.0\end{array}$ & $\begin{array}{r}0 \\
5777 \\
0\end{array}$ & $\begin{array}{l}5616 \\
5777 \\
0.97\end{array}$ & $\begin{array}{r}0 \\
5906 \\
0\end{array}$ & $\begin{array}{l}5740 \\
5906 \\
0.97\end{array}$ \\
\hline
\end{tabular}

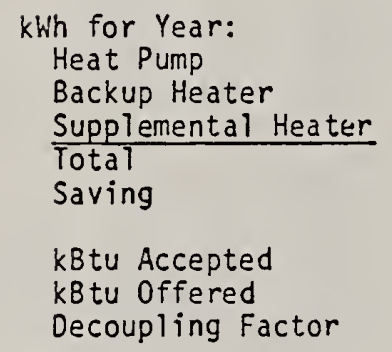

\section{Location: Atlanta, GA}

\begin{tabular}{rrrrrr}
4973 & 5255 & 5053 & 5345 & 4728 & 5033 \\
5355 & 4099 & 5356 & 4093 & 5356 & 4149 \\
10 & 14 & 0 & 4 & 0 & $\frac{0}{10084}$ \\
\hline 10338 & 9368 & $\frac{0}{10409}$ & 9442 & $\frac{0}{102}$ \\
NA & 970 & NA & 967 & NA & 902 \\
10 & 4399 & 0 & 4309 & 0 & 4116 \\
4399 & 4399 & 4401 & 4401 & 4208 & 4208 \\
0 & 1.0 & 0 & 0.98 & 0 & 0.98
\end{tabular}

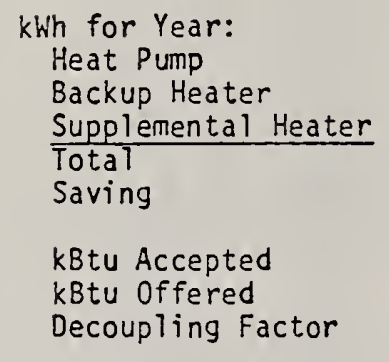

\section{Location: Chicago, IL}

$\begin{array}{rrrrrr}8232 & 8759 & 8363 & 8917 & 8344 & 8910 \\ 5355 & 3808 & 5356 & 3787 & 5356 & 3784 \\ \frac{688}{14275} & \frac{731}{13298} & \frac{594}{14313} & \frac{609}{13313} & \frac{451}{14151} & \frac{466}{13160} \\ \text { NA } & 977 & \text { NA } & 1000 & \text { NA } & 991 \\ & & & & & \\ 0 & 5418 & 0 & 5352 & 0 & 5361 \\ 5419 & 5419 & 5432 & 5432 & 5439 & 5439 \\ 0 & 1.0 & 0 & 0.99 & 0 & 0.99\end{array}$

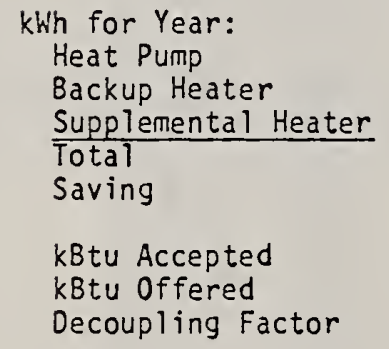

Location: Seattle, $W A(b)$

$\begin{array}{rrrrrr}5672 & 6263 & 5680 & 6349 & 5636 & 6304 \\ 5370 & 3833 & 5370 & 3804 & 5370 & 3814 \\ 0 & 0 & 0 & 0 & 0 & 0 \\ \frac{11050}{10982} & \frac{0}{10096} & 153 & 11006 & \frac{0}{0118} \\ \text { NA } & 886 & \text { NA } & 897 & \text { NA } & 888 \\ & & & & & \\ 0 & 5375 & 0 & 5344 & 0 & 5309 \\ 5375 & 5375 & .5374 & 5374 & 5338 & 5338 \\ 0 & 1.0 & 0 & 0.99 & 0 & 0.99\end{array}$

(a) Results are for 52 gallon systems. Hourly data are from the hour-by-hour simulation. "Bin Average" data are based on hour-by-hour house loads averaged for each five degree outdoor temperature bin. "Bin Linear" refers to house load inputs generated by 1 inear regression of "Bin Average" data.

(b) Seattle data are for a leap year of 8784 hours. 


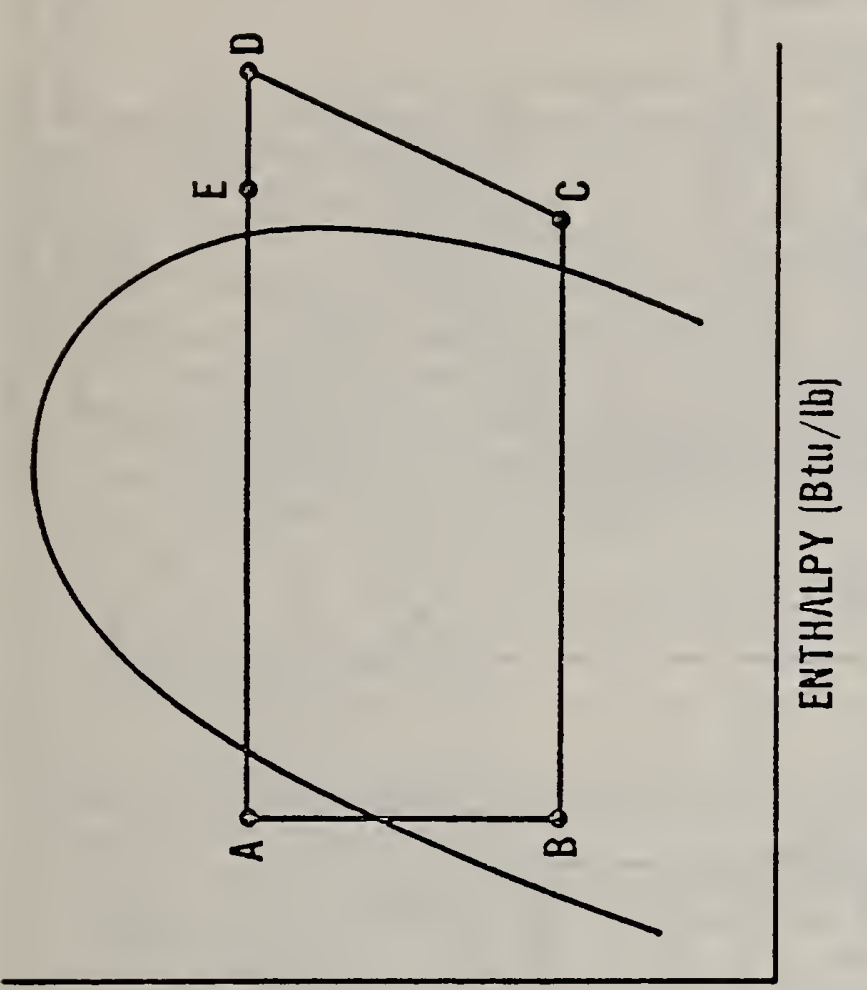

(e!sd) Junnsşud

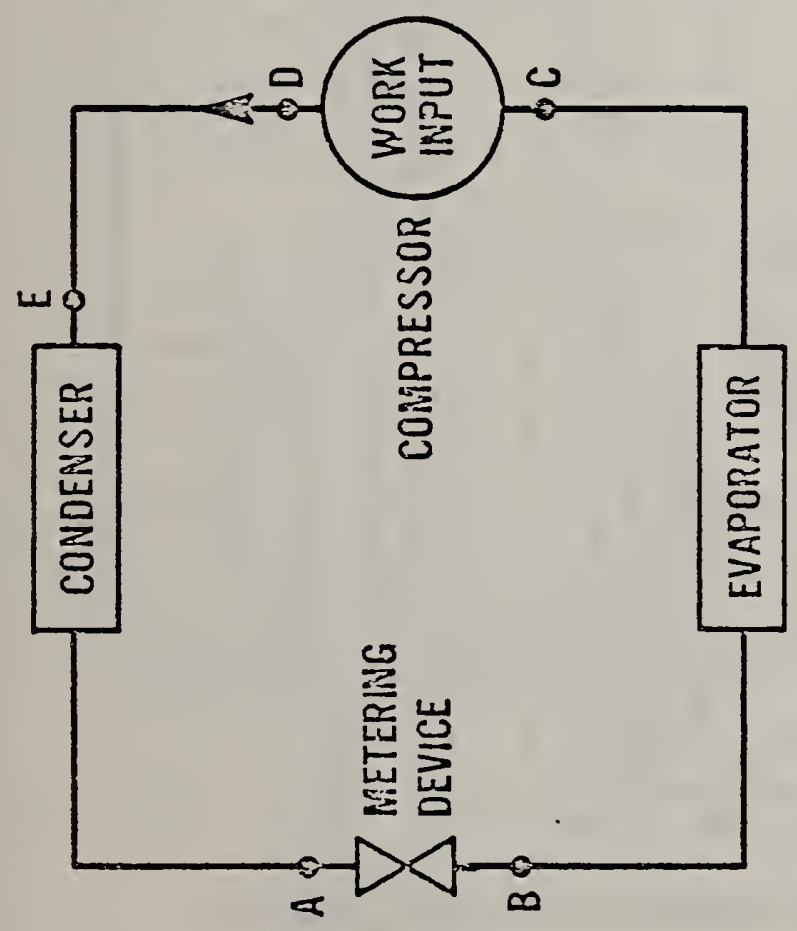

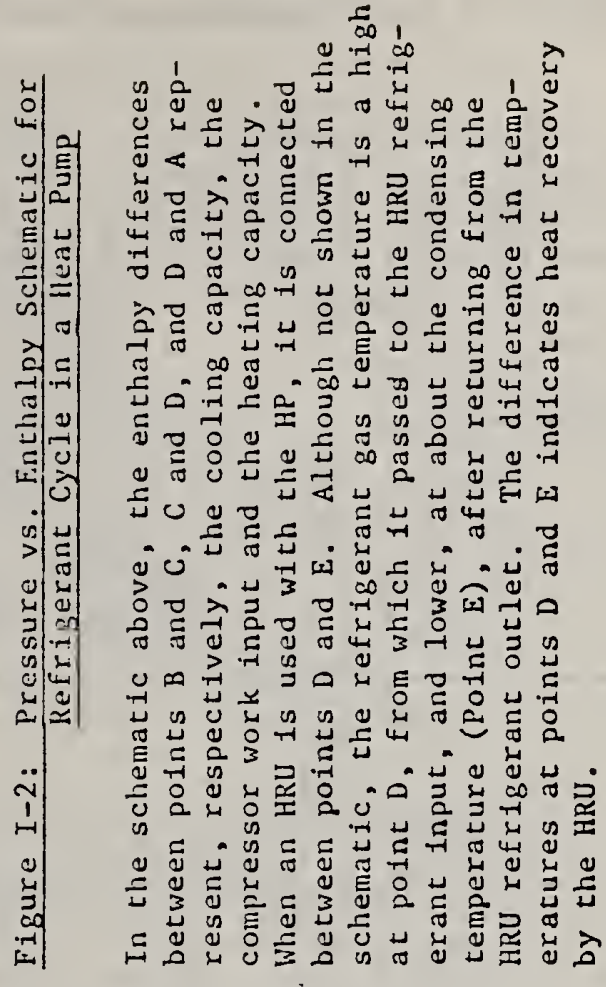

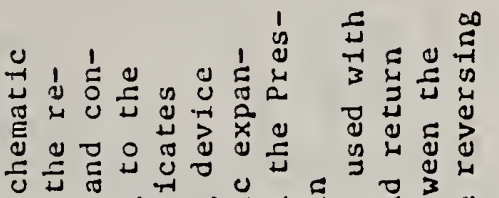

诵 论

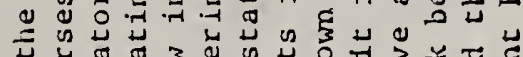

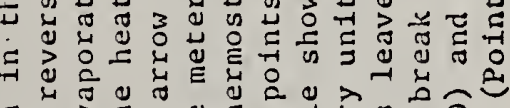

उ

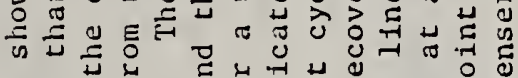

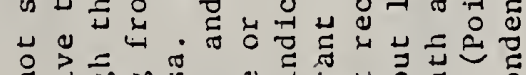

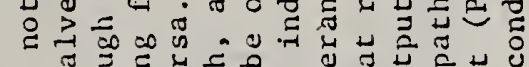

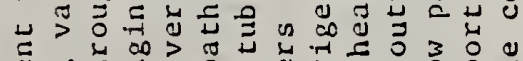

过

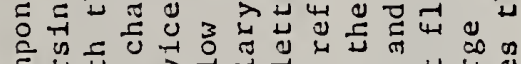

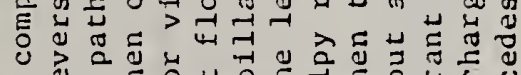

म

मे

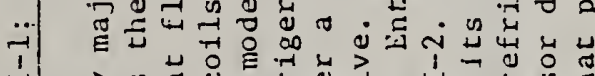

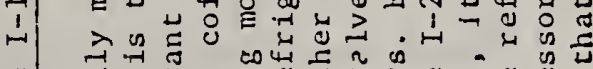

㫕 ठี

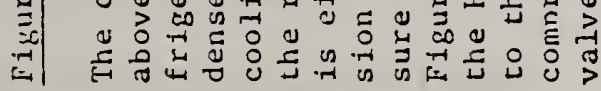


ENTHALPY (BTU/lb above saturated liquid at $-40^{\circ} \mathrm{F}$ )

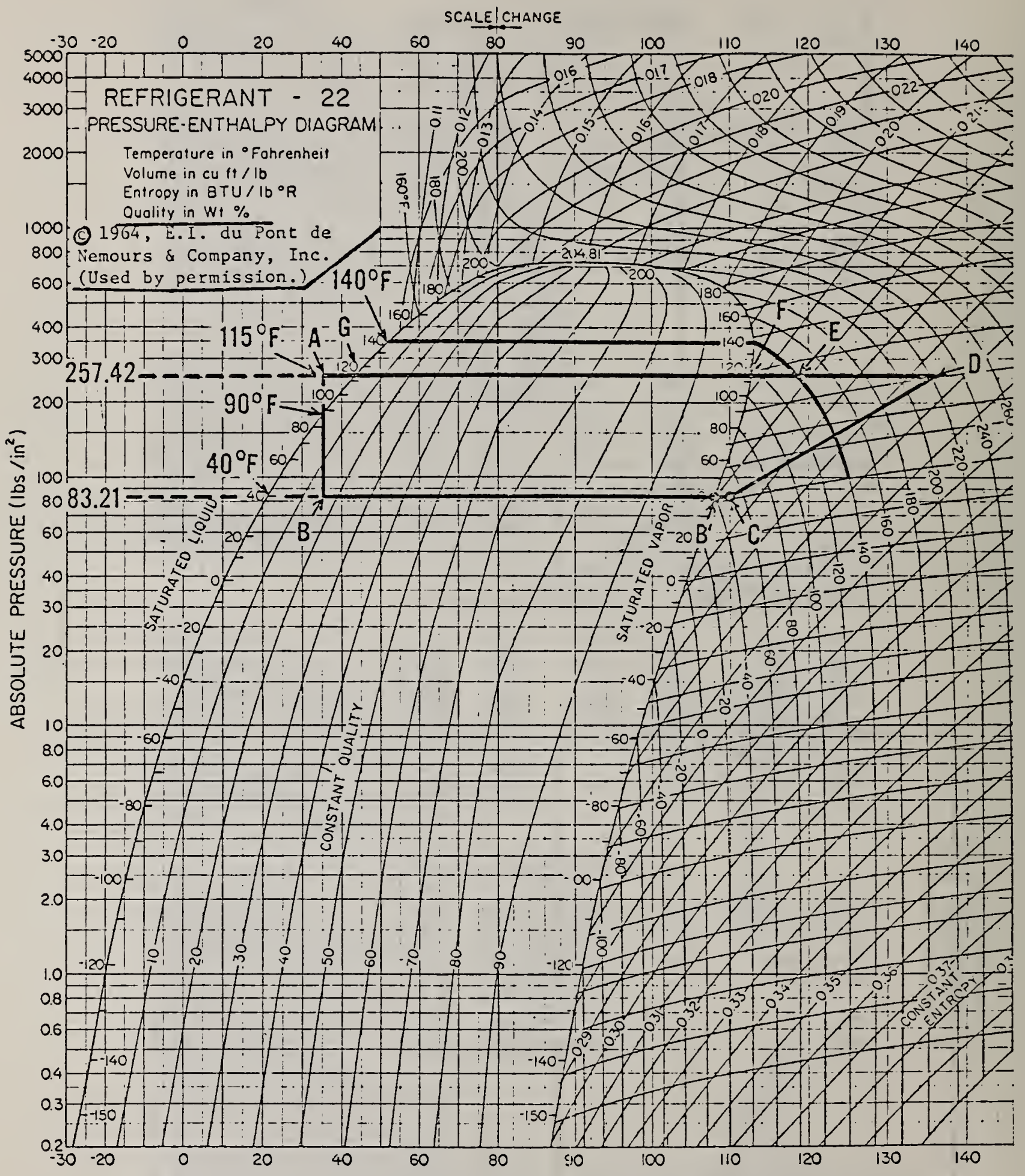

Figure II-1 : Detailed Sample Pressure vs. Enthalpy Diagram 


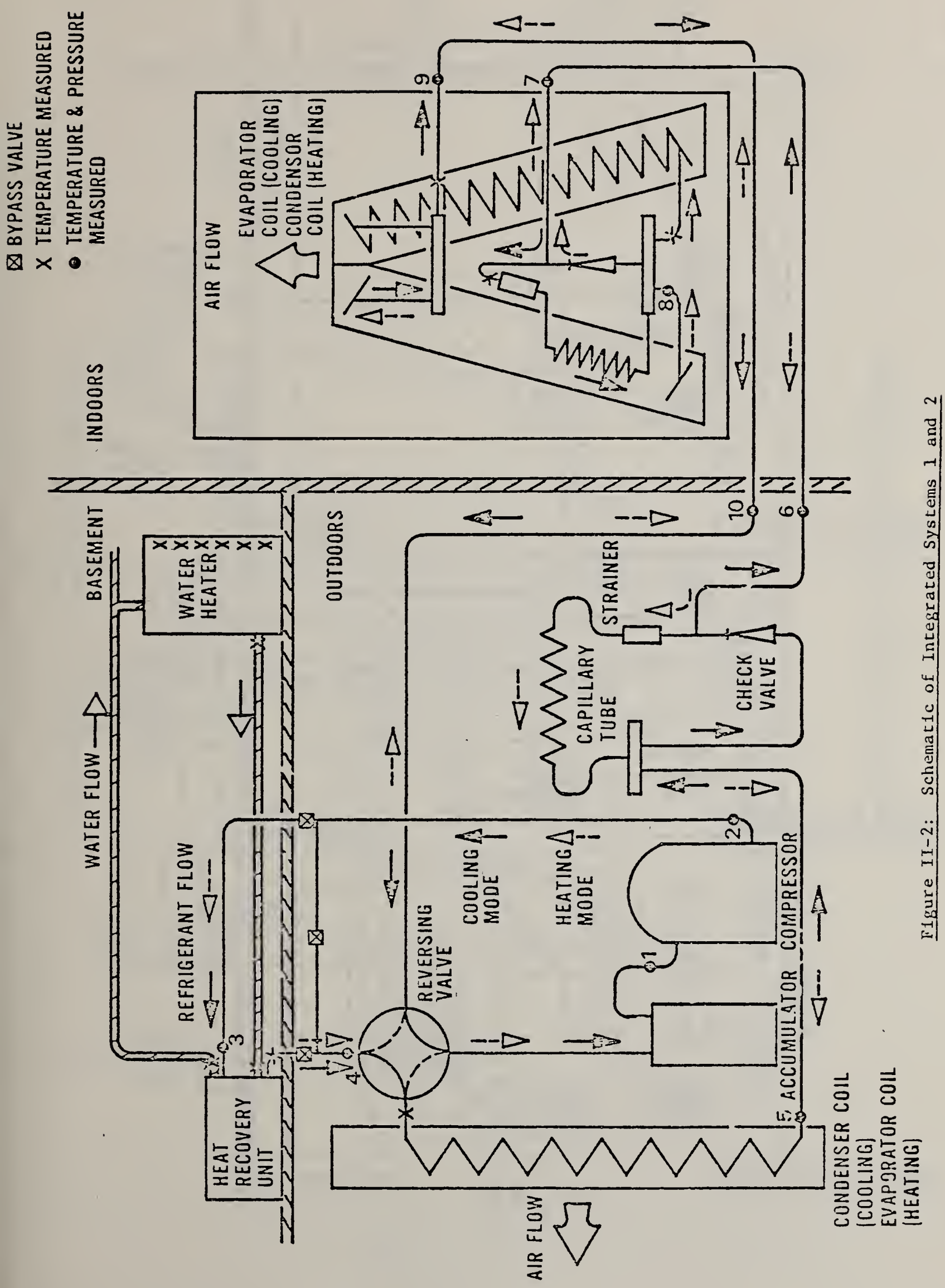


SCHEMATIC REPRESENTATIONS

OF HEAT RECOVERY UNITS $1-3$

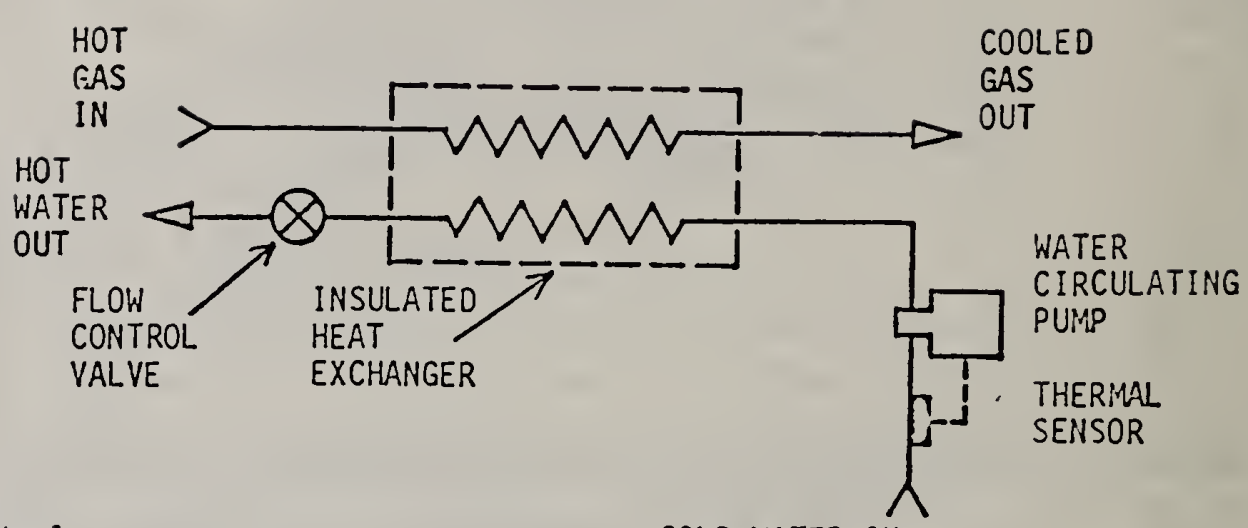

Figure II-3: HRU No.I

COLD WATER IN

CIRCULATING

THERMAL
SENSOR

Figure II -4 : HRU №.?
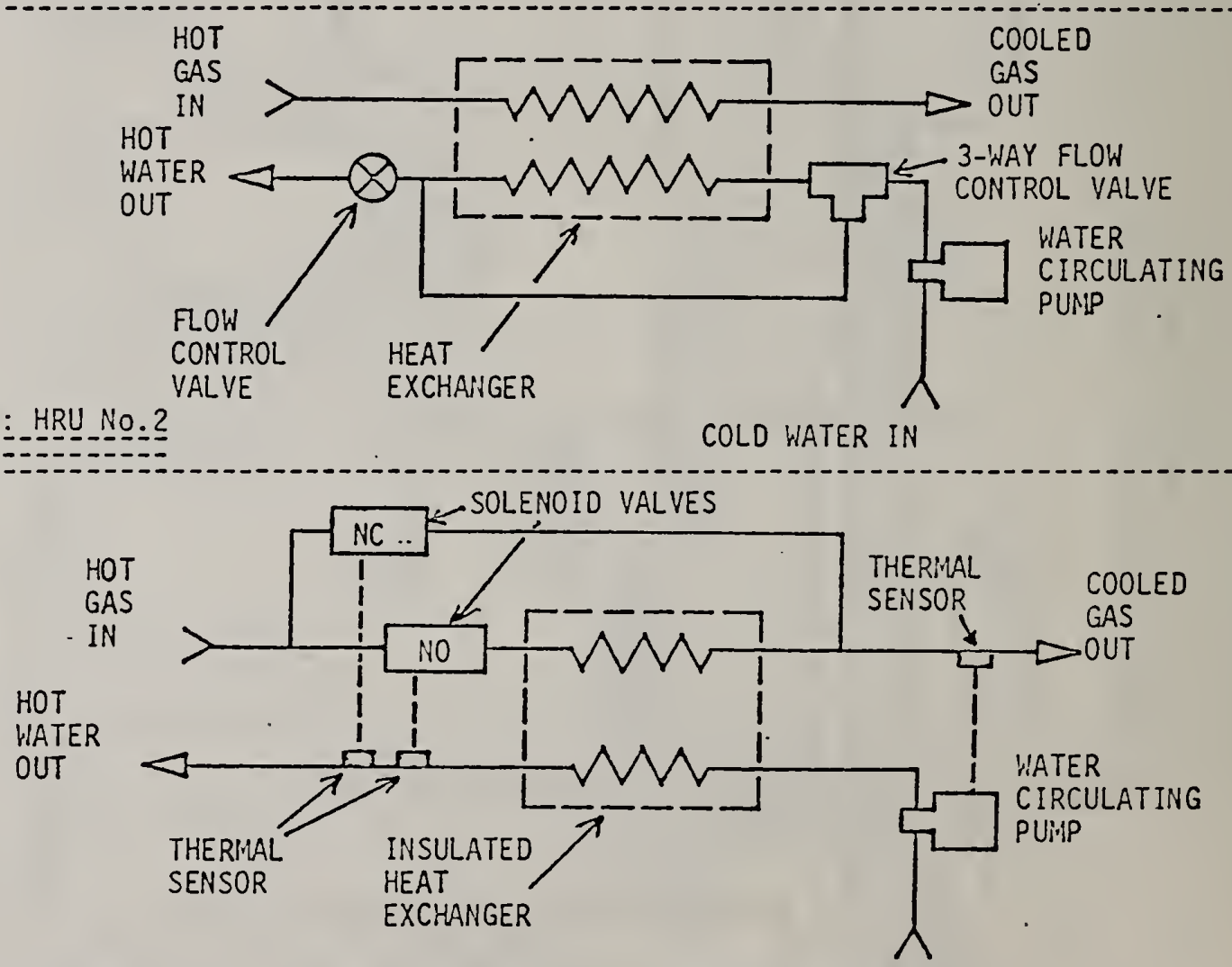

Figure II -6: HRU No. 3 


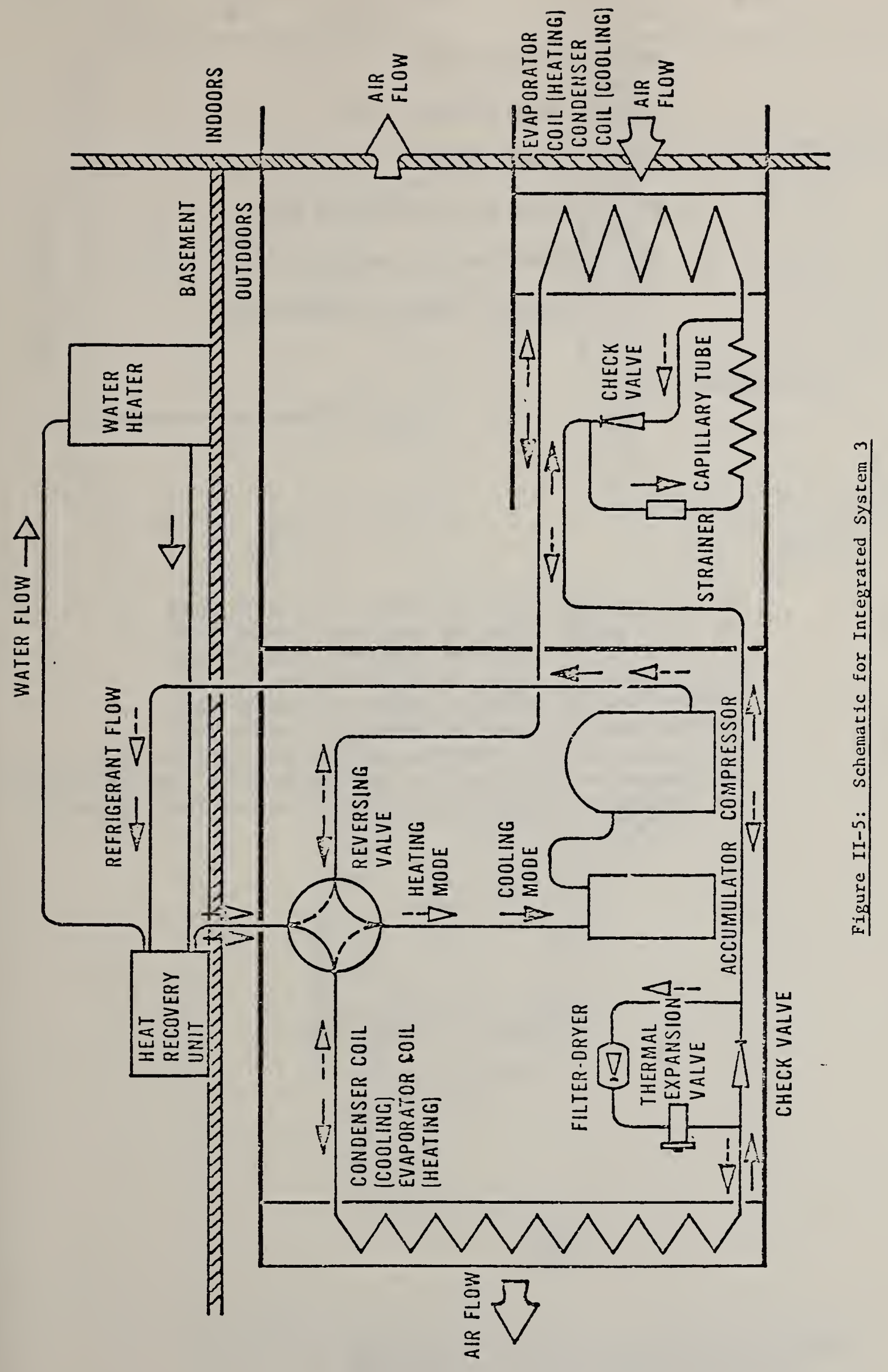




$$
\begin{aligned}
& \mathrm{TC}=\text { Thermocouple } \\
& \mathrm{HRU}=\text { Heat Recovery Unit } \\
& \mathrm{WH}=\text { Water Heater } \\
& \mathrm{HP}_{\mathrm{C}}=\text { Heat Pump in Cooling Mode } \\
& \mathrm{HP}_{\mathrm{h}}=\text { Heat Pump in Heating Mode } \\
& \mathrm{T}_{0}=\text { Nominal Outroor Temperature }
\end{aligned}
$$

TC $I$ is 3-7/8" from the Bottom of the WH Tank

TC 2 is 11-5/8" from the Bottom of the "WI Tank

TC 3 is 19-3/8" from the Bottom of the $\mathrm{WH}$ Tank

TC 4 is 27-1/8" from the Bottom of the $1: H$ Tank

TC 5 is 34-7/8" from the Bottom of the WH Tank

TC 6 is 42-5/8" from the Bottom of the WH Mank

TC 7 measures the water temperature entering the HRU

TC 8 measures the water Cut-Out Temperature leaving the HRU

TC 9 measures the water Cut-In Temperature leaving the HRU

Addendum to Figure II-7A-C 

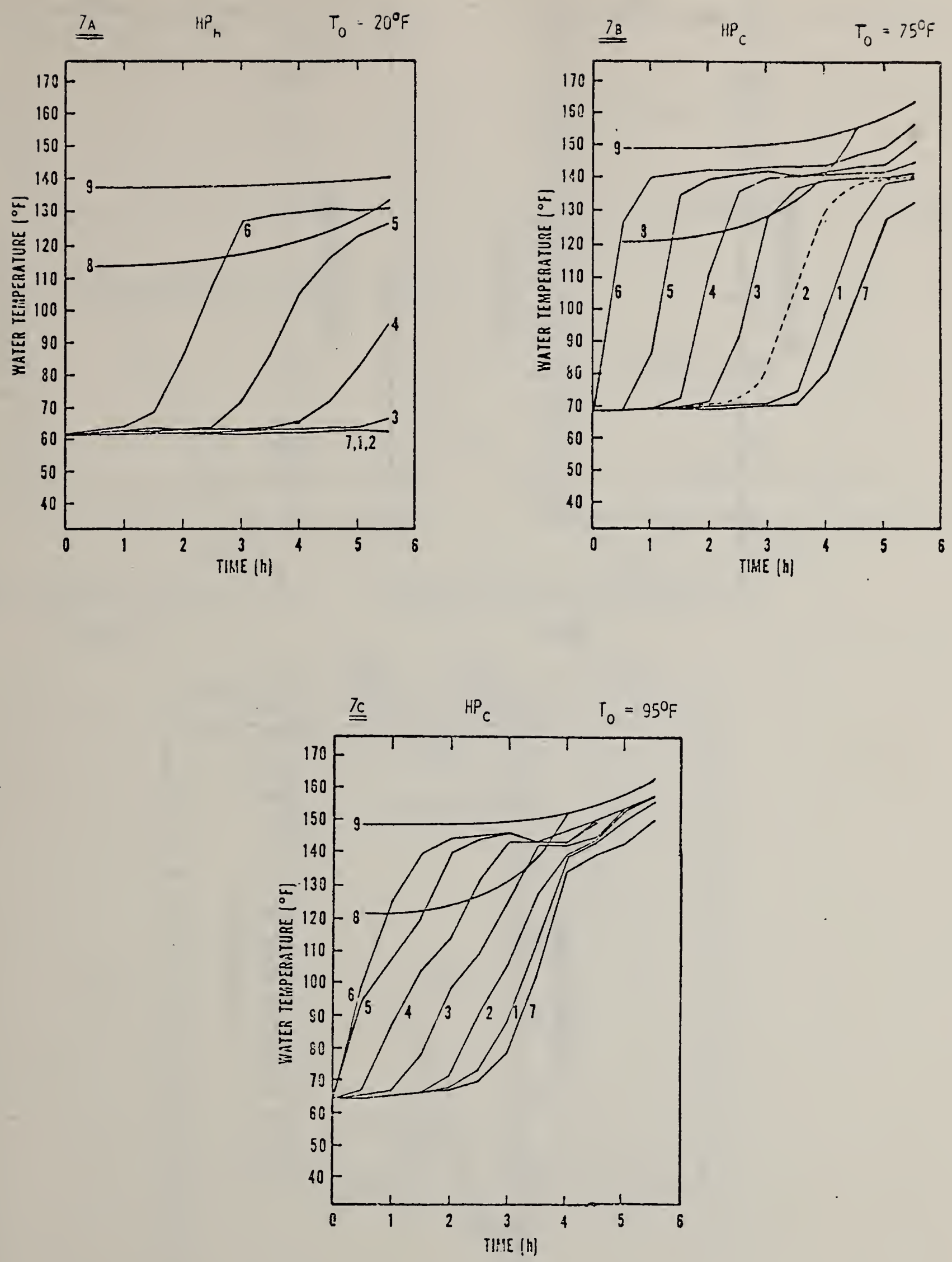

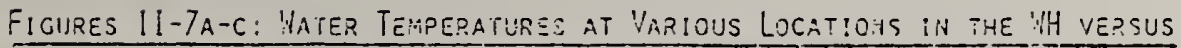
TIME OF OPEAMTIOA OF THE MP - MRIJ - WH IITERTARED

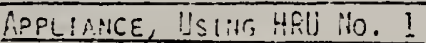



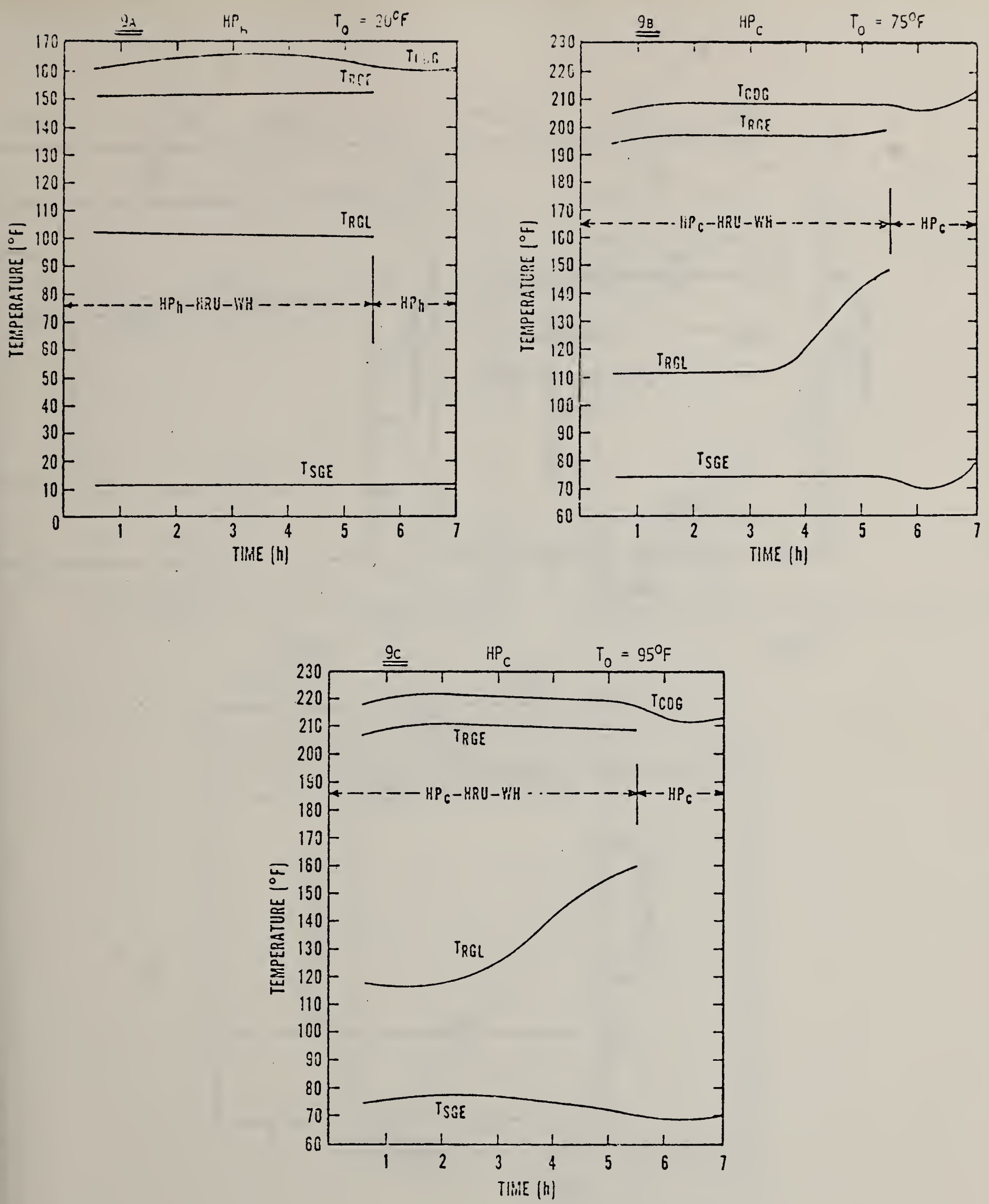

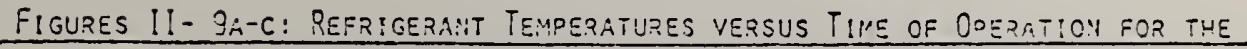

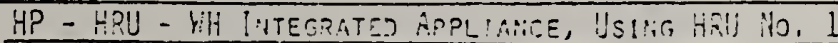

NOTES: $T_{\text {CDG }}=$ TEMPERATURE OF COMP? ESSCr DISCHARGE CAA.

$T_{\text {RGE }}=$ TEMPERATURE OF Refrigezant SAS ENTERIMG HRU

$T_{\text {PGL }}=$ TEM.OERATISE OF REFRIGERAMT Gás LEAV!NG HRU

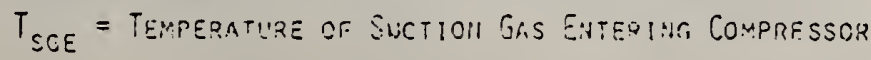



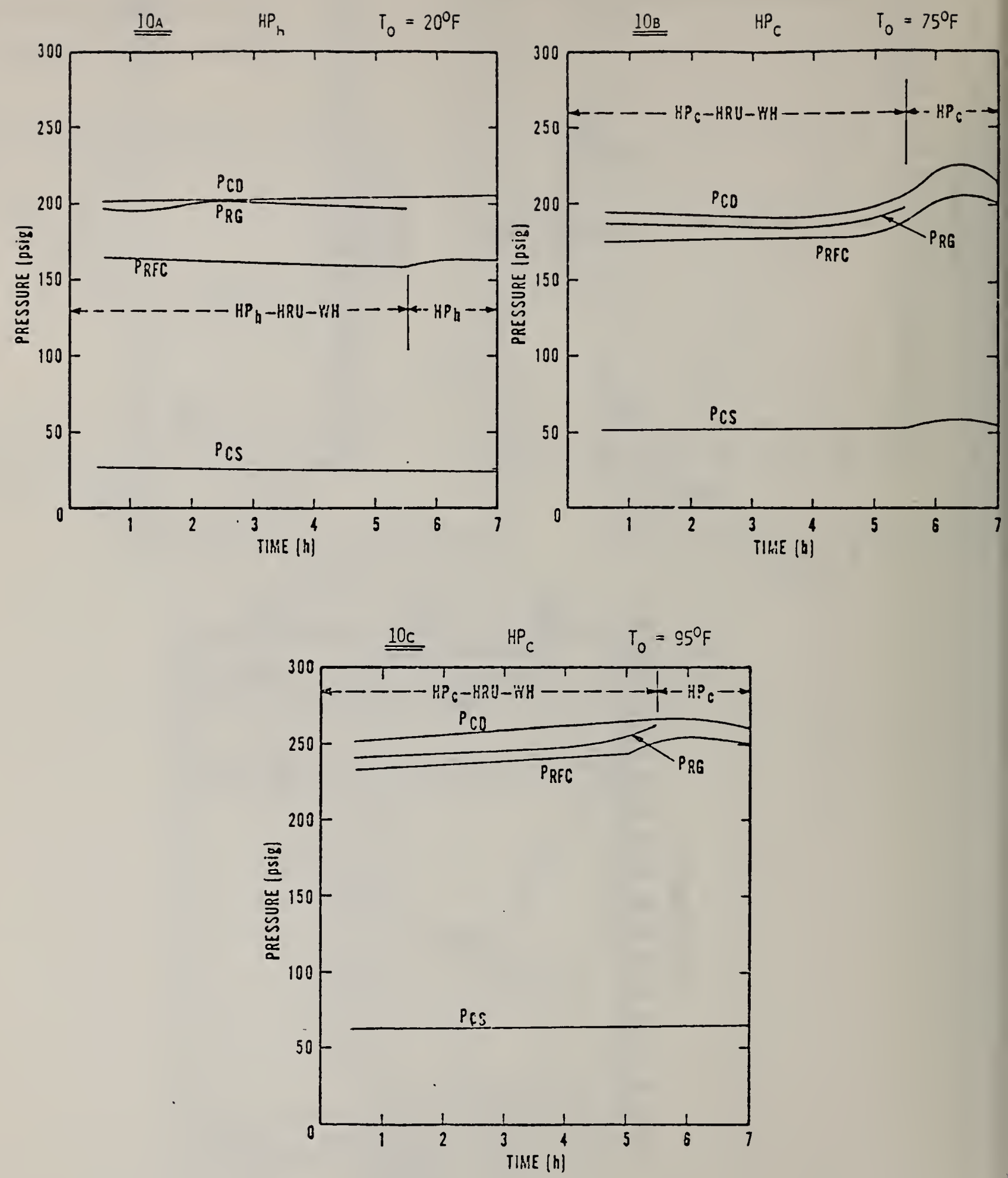

F!gures 11 -10a-C: Refrigegant PoEssures versus TIME of Opeopation of the HP - HRU - HH IMTEGPATEO APPLLIAICE, USIUG HFI] Ü. I NOTES: $P_{C D}=$ COMPóSSOR DISCHARGe PRESSURE PRECEDING GAS LINE TO HRU

$P_{\text {RG }}=$ Refrigerant Gas Pressure folloh!ne Gas Line from hill

$P_{\text {CS }}=$ Compressor Suction fressure

$P_{\text {RfC }}=$ Refrigerait Pressure Foligoning Condenser 

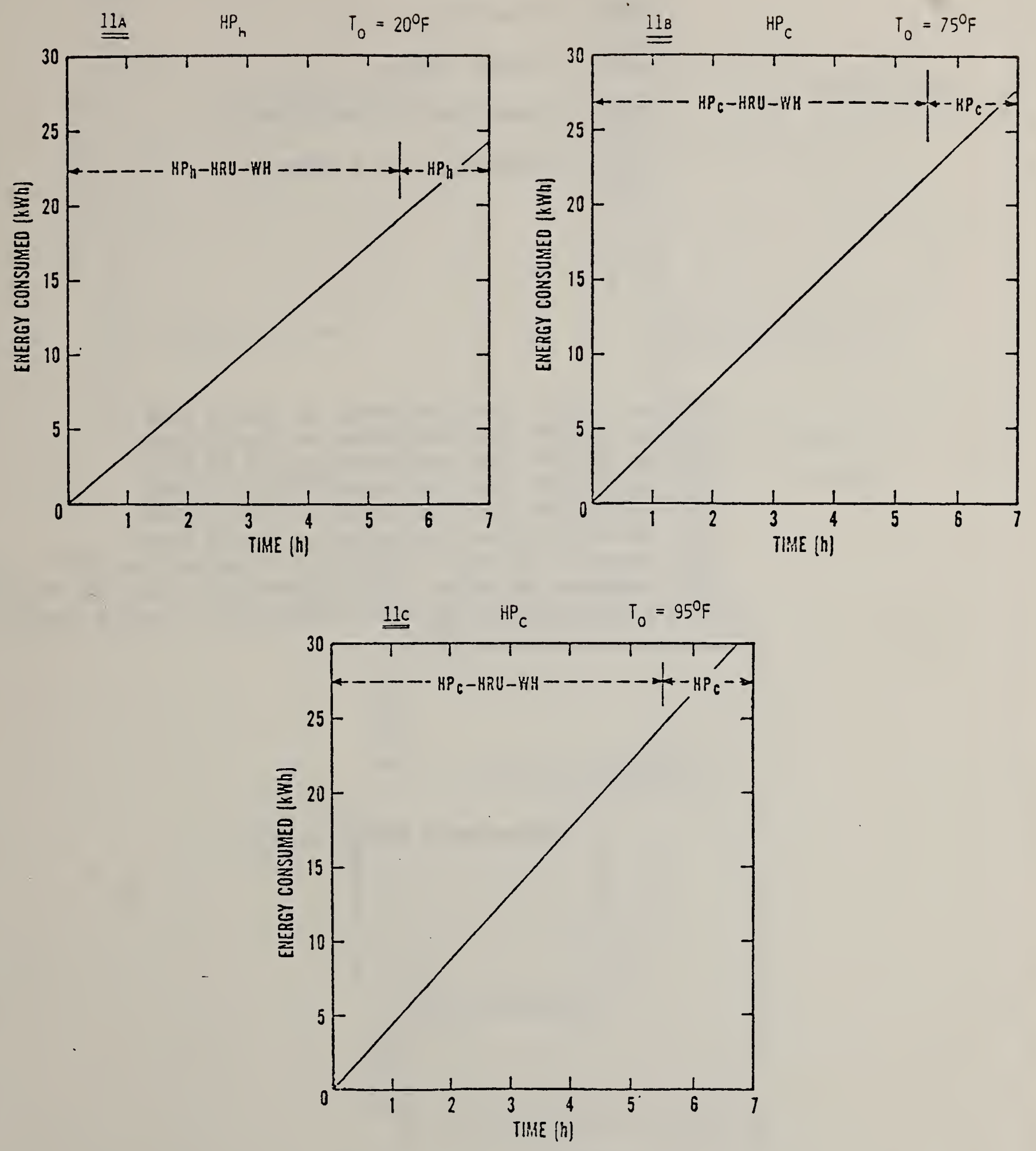

FIGURES 11-11A-C: EMiEgGY COHSIMED VERSUS TME DF OPERATIOH CF THE

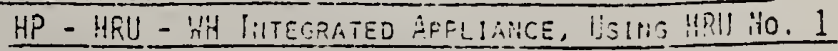




$$
\begin{aligned}
& \mathrm{TC}=\text { Thermocouple } \\
& \mathrm{HRU}=\text { Heat Recovery Unit } \\
& \mathrm{WH}=\text { Water Heater } \\
& \mathrm{HP}_{C}=\text { Heat Pump in Cooling Mode } \\
& \mathrm{T}_{O}=\text { Nominal Outdoor Temperature }
\end{aligned}
$$

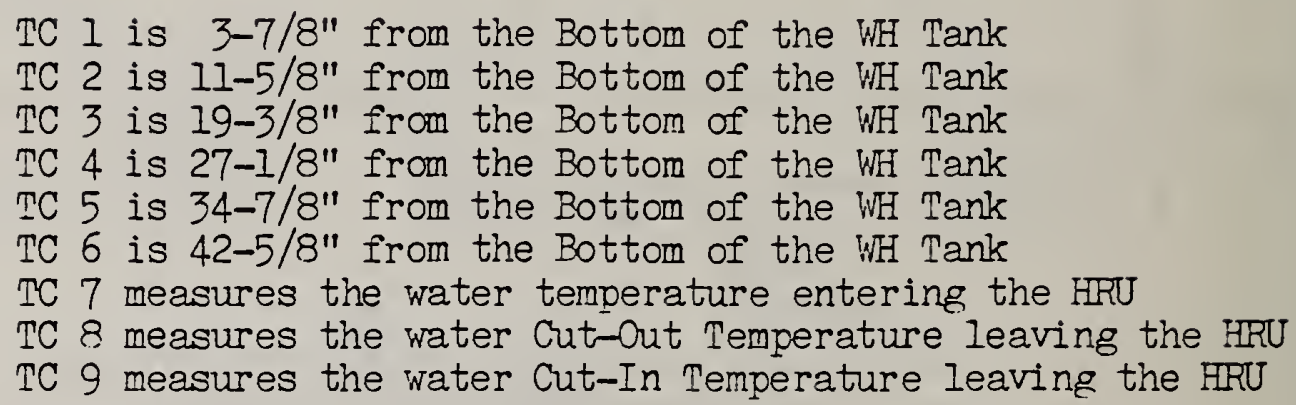

Addendum to Figure II-12A-C 

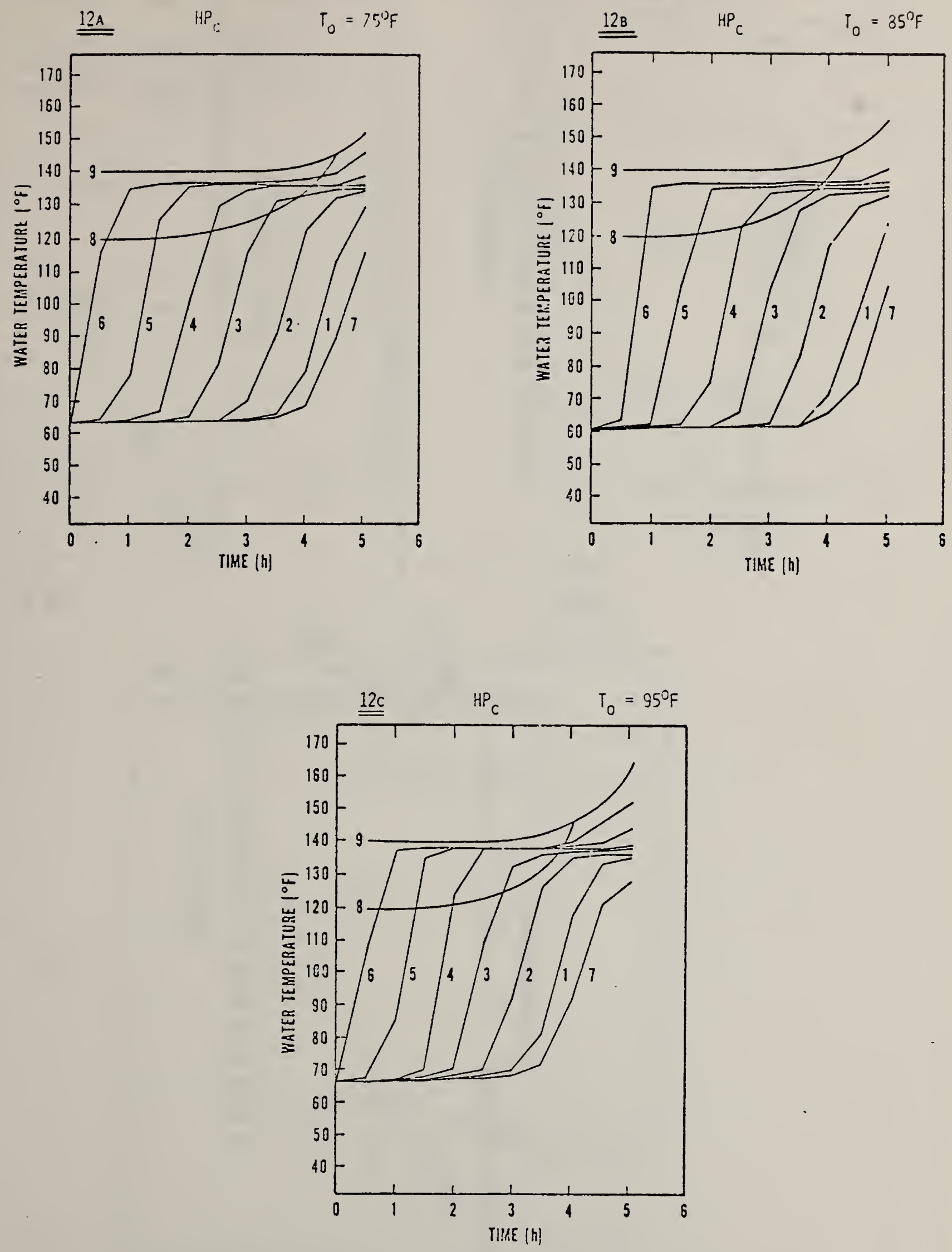

FlgURES 11 -12A-C: WaTER TEMPERATURES AT VARIOUS LOCATIONS IN THE IHH VEPSUS

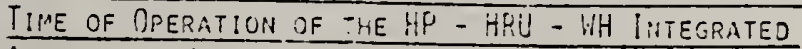
AFPLIAIICE, ISSIIIG WRII I! . 2 

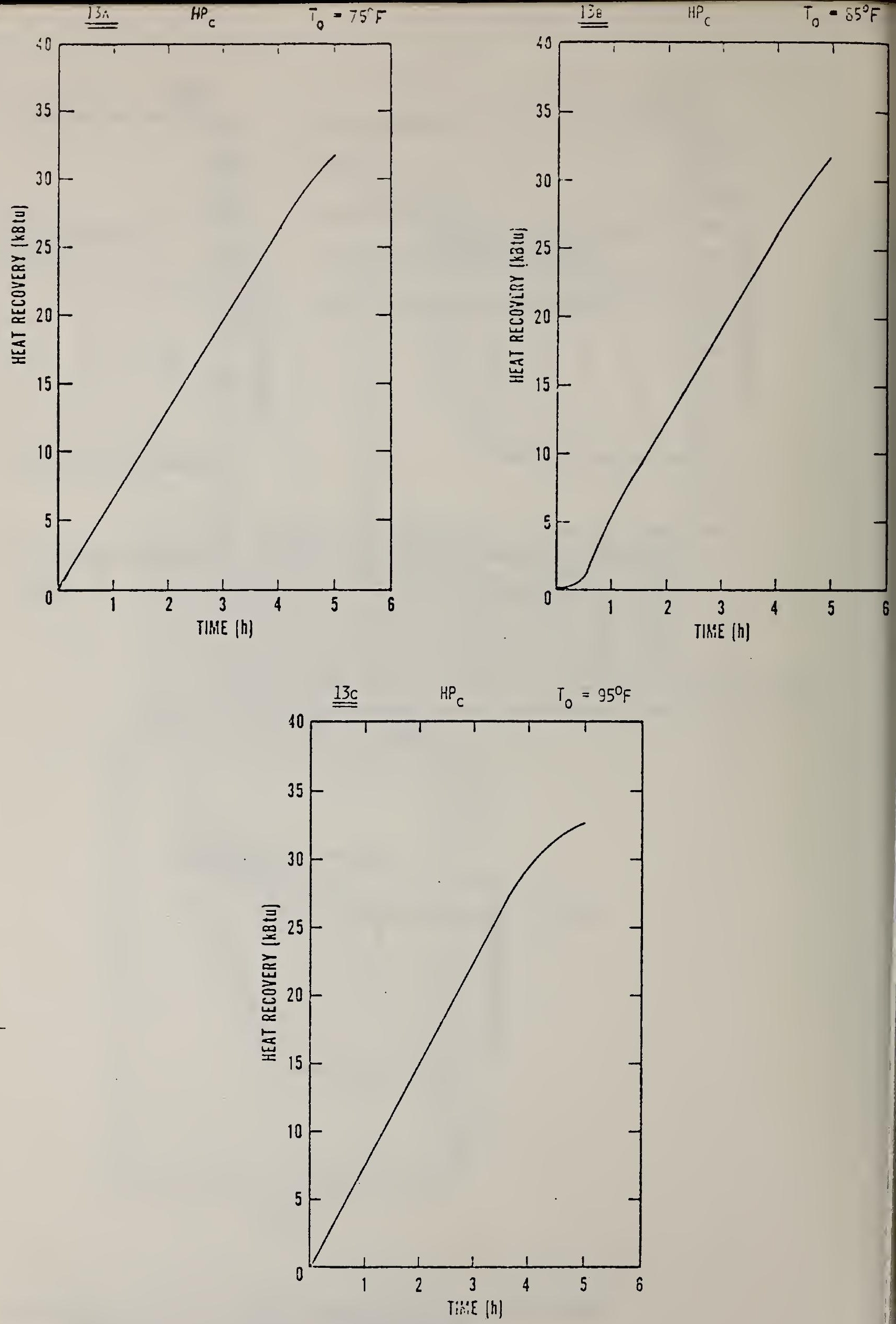

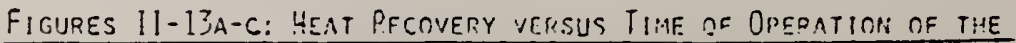
HP - HRII - WH [NTEGRITED GPP!IFNCE, USING HRIN NO. 2 40 

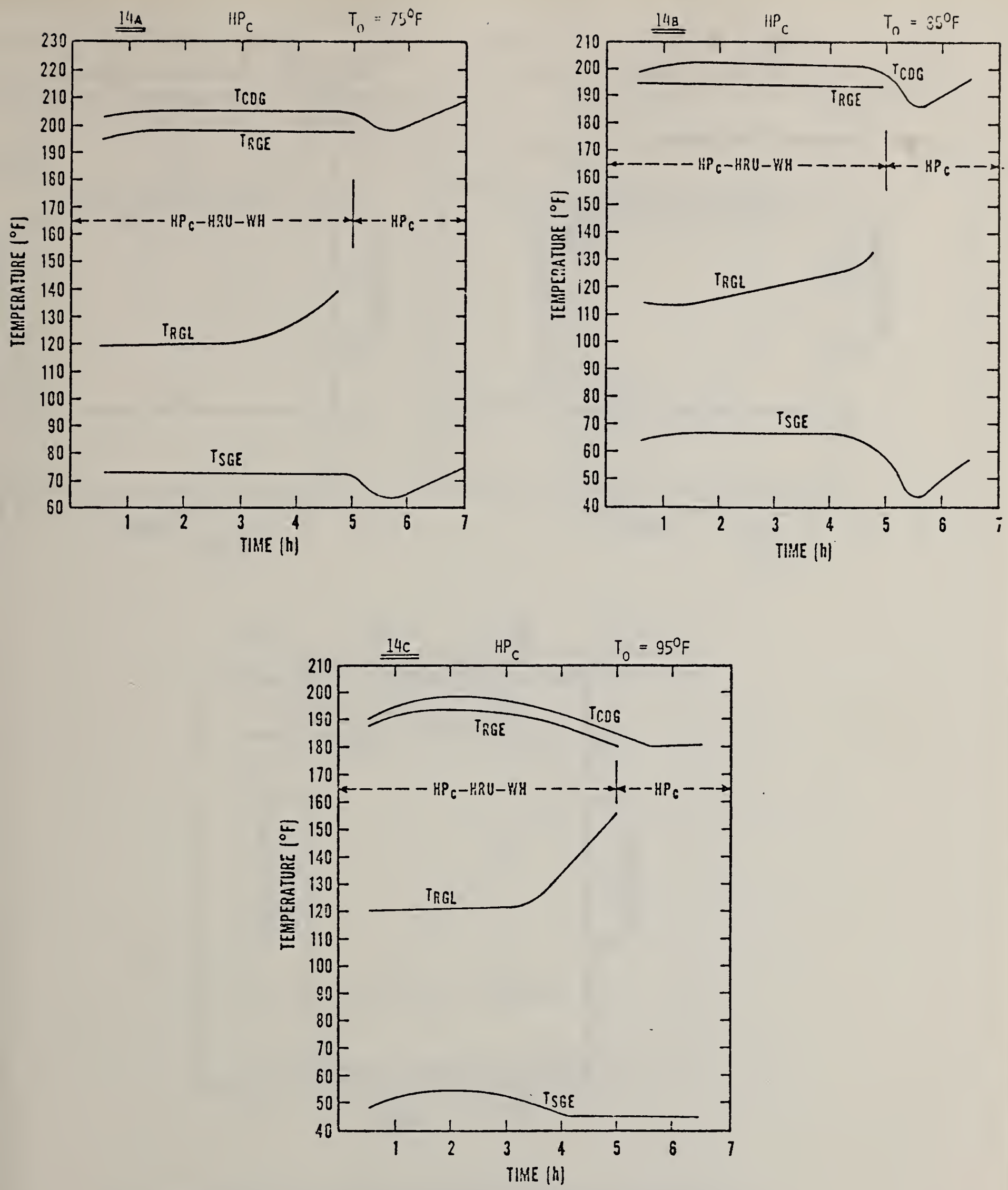

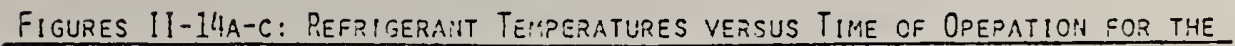

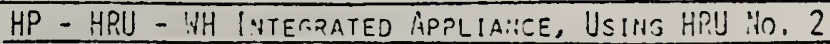

Notes: $T_{\text {C.DG }}=$ TeMperature of Coilpressor Discharge Gas

$T_{\text {RGE }}=$ Telipefature of Refrigerait Gas EHTERING HRU

$T_{\text {RGL }}=$ TE:PERATI,PE OF REFIIIGERANT GAS LE:VING HPU

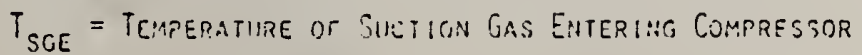



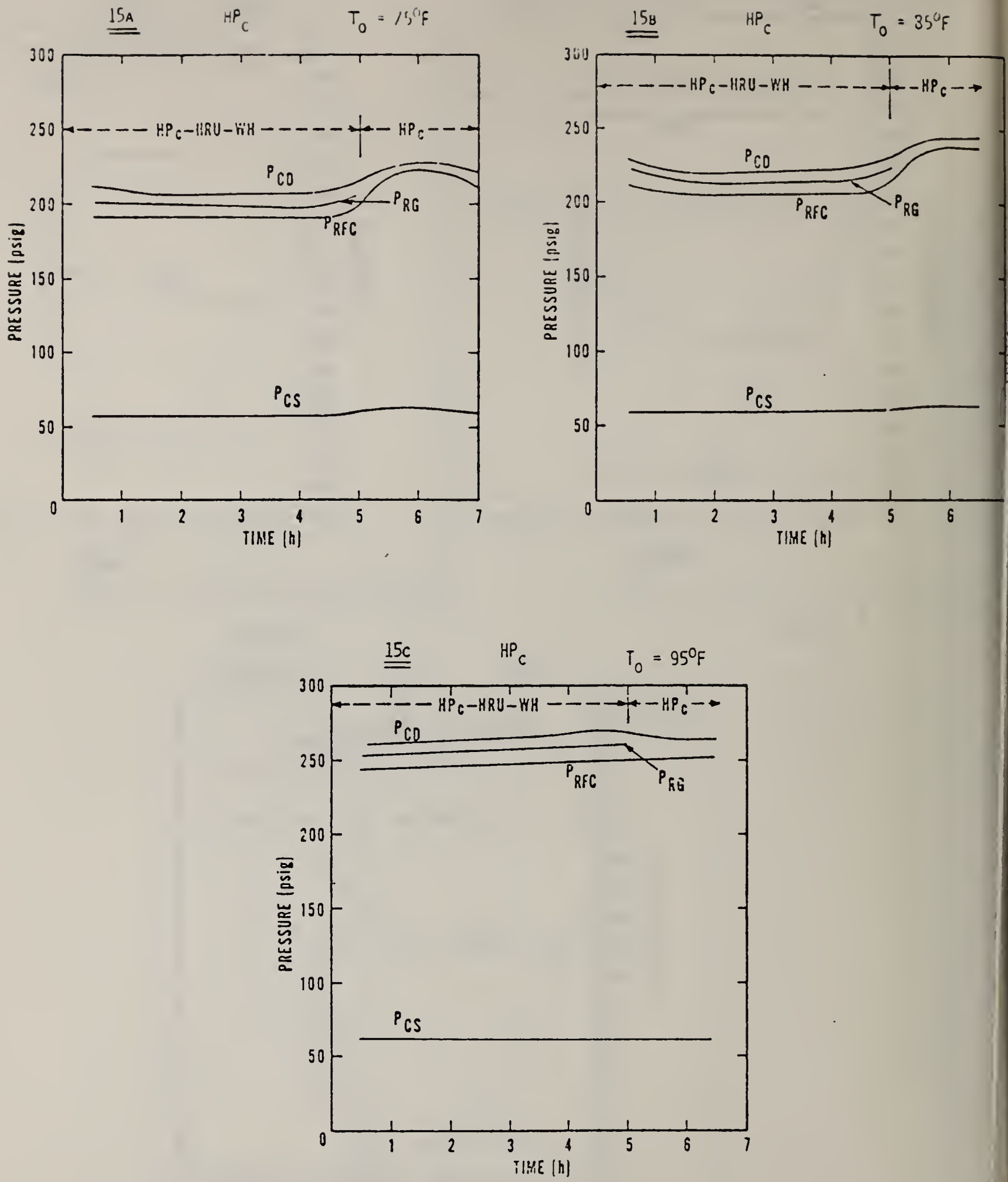

Figures 1I-15a-C: Refrigerant Pressures versus Time of Operation of the

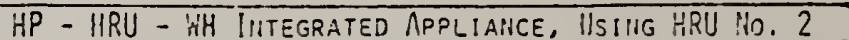
Notes: $P_{\text {CD }}=$ Coippressor Discharge fressure Preceding gas Line to HRU

$P_{R G}=$ Refrigerant Gas Pressure following Gas Line from HRII

$P_{C S}=$ Compressor SUCTIOH PRESSURE

$P_{\text {RFC }}=$ Refrigerant Pressure Folloning C.Nidenser 

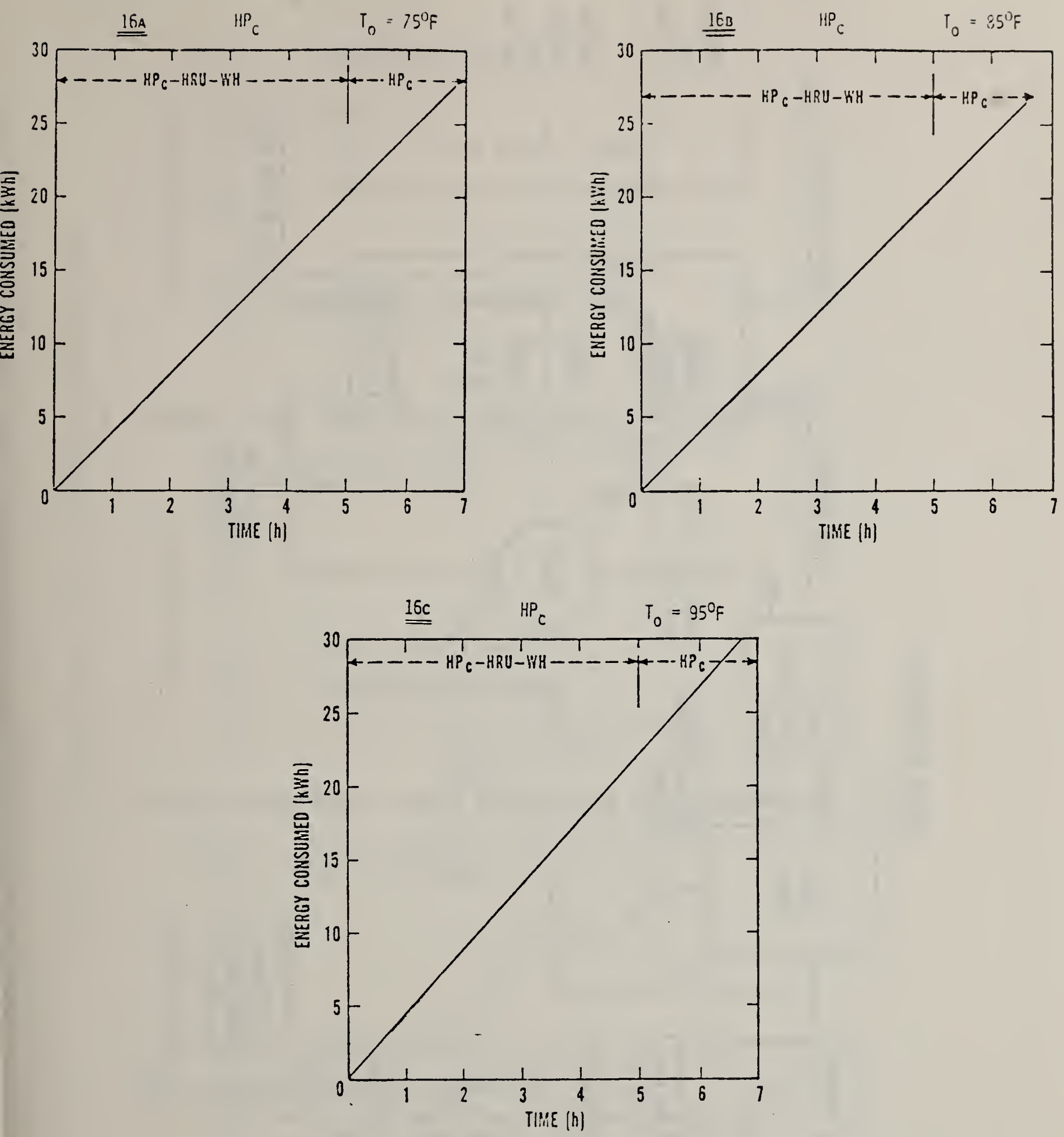

Figures 11-16a-c: Energy Consumed Versus TIME of OpEration of the HP - HRU - WH INTEGRATEd APPLIANCE, US I::G HRU:ilo. 2 


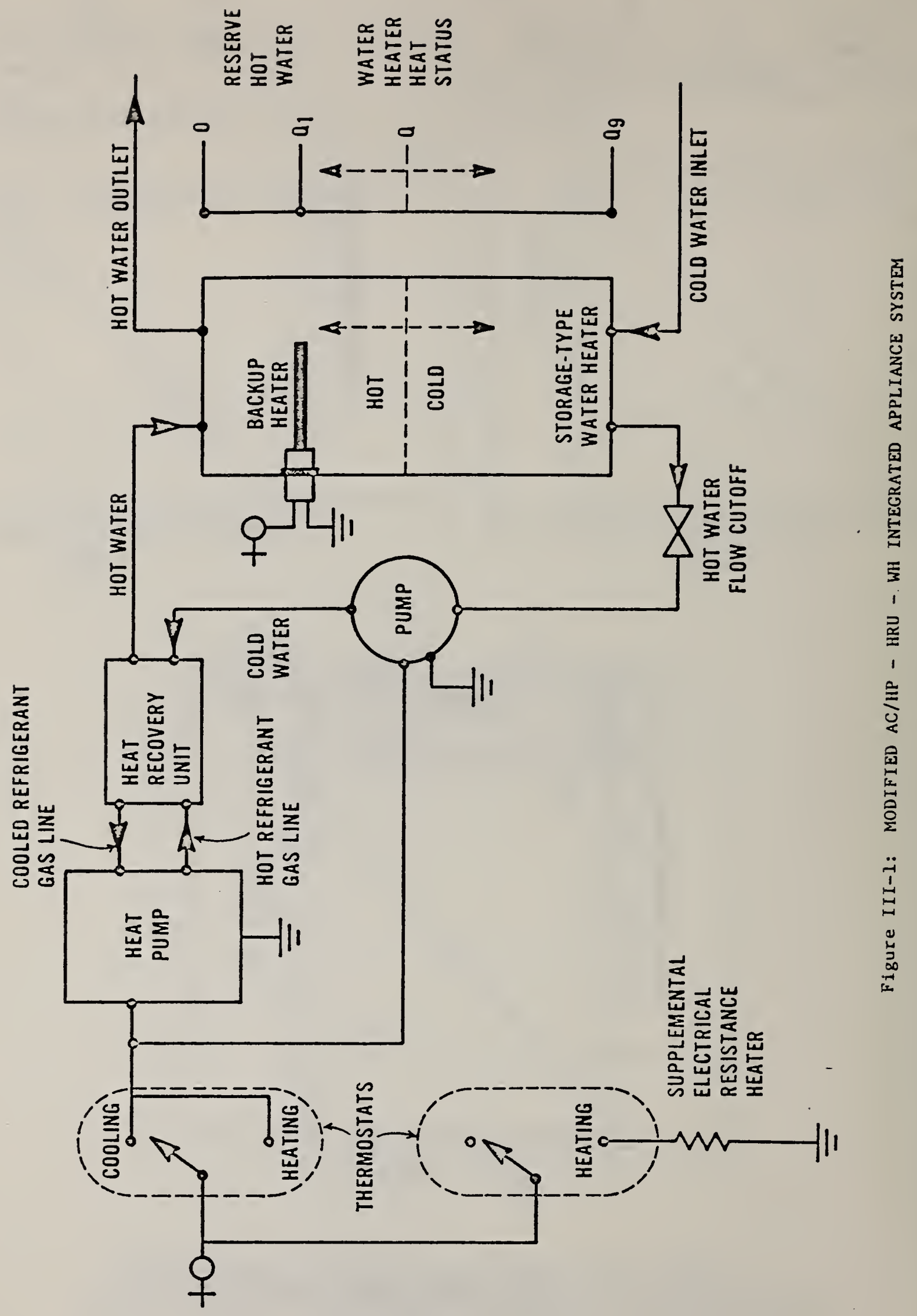




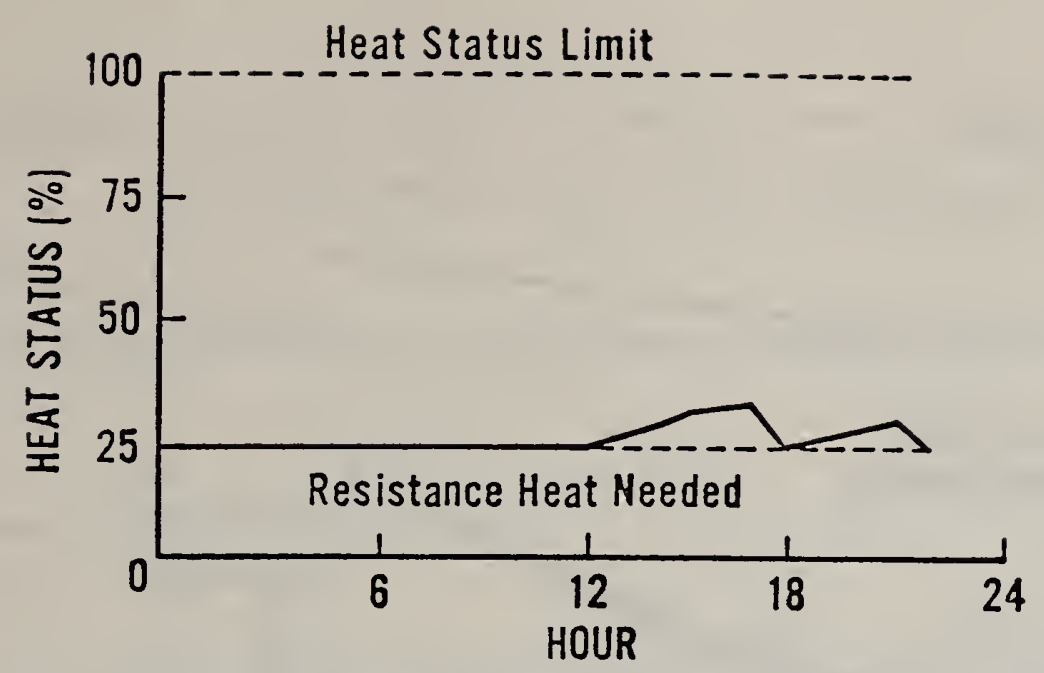

a. Sample hourly water heater status using a 40 gallon tank

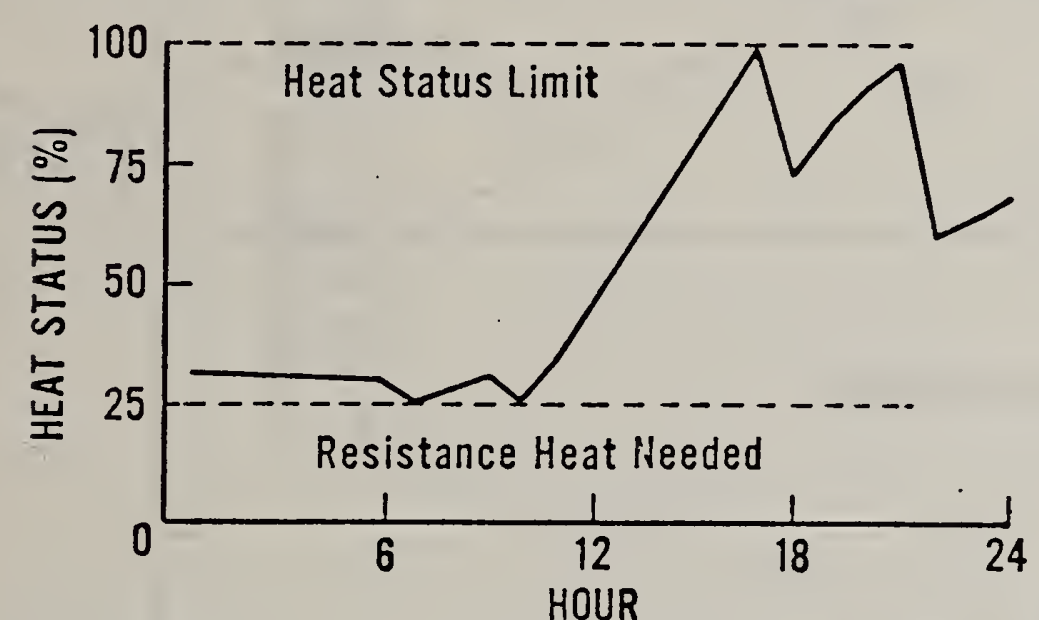

b. Sample hourly water heater status using a 40 gallon tank

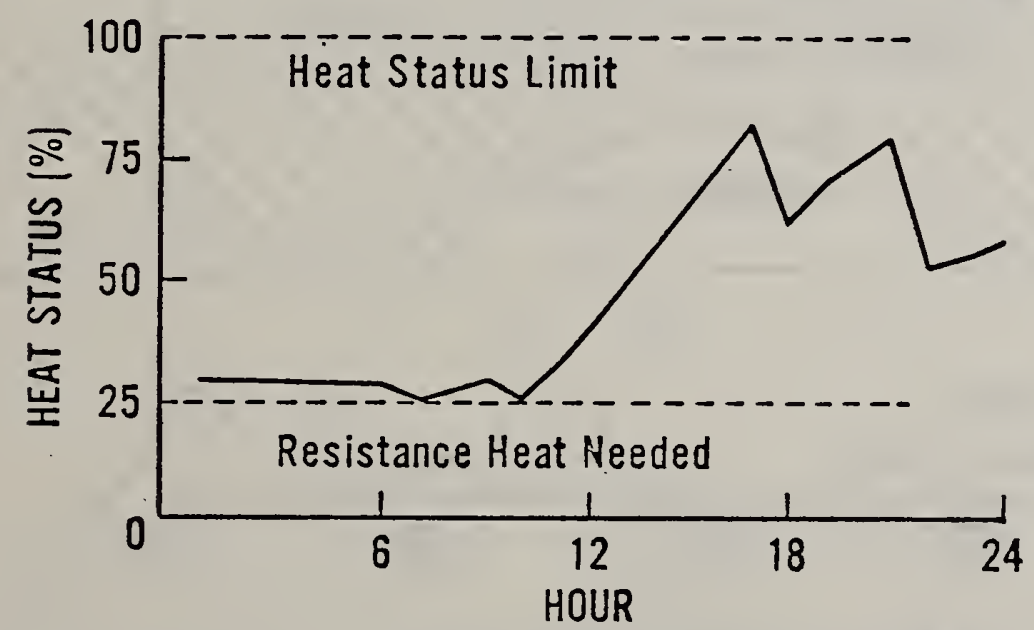

c. Sample hourly water heater status using a 52 gallon tank

Figure III-2 $a, b$, and $c$ : Heat Status vs. Time of Day, for Washington, D.C. $a$ and $b$ : different days, $b$ and $c$ : same day 

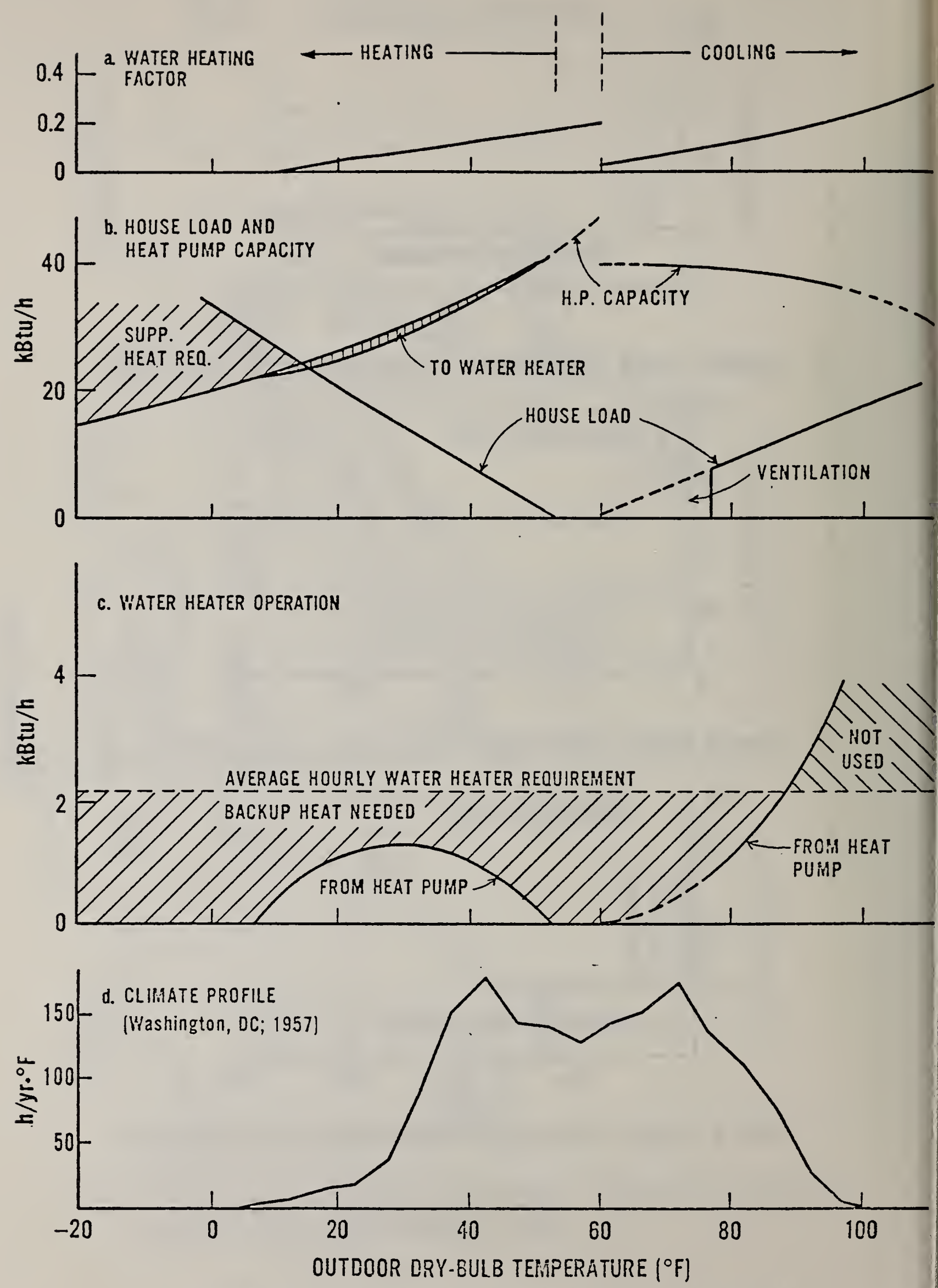

Figure III-3: Heat Recovery Factors vs. Outdoor Temperature 


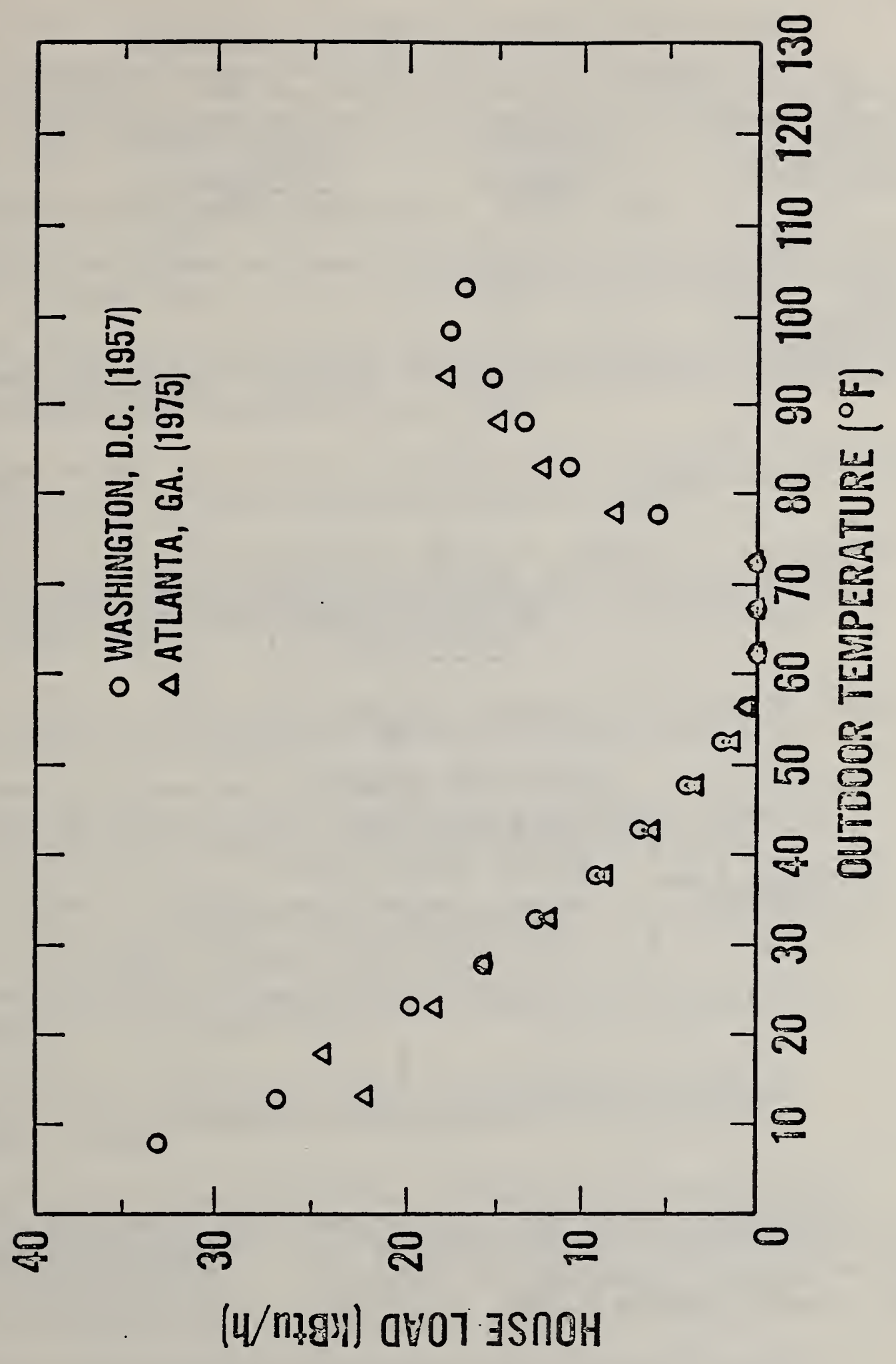




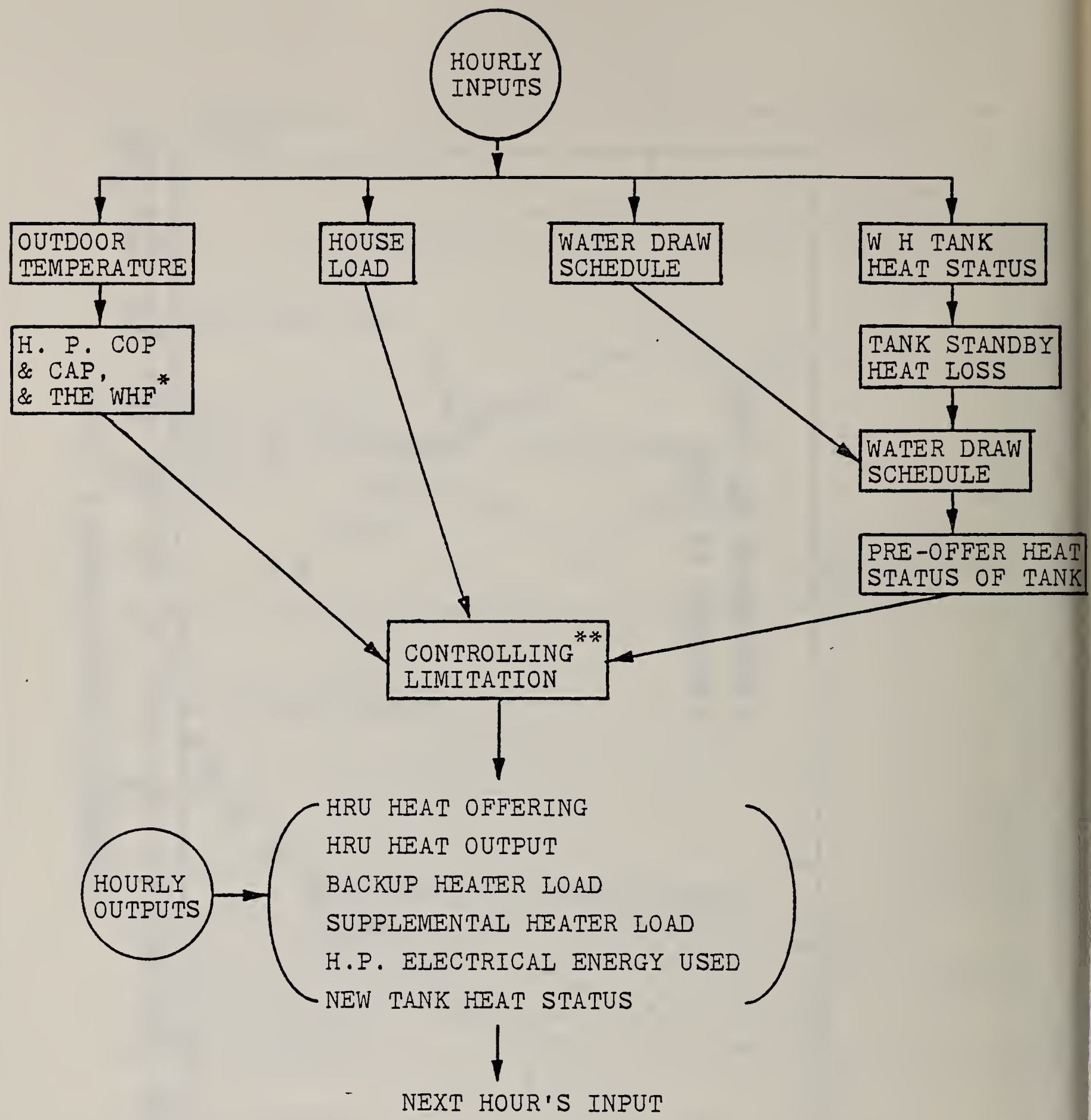

* COP = COEFFICIENT OF PERFORMANCE

CAP = CAPACITY (HEATING OR COOLING)

WHF = WATER HEATER FACTOR

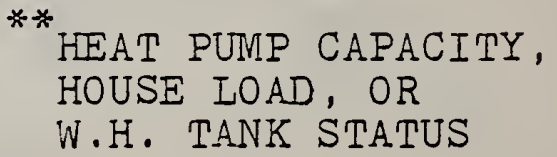

Figure III-5: Simulation Outline Diagram 


\section{Bibliography}

1. Ambrose, E. R., Heat Pumps and Electric Heating; Wiley and Sons.

2. American Society of Heating, Refrigerating and Air Conditioning Engineers (ASHRAE), ASHRAE Handbook and Product Directory, 1977 Fundamentals, ASHRAE, 1977.

3. _- ASHRAE Psychrometric Chart No. 1, ASHRAE, 1963.

4. E. I. DuPont de Nemours \& Company, Refrigerant - 22 Pressure-Enthalpy Diagram; duPont, 1964.

5. Kelly, G., Potential of Air-to-Air Heat Pumps for Energy Conservation in Residential Buildings, Proceedings of Heat Pumps and Thelr contribution to Energy Conservation, Noordhoff-Leyden, 1976.

6. U.S. Department(s) of Air Force, Army, and Navy, Engineering Weather Data, AFM 88-8, chapter 6, TM 5-785, NAVFAC P-89, June 15, 1976.

7. National Bureau of Standards, Kelly, G., Parken. W., Method of Testing, Rating and Fstimating the Seasonal Performance of Central Air-Conditioners and Heat Pumps Operating in the Cooling Mode, NBSIR 77-1271, 1978.

8. Kusuda, T., NBSTD, The Computer Program for Heating and Cooling Loads in Buildings, NBS Building Science Series 69, JulJ 1976.

9. Energy, Argonne National Iaboratory, Ashbury, J. and Others, Assessment of Energy Storage Technologies and Systems, Phase II: Heat Pump and Solar Energy Applications, ANL/SPG-3, 1978.

10. Division of Buildings and Community Systems, Concept Paper for Air Conditioner/Heat Pump - Water Heater, 1979.

11. Oak Ridge National Laboratory, Fischer, H., Ice-Maker Heat Pump-Part II, RSC February 1977.

12. , O'Neal, D., Carney, J., Hirst, E., Regional Analysis of Residential Water Heating Options: Inergy Use and Iconomics, ORNL/CON-31, 1978.

13. Housing and Urban Development, Intermediate Minimum Property S̄tandards Supplement, 1977 Edition, Solar Heating and Domestic Hot Water Systems, HUD 4930.2, 1977.

14. Weather King, Feat Pumps, Models QH, AH, Addison Products, 1978.

15. Ritchie, D., Water Heating by Refrigeration, Weather King, Inc., March 1974.

16. Wetherington, T., Heat Recovery Water Heating, Energy Conservation Unlimited, (undated). 


\section{A-I. House Feating, Cooling and Hot water Ioads}

Hourly data developed on another project at NBS were used as the source of outdoor temperatures and loads on the heating and cooling system. Detailed weather data and a suitable description of a house and its operation were analyzed using portions of the NRSTD (National Bureau of Standards Ioad Determination) program. Weather data for several years have been examined for several locations in the United States, and for each location a reasonably typical year, called a Test Reference Year (TRY) has been chosen for use in weather dependent studies. The TRY's are 1957 for Washington, DC, 1975 for Atlanta, GA, 1974 for Chicago, II, and 1960 for Seattle, NA. Dry- and wet-culb temperatures, wind speeds, cloud cover and solar radiation are among the important environmental input data.

The same house was used in all locations for which the load data are available and has the following features:

- Single family, one story detached dwelling

- 1800 square feet of floor over a crawl space $\left(49^{\prime} \times 36^{\prime} 9^{\prime \prime}\right)$

- Insulation includes R-38 for the ceiling, R-13 for the walls, R-19 for the Iloor and double glazing for windows and glass doors.

- Infiltration was calculated separately for each hour, depending on wind speed and the indoor/outdoor temperature differential.

Thermostat settings were $68^{\circ} \mathrm{F}$ for heating and $78^{\circ} \mathrm{I}$ for ccoling.

$\circ$

Indoor relative humidity was maintained between 20 percent and 60 percent.

- Natural ventilation was used only when it could keep the house temperature at 68 to $78 \mathrm{~F}$, while maintaining the indoor relative humidity in the specified range. The amount of ventilation was variable and vents were closed if the humiditu requirement could not be met with ventilation or the ventilated indoor dry-bulb temperature would be either above or below $78 \mathrm{~F}$.

- Occupants were two adults and two children.

- The use of ligits and equipnent was given on an hourly schedule.

Data used in the present simulation include the hourly streams of outdoor temperature and the heating and cooling loads on the environmental control equigment. A daily cycle of hourly drars of hot water that was developed at MRS was added to complete the description of the enviroment in which the heat recovery system operates. This schedule is given in Table A-I, in which the Iractional draws were first translated into gallons on the basis of 64.3 gallons of hot-iater use per day, aggregated by hour of the day and translated into kBtu 
on the basis of a $90^{\circ} \mathrm{F}$ temperature rise and 8.25 pounds per gallon. Heat losses from the WH were computed on the basis of one percent per hour of the thermal energy in the water (i.e., the tank heat status, Q) at the beginning of each hour. NBS tests indicate that this one percent factor is reasonable for well insulated WH.

The input data from the NBS house load simulation studies consist of the temperature for each hour and the corresponding sensible and latent heat movement loads on the heat pump. Sensible loads are the amounts of thermal energy that must be added or removed to control the indoor dry-bulb temperature. latent loads refer to humidity control. Both loads were computed using the NBSID program and are the resultants remaining after all other thermal energy gains and losses have been considered. These loads were added for each hour to yield the total load on the heat pump. Total loarls for the year are the sums of the absolute values of these hourly loads.

\section{A-II. Heat Pump and Heat Recovery System}

Three parameters were used to describe the essential characteristics of the $\mathrm{HP}$ and HRU. These are the HP capacity, CAP, the HP coefficient of performance, COP, and the water heating factor, WHF, for the HRU. WHF is the fraction of the HP output that is available for heating water. CAP and COP depend on hoth the indoor and outdoor temperatures and WHF depends on the temperature of the refrigerant leaving the compressor. CAP, COP and WHF were evaluated at the midpoints of five degree temperature bins from $110^{\circ} \mathrm{F}$ down to $-40^{\circ} \mathrm{F}$ to cover the main climate range in the U.S., taking into consideration the indoor temperatures associated with heating and cooling situations. The reference HP for these estimates is one of the two used in the experimental phase of this study. It has a cooling capacity of 35,000 Btu per hour under standard ARI rating conditions of $95 \mathrm{~F}$ outdoor dry-bulh temperature and indoor temperatures of $80^{\circ} \mathrm{F}$ dry-bulb and $67^{\circ} \mathrm{F}$ wet-bulb. Rated heating capacities for $78^{\circ} \mathrm{F}$ indoors and outdoor dry- and wet-bulb combinations of $47 \mathrm{~F} / 43 \mathrm{~F}$ and $17 \mathrm{~F} / 15^{\circ} \mathrm{F}$ are 37,000 and 24,000 Btu per hour, respectively. The values for CAP, COP and WHF that were used in the simulation and in the alternate calculation procedures are given in Table A-2 and are compatible with the results of laboratory tests of a sample HP-HRU-WH system. The values for a given bin were used for all hours with outdoor temperatures falling within the range of the bin. Since it would be more economical to rely on supplemental resistance heat when the COP is less than 1.0, CAP and COP are set to zero for these cold-weather conditions.

The COPs apply to steady state operation at the corresponding CAPs. However, when the load, I, is less than the CAP, the HP will cycle on and off and this part load COP will be less than the full load COP. (If I exceeds CAP, the HP output is limited to CAP.) This means that actual seasonal operating costs will be somewhat higher than would be estimated using full load COP's throughout the year. A part load COP adjustment factor developed at NBS was used in the calculation of energy consumption for each hour or each bin, depending on the computing model in use.

$$
\frac{\mathrm{COP}}{\operatorname{COP}(\text { part load })}=0.75+0.25 \times \frac{\mathrm{I}}{\mathrm{CAP}}
$$




\section{A-III. Simulation Processing}

The main loop in the hourly simulation was described in Section III, along with two hin procedures. Figures A-1 and A-2 are more detailed flow diagrams of the computational logic of the hourly simulation and the alternate methods, respectively. Details of the initializing print array generation and printout are not shown. A page of symbol definitions accompanies each flow diagram. The bin procedures do not consider the hourly variations of the heat status, $Q$, of the water heater tank. Annual results are derived by computing results for one hour under stable conditions at the selected location for each bin and then weighting the results by the number of hours per year at the location. Otherwise, the engineering concepts are identical for the hourly and bin methods.

Briefly, the steps in the hourly simulation are:

1. Specify the COP, CAP and WHF (described above) together with the initial value of the tank heat status, $Q$, and the maximum and reserve heat statuses, Q9 and Q1, respectively, for the tank being modeled.

2. Read the outdoor temperature and the house load for each successive hour, carrying out the steps and making the accumulations described in Section III.

\section{A-IV. Additional Temperature Profiles}

The outdoor dry-bulb temperature correlates quite well with the average total sensible and latent house loads. Data from Bibliography Item 1 were used to generate anmal temperature profiles for several locations in the country. The data were compiled in each case from hourly readings covering a period of ten years or more. These profiles (Figures A-3-A-13) correspond in their application to the climate profile at the bottom of Figure III-3. 
Table Al: Water Draw Schedule

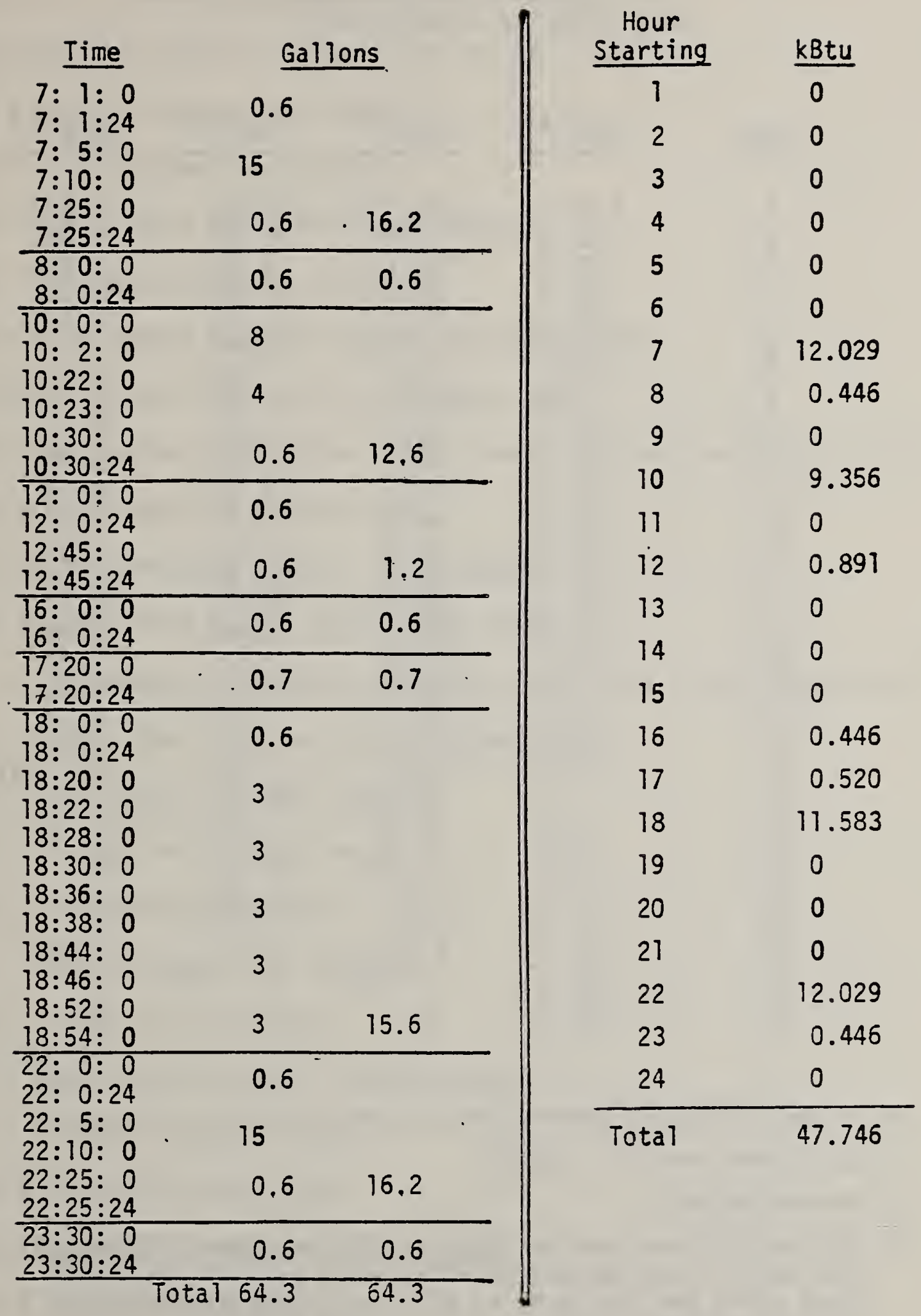


Table A2: Heat Pump Capacities (CAP), Heat Pump Coefficients of Performance (COP) and Water Heating Factors (WHF)

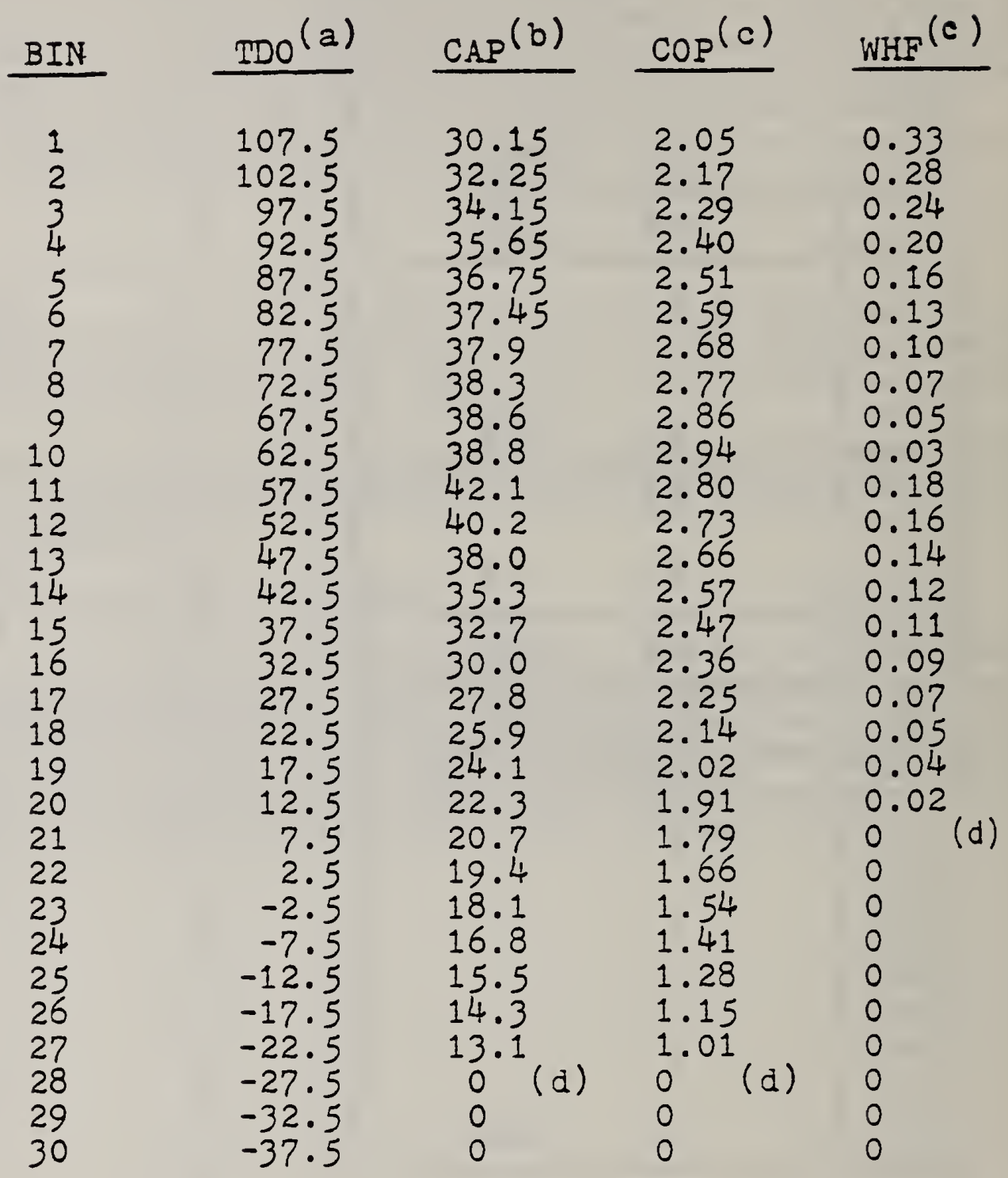

(a) Outdoor dry-bulb temperatures at the midpoints of the bins.

(b) Full-load capacity, kBtu/h.

(c) Dimensionless.

(d) CAP and COP were set to zero for COP less than 1.0 because the use of resistance heat alone would be more economical than using the heat pump at all under these conditions. WHF is zero when water at the required temperature cannot be delivered to the tank. 


\section{Notes for Figure $A-1$}

$\operatorname{INT}(x x)=$ Find the integer component of $(x x)$.

TDO = Outdoor dry-bulb temperature for bin, deg. $F$.

HLS = Sensible house load, kBtu/h.

HLL = Latent house load, kBtu/h.

$H L N=H L S+H L L=$ Net house load, $\mathrm{kBtu} / \mathrm{h}$.

WOR $=$ Hot water draw for hour, kBtu.

$B I N=$ Five-degree temperature bin containing $T D O$.

$Q=$ Heat status of WH at start of hour, kBtu.

Q4 = Heat status of WH after jacket losses and WDR for the hour, kBtu.

$Q 9=$ WH maximum heat status, kBtu.

$Q 1=W H$ reserve heat status $=Q 9 / 4, \mathrm{kBtu}$.

BHLT = Cumulative backup heater load, kBtu.

(Accumulation formulas take the form; New Total = 01d Total + Increment.)

Q6 $=Q 9-Q 4=$ Heat that the WH can accept, kBtu.

$H P L=$ Heat pump (HP) load, kBtu/h.

$H P K=H P$ electricity use, $\mathrm{kWh} / \mathrm{h}$.

HPKT = Cumulative HPK, KWh.

HOF = Heat offered to WH, kBtu/h.

HOFT = Cumulative HOF, KBtu.

WHF $=$ Water heater factor, dimensionless.

$W H R=W H$ heat refusal, $\mathrm{kBtu} / \mathrm{h}$.

WHRT = Cumulative WHR, KBtu.

SHL = Supplemental heater load, $\mathrm{kBtu} / \mathrm{h}$.

SHLT = Cumulative SHL, kBtu.

SHKT = Cumulative SHK, KWh.

BHKT = Cumulative BHK, KWh. 


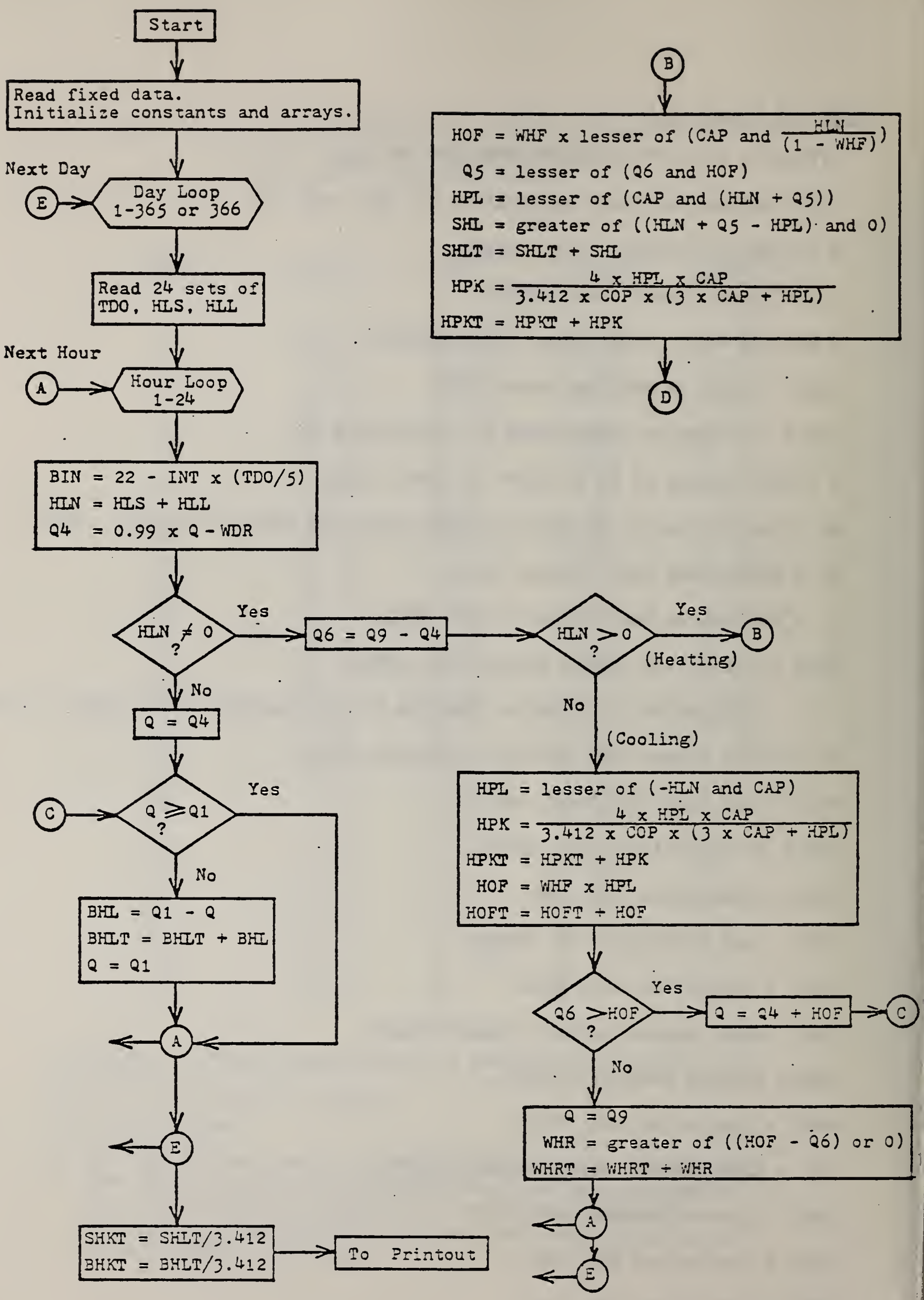




\section{Notes for Figure $A-2$}

There are 30 five-degree temperature bins covering the range from $110^{\circ} \mathrm{F}$ to $-40^{\circ} \mathrm{F}$. Data from curves are evaluated at the mid-point of each bin. There is one value per bin for the following data items:

COP $=$ HP coefficient of performance, dimensionless.

CAP $=$ HP capacity, kBtu/h.

WHF = Water heater factor, dimensionless.

HRS = Site bin-hours per year.

$H L I=$ House load, bin average from detailed simulation input tape, $k B t u / h$.

$H L 2=$ House load, from linear regressions of $H L 1, \mathrm{kBtu} / \mathrm{h}$.

$H L X=H L 1$ for $B$ in Average method $=H L 2$ for $B$ in $L$ inear method, $k B t u / h$.

Bin variables derived in the course of the analysis include:

$H P L=H P$ load, $k B t u / h . \quad(H P L$ is not allowed to exceed CAP).

$H P K=H P K W h$ for the bin, corrected for part load effects on the HP, kWh/yr.

$=H R S \times \frac{H P L}{3.412 \times C O P} \times \frac{4 \times C A P .}{3 \times C A P+H P L}$

SHK = Supplemental heater load for bin, kWh/yr.

HOF $=$ Heat offered to $W H, k B t u / h$.

WHD = Average hourly heat demand by WH, covering water draws and jacket losses. For a 52 gallon tank,

$=\left(\frac{52 \text { gal }}{4} \times .01\right.$ loss per hour $+365 \times 64.3$ gal per day $/ 8760 \mathrm{hrs}$ per $\left.\mathrm{yr}.\right)$

$\times 8.25$ ib per gal $\times 90^{\circ} \mathrm{F}$ rise $/ 1000=2.086 \mathrm{kBtu} / \mathrm{h}$.

WHA $=$ Water heater acceptance, kBtu per hour.

WHK $=$ Electricity demand on backup heater $=$ HRS $\times$ WHA $/ 3.412, \mathrm{kWh} / \mathrm{yr}$.

Comparable bin results without heat recovery are also computed;

SHKO = Supplemental heater electrical load, $\mathrm{kWh} / \mathrm{yr}$.

HPLO = Heat pump load, $\mathrm{kBtu} / \mathrm{h}$.

HPKO = Heat pump electrical load, kWh/yr.

WHKO = Backup heater electrical load, $\mathrm{kWh} / \mathrm{yr}$. 


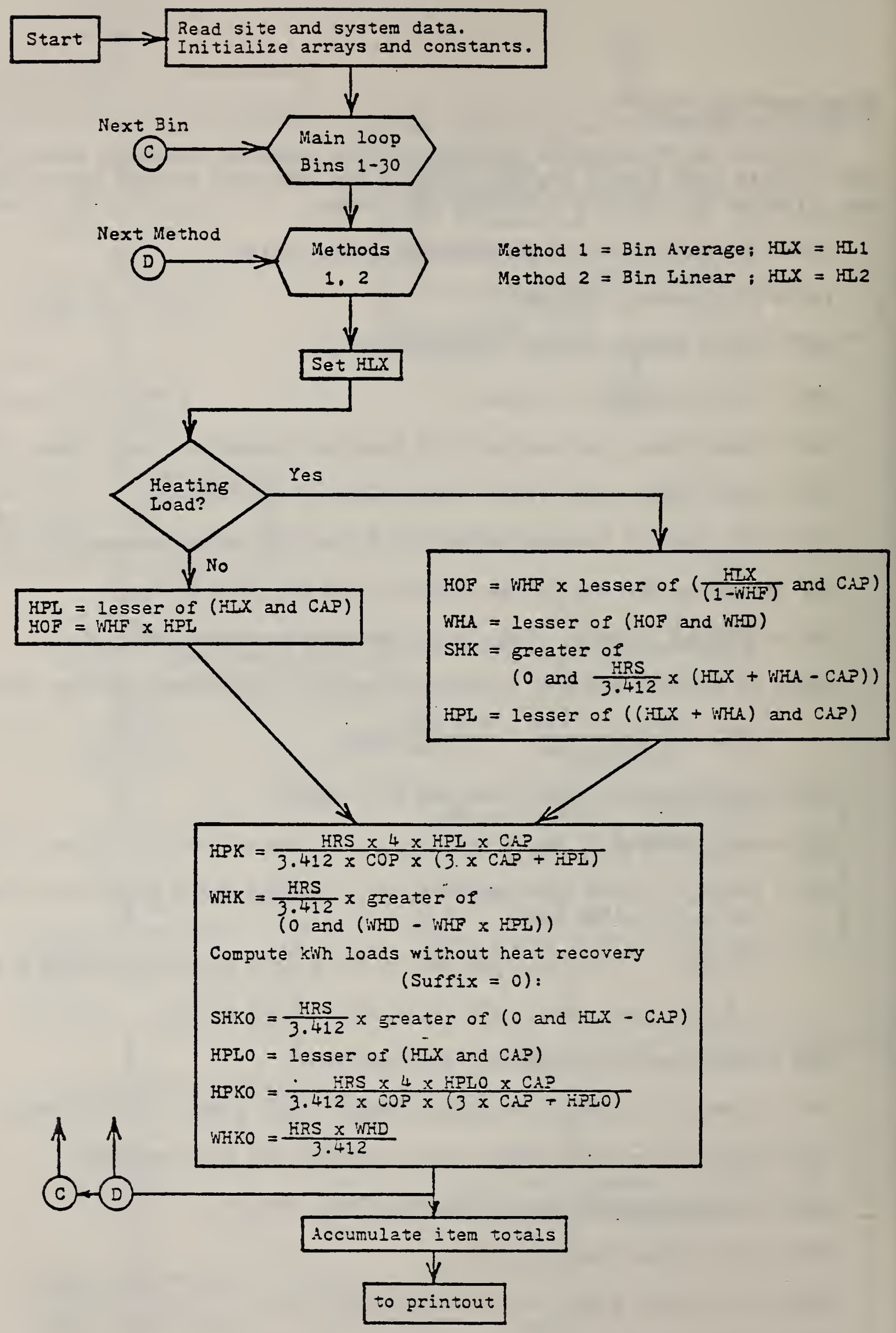

Figure $A-2$. Flow Diagram for $3 i n$ Average and Sin Linear Methods 


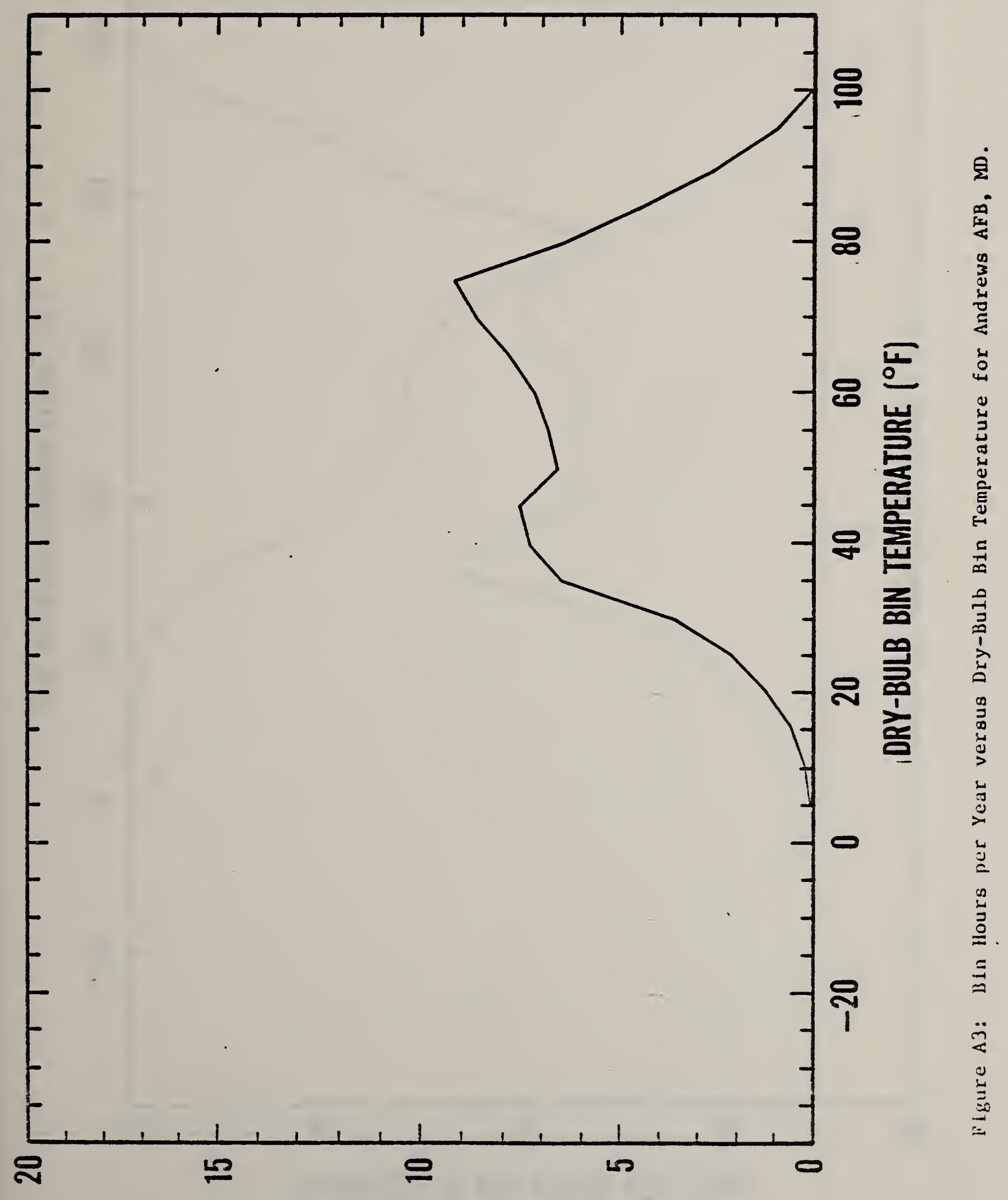

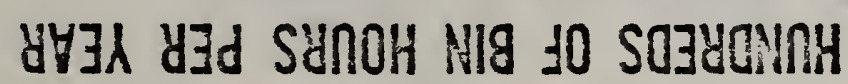




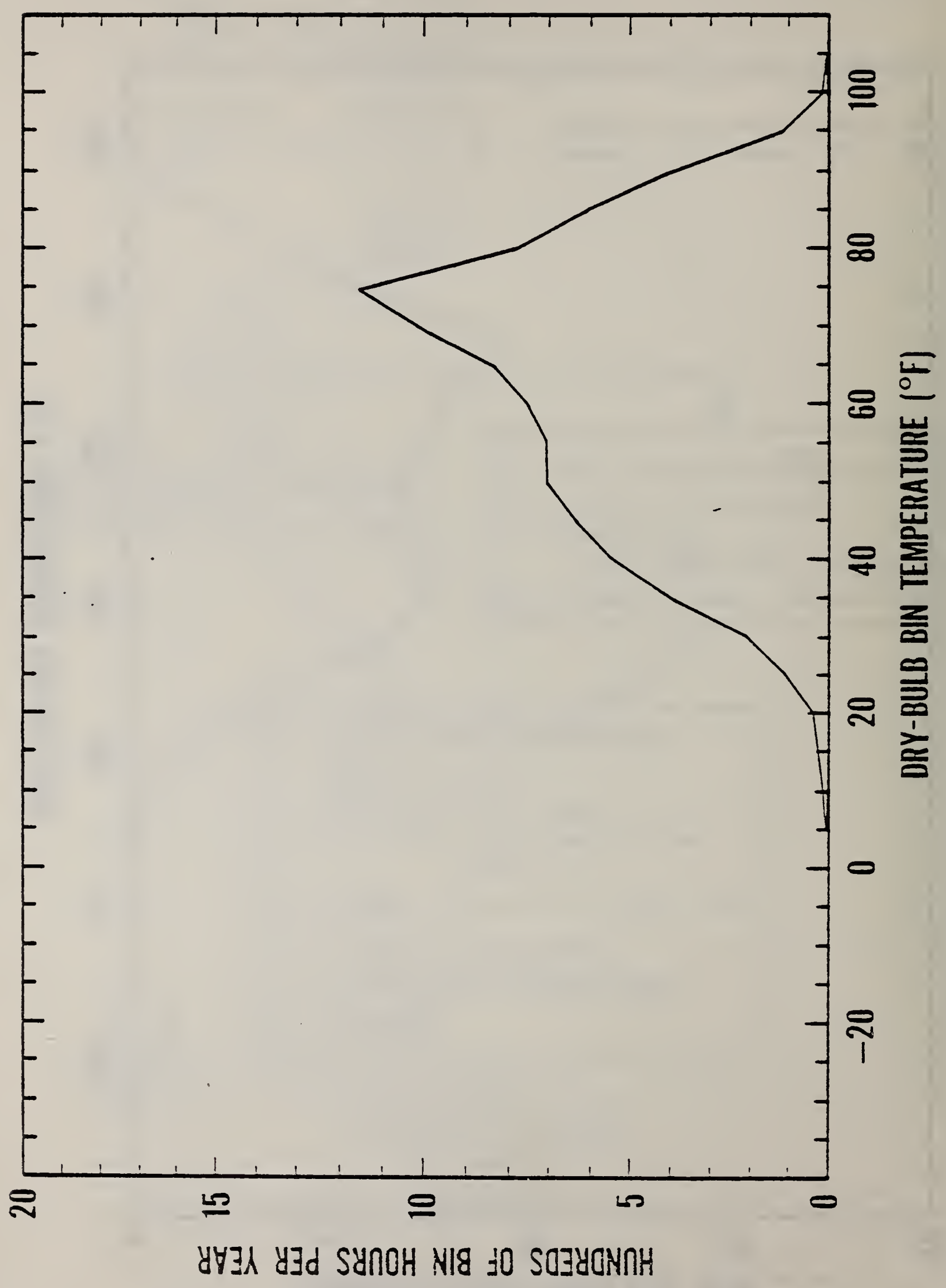




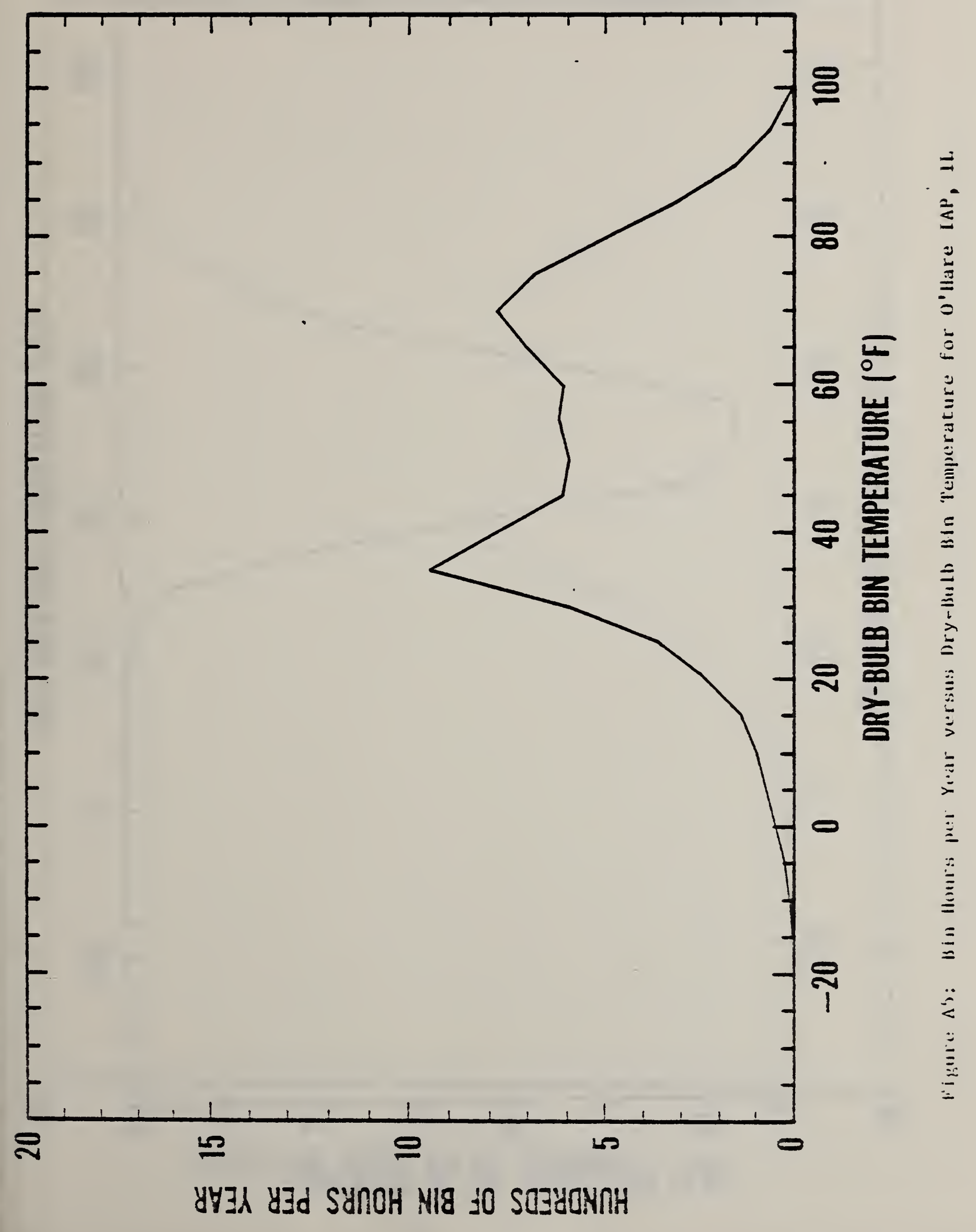




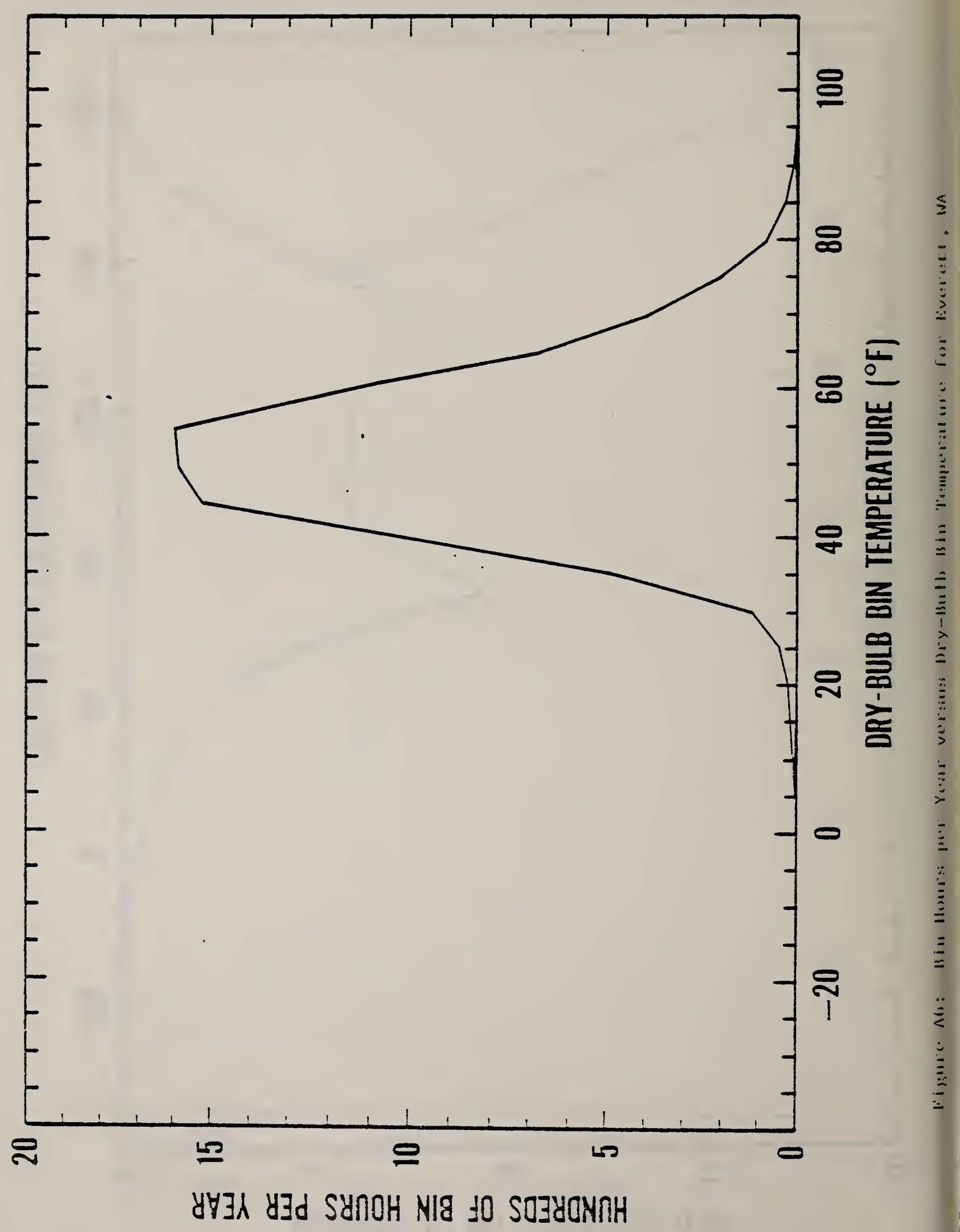




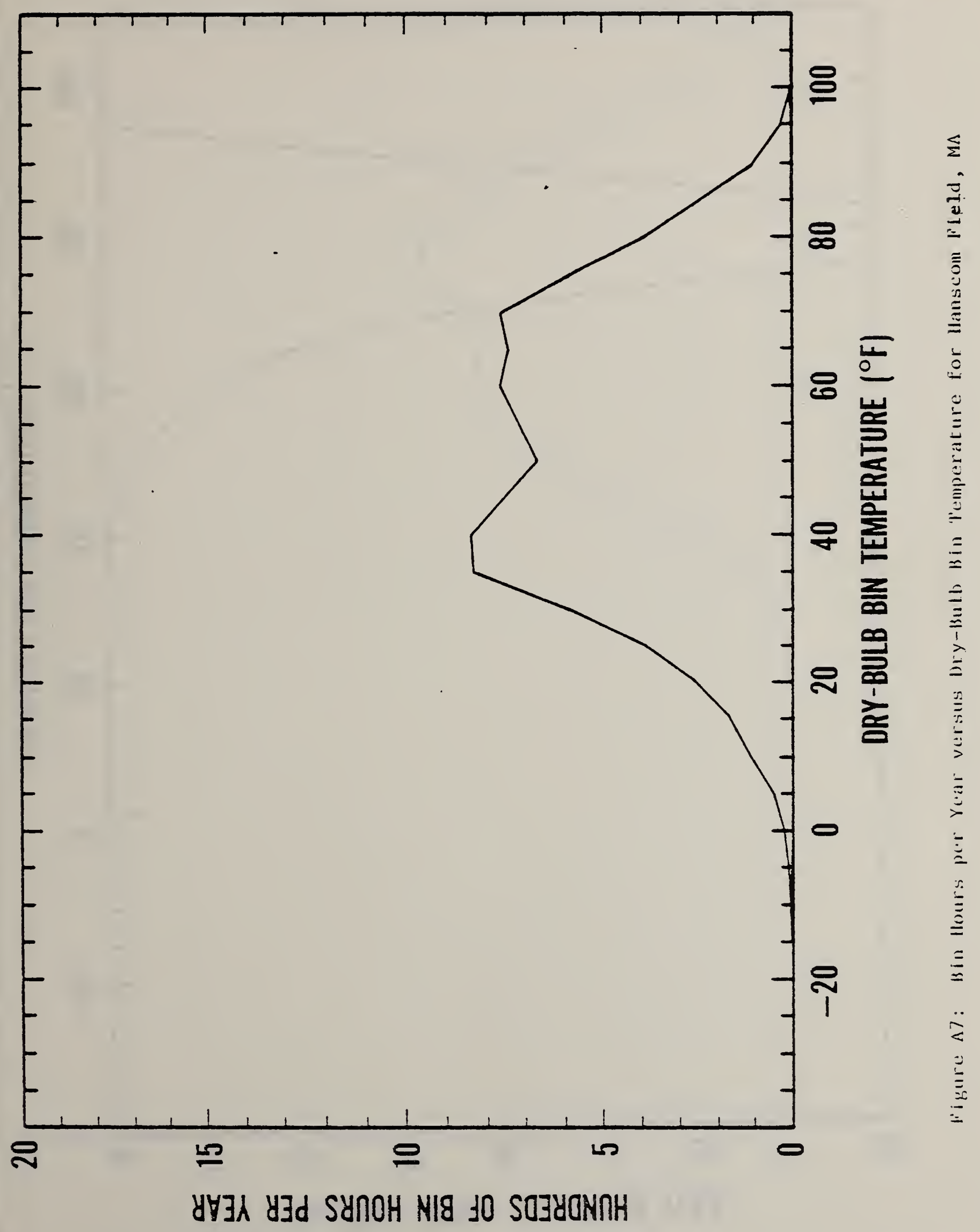




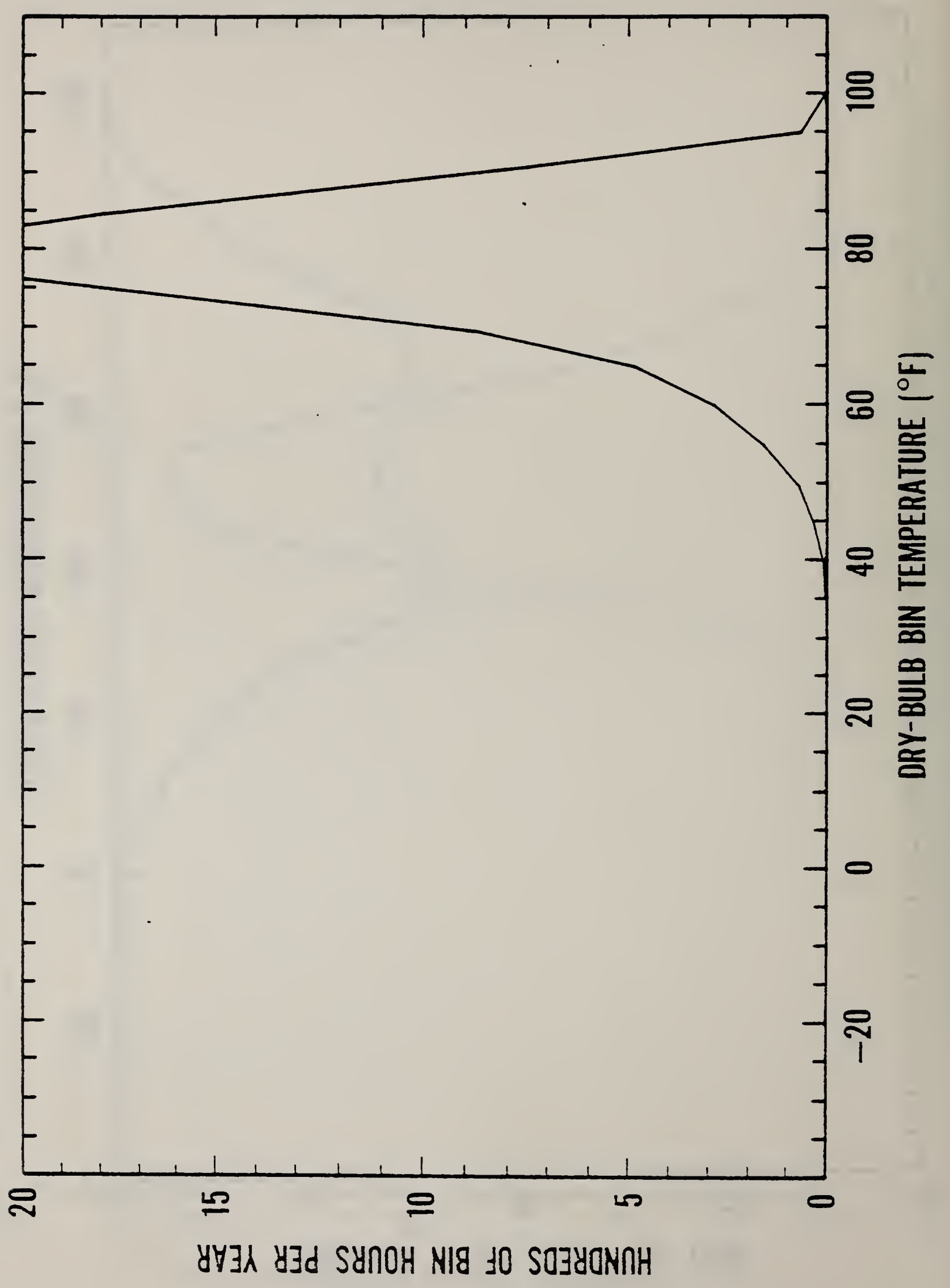




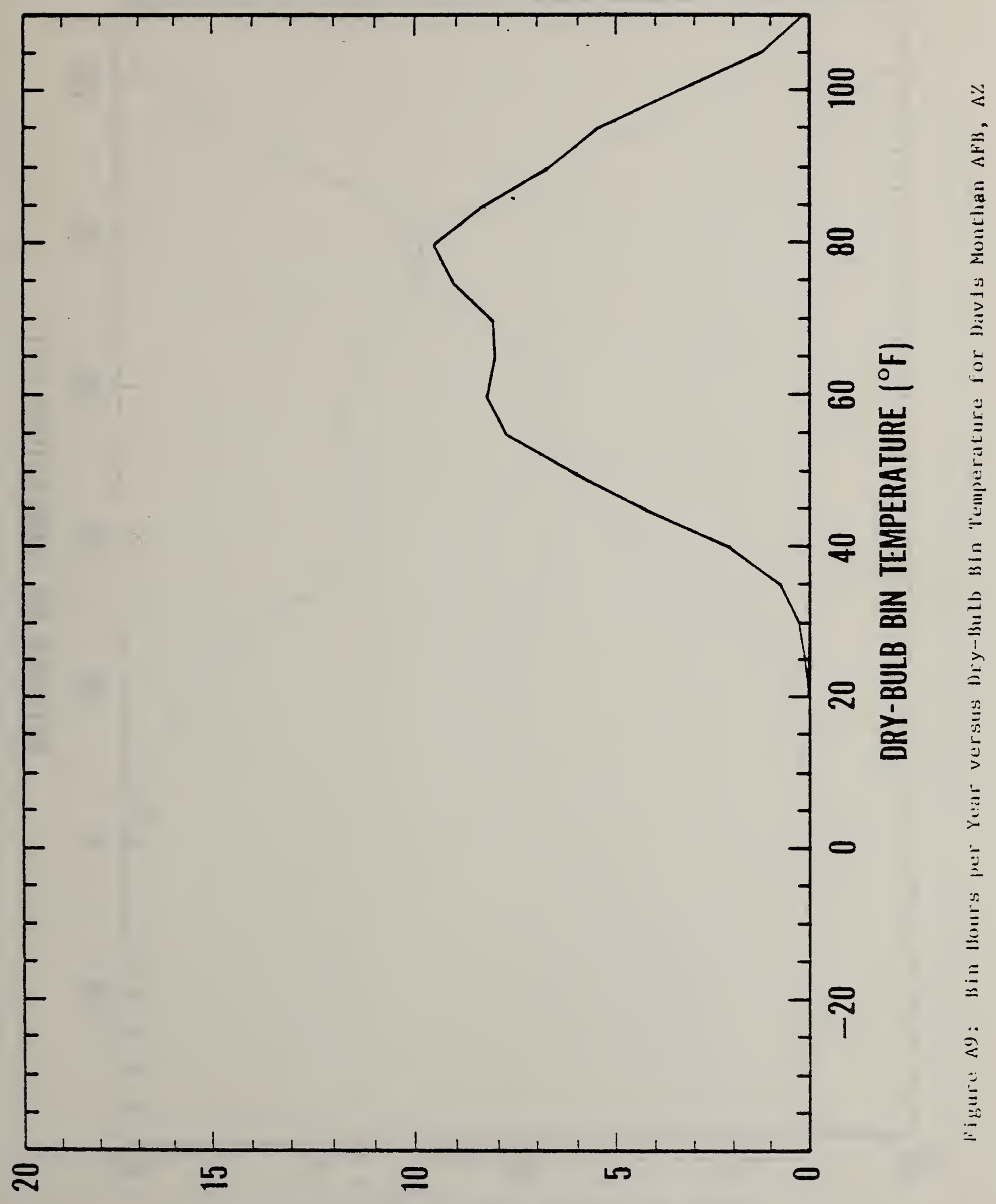

y $\exists$ y y 


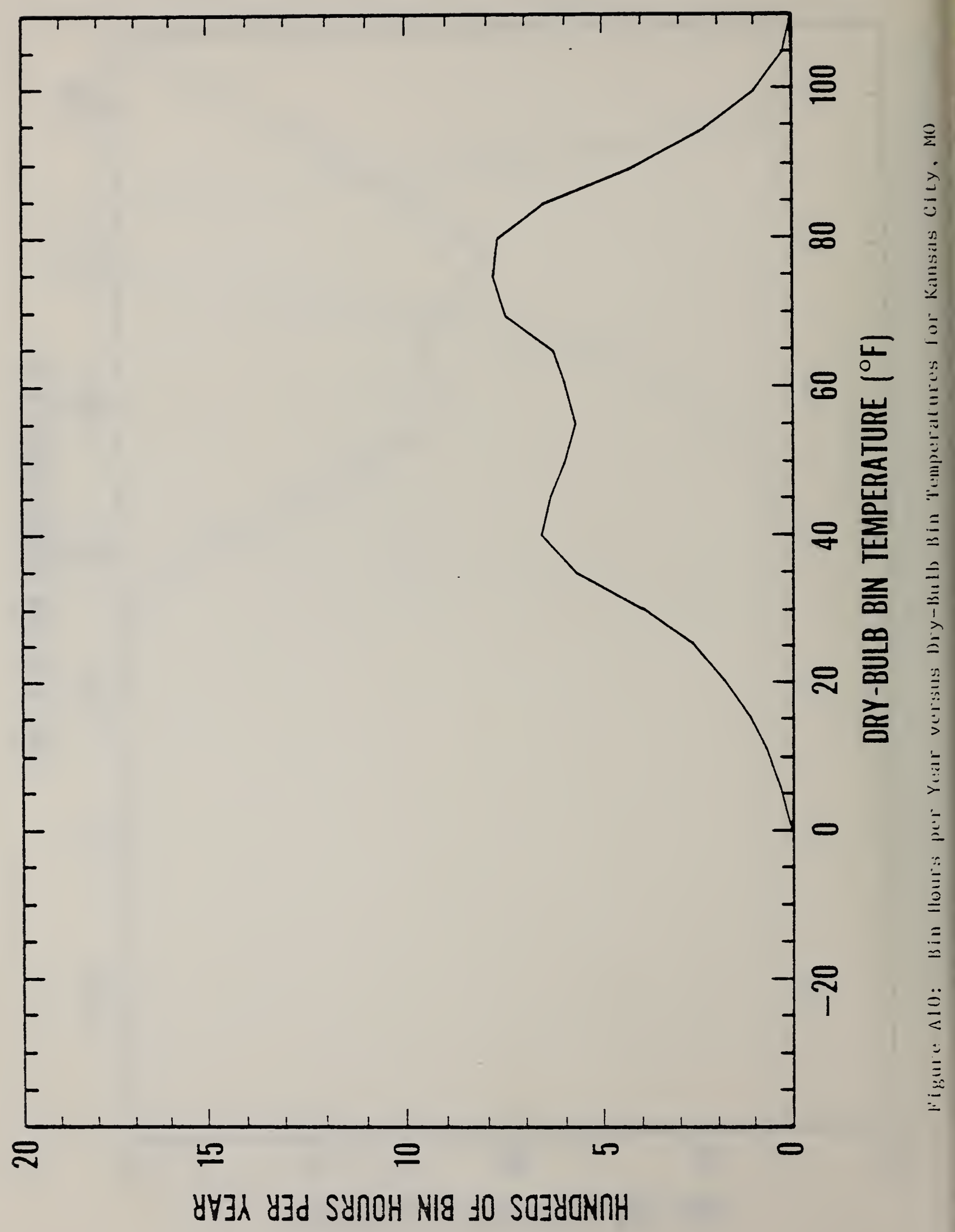




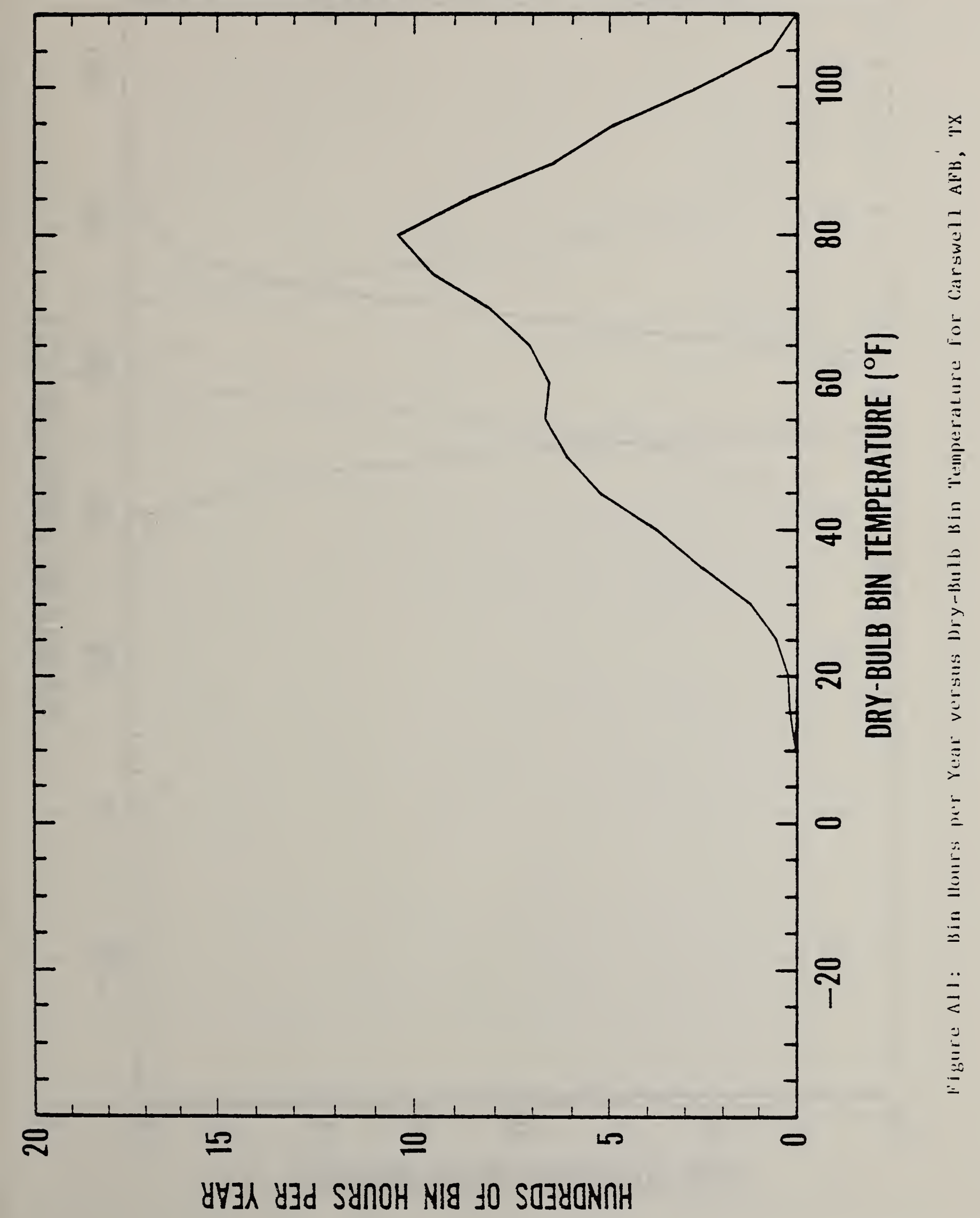




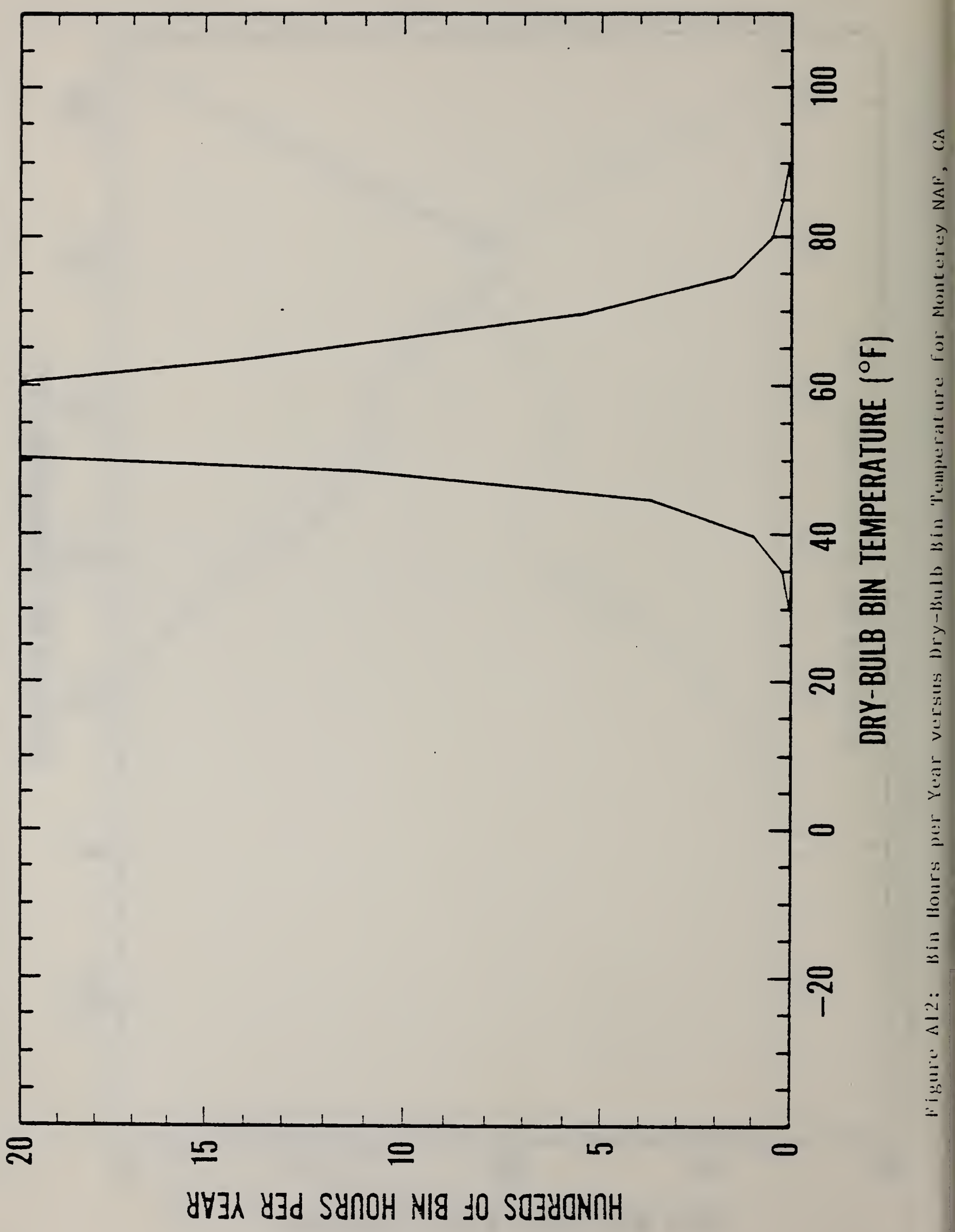




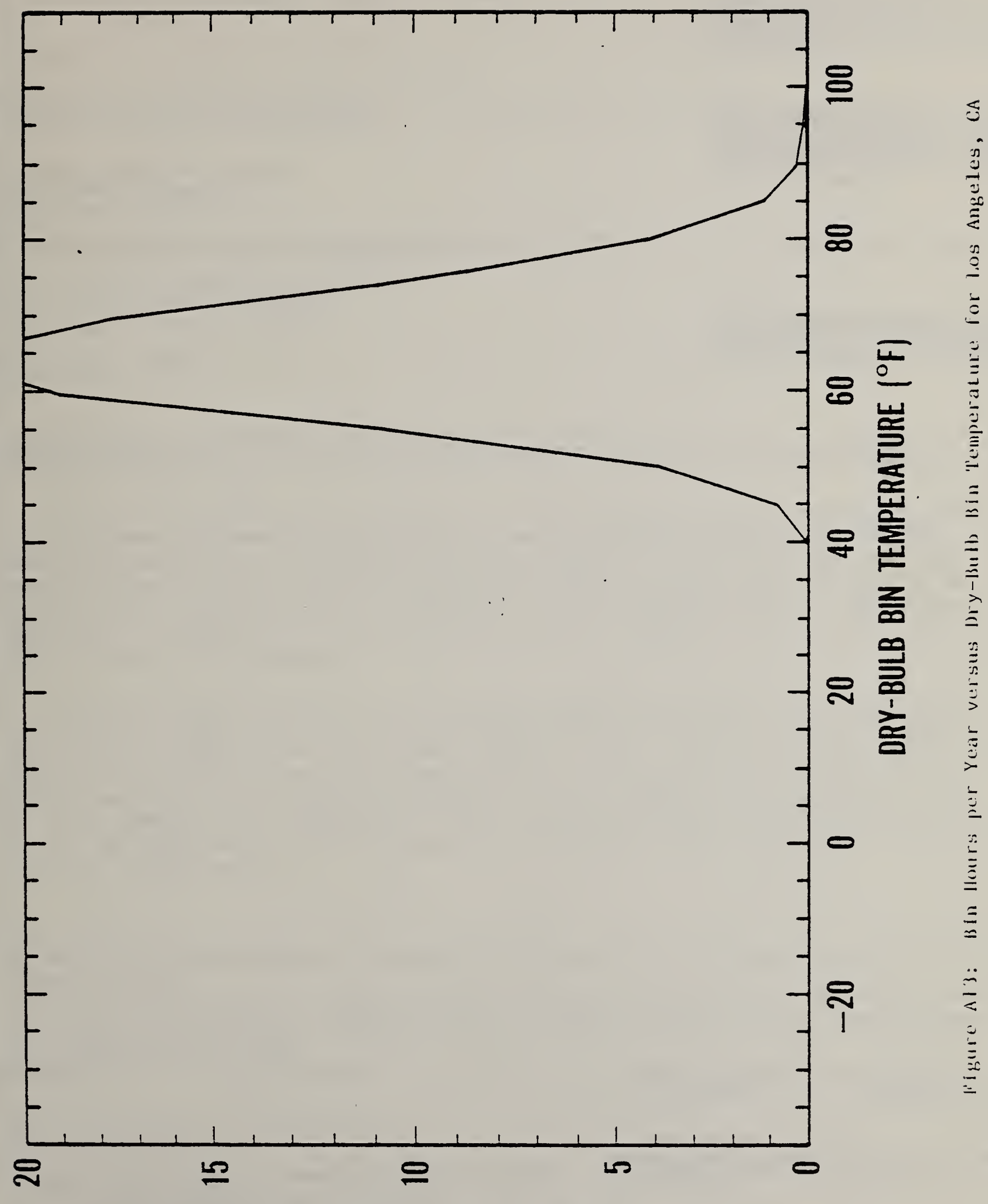

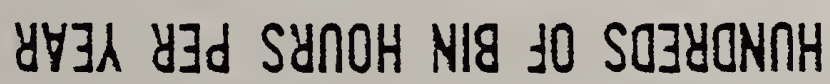


U.S. DEPT. OF COMM.

BIBLIOGRAPHIC DATA SHEET
1. PUBLICATION OR REPORT NO.

NBS" $^{*} 30-2145$

\section{TITLE AND SUBTITLE}

A Study of an Integrated Appliance, the Air Conditioner/Heat Pump-Heat Recovery Unit-Water Heater

\section{AUTHOR(S)}

King-Mon Tu, Alan Davies, Sidney Fischler

\section{PERFORMING ORGANIZATION NAME AND ADDRESS}

NATIONAL BUREAU OF STANDARDS

DEPARTMENT OF COMMERCE

WASHINGTON, DC 20234

\section{SPONSORING ORGANIZATION NAME AND COMPLETE ADDRESS (Streot, City, Stato, ZIP)}

United States Department of Energy

Oak Ridge National Laboratory

Oak Ridge, Tennessee 37830

5. Publication Date

Bebruary ?98!

S. Perforaing Organization Code

8. Performing Organ. Report No.

\section{Project/Task/Uork Unit No.}

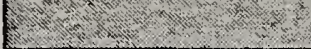

11. Contract/Grant No.

13. Type of Report \& Period Covered

15. SUPPLEMENTARY NOTES

Document describes a computer program; SF-185, FIPS Software Summary, is attached.

16. ABSTRACT (A 200-word or less factual summary of most significant information. If document includes a significant bibliography or literature survey, mention it here.)

Three integrated heat pump-heat recovery unit-water heater appliances were tested under various environmental conditions to measure the functional parameters and study the operating characteristics of these systems. It was found that the heat recovery, heat recovery rate and heat recovery efficiency were dependent on the heat recovery unit's characteristics. The use of the heat recovery unit in the system resuited in a reduced work load for the heat pump's compressor and slightly improved the heat pump's performance.

A computer simulation model of the integrated system was developed to study the interactions between several of the pertinent system variables on an hourly basis for selected situations and to estimate energy savings. Two alternative estimation methods that utilize five-degree temperature bin data were also developed. The estimated savings determined by using the alternative methods were about the same as those estimated using the hourly data. Conclusions were also reached concerning the use of water heaters with different tank capacities and on methods of increasing potential energy savings.

17. KEY WORDS (six to twelve entries; alphabetical order; capitalize only the first letter of the first key word unless a proper name; separated by semicolons)

Air conditioner retrofit; energy recovery system; heat recovery device; heat recovery unit; heat pump retrofit; integrated energy recovery system; retrofit energy saver; water heater energy saver

18. AVAILABILITY $\square$ Unlimited

Xं For Official Distribution. Do Not Release to NTIS

$\square$ Order From Sup. of Doc., U.S. Government Printing Office, Washington, DC 20402, SD Stock No. SNỎ03-003-

$\square$ Order From National Technical Information Service (NTIS), Springfield, VA, 22161

\begin{tabular}{|l|l|}
\hline $\begin{array}{l}\text { 19. SECURITY CLASS } \\
\text { (THIS REPORT) } \\
\text { UNCLASSIFIED }\end{array}$ & $\begin{array}{l}\text { 21. NO. OF } \\
\text { PRINTED PAGES }\end{array}$ \\
\hline $\begin{array}{l}\text { 20. SECURITY CLASS } \\
\text { (THIS PAGE) }\end{array}$ & 22. PrICe \\
UNCLASSIFIED & USCOMM-DC \\
\hline
\end{tabular}


